\title{
AIR SCALING AND MODELING STUDIES FOR THE 1/5-SCALE MARK I BOILING WATER REACTOR PRESSURE SUPPRESSION EXPERIMENT
}

W. Lai and E. W. McCauley

January 4, 1978

Work performed under the auspices of the Department of Energy contract No. W-7405-Eng-48 for the United States Nuclear Regulatory Commission contract 189A No. A0118-6.

\section{IL LAWRENCE INERMORE LABORATORY}

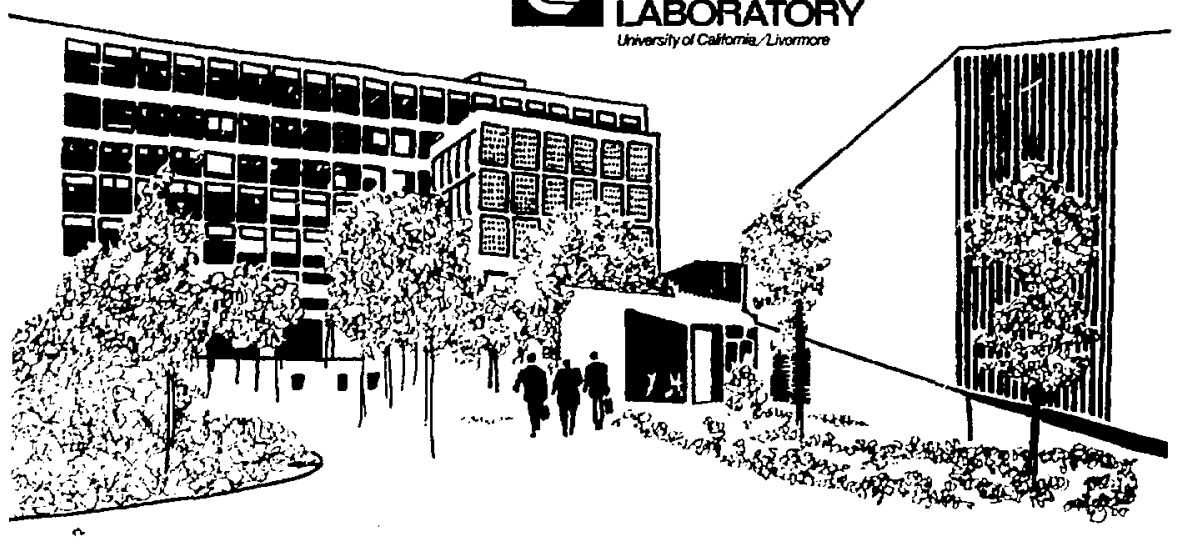




\section{近 \\ LAWRENCE I.NERMORE LABORATORY}

University of Cahtornia Livermore,Calfornia 94550

UCRL-52383

\section{AIR SCALING AND MODELING STUDIES FOR THE 1/5 SCALE MARK I BOILING WATER REACTOR PRESSURE SUPPRESSION EXPERIMENT}

W. Lai and E. W. McCauley

MS. date: January 4, 1978

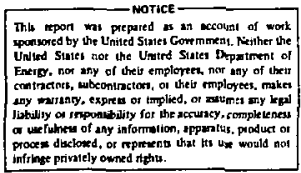




\section{CONTENTS}

Abstract . . . . . . . . . . . . . . . . . . . . . . 1

1. Introduction............................. 1

Purpose of this Report .. . . . . . . . . . . . . . . . . . 2

Organization of this Report . . . . . . . . . . . . . . . . . . 2

2. Highlights and Implications . . . . . . . . . . . . . . . . . . 3

Three-dimensional Effects . . . . . . . . . . . . . . . . 3

Effect of Enthalpy flux . . . . . . . . . . . . . . . . . 4

Character of the VLF . . . . . . . . . . . . . . . . . . . 4 4

Effect of Downcomer Fill Level on the VLF . . . . . . . . . . . . . 10

3. Cinematographic Studies . . . . . . . . . . . . . . . . . 14

Rectangular Pool . . . . . . . . . . . . . . . . . . . . 14

Test Apparatus . . . . . . . . . . . . . . . . . . . 15

Results and Discussion . . . . . . . . . . . . . . . . 16

Conclusions . . . . . . . . . . . . . . . . . . . . 16

Cylindrical Pool . . . . . . . . . . . . . . . . . . . . 17

Test Apparatus . . . . . . . . . . . . . . . . . . 17

Results and Discussion ..................... 18

Conclusions . . . . . . . . . . . . . . . . . . . . 24

1/64-Scale Torus Model Study . . . . . . . . . . . . . . . . . 24

Test Apparatus . . . . . . . . . . . . . . . . . . 24

Results and Discussion . . . . . . . . . . . . . . . 25

Conclusions . . . . . . . . . . . . . . . . . . . . . 27

4. Instrumented studies . . . . . . . . . . . . . . . . . . 30

Scaling Law Experiments . . . . . . . . . . . . . . . . . . . 30

Method and Test Apparatus . . . . . . . . . . . . . . . 30

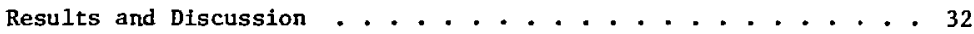

Effect of Pool Fluid Denstty . . . . . . . . . . . . . 36

Test1ng Signiflcance of Groups ............... . 38

Conclustons ... . . . . . . . . . . . . . . . . . . 4 4

Benchmark Experiments . . . . . . . . . . . . . . . . . . . 42

Test Apparatus . . . . . . . . . . . . . . . . . . . . 42

Measurements . . . . . . . . . . . . . . . . . . . 42

Test Procedure . . . . . . . . . . . . . . . . . . . 44

Results and Discussion .................... . . 44 


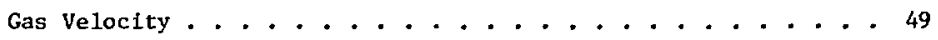

Gas Temperature .. . . . . . . . . . . . . . 51

Flask Rigidity . . . . . . . . . . . . . . . . . . 51

Conclusions ........................ . 51

Characterization of the VLF ... . . . . . . . . . . . . . 52

Test Apparatus . . . . . . . . . . . . . . . . . . 52

Results and Discussion . . . . . . . . . . . . . . . . 52

Maximum Upload . . . . . . . . . . . . . . . . 55

Damped Carrier Wave ................... . . 57

Damped High Frequency Oscillations... . . . . . . . . . 58

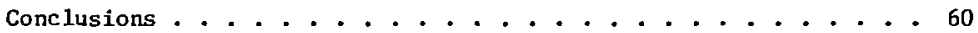

Effect of Downcomer Fill Level on the VLF . . . . . . . . . . . . 61

Test Apparatus . . . . . . . . . . . . . . . . . 61

Results and Discussion ........................ 61

Conclusions ....................... 64

5. Overall Conclusions . . . . . . . . . . . . . . . . . . 64

Acknowledgments. . . . . . . . . . . . . . . . . . . 65

Glossary of Terms . . . . . . . . . . . . . . . . . . . . . 05

References and Notes........................... 66

Appendix A. Typlcal Transducer Data Sheets . . . . . . . . . . . . 69

Appendix B. Reanalysis of Air-Water Pool Dynamics Scaling . . . . . . 73

Appendix C. Vibration Study of the Flask Support System . . . . . . . . 75 


\section{AIR SCALING AND MODELING STUDIES FOR THE 1/5-SCALE MARK I BOILING WATER REACTOR PRESSURE SUPPRESSION EXPERIMENT}

\section{PREFACE}

In this report we attempt to consolidate the work of several researchers whose bench-top exper1mentation has enriched our knowledge of the dynamic behavior of the boiling water reactor (BWR) pressure suppresstion system. The behavior of particular interest is the characteristics of the hydrodynamic forces and pool motion of the Mark I pressure suppression system during the afrclearing phase of the postulated loss-of-coolant accldent (IOCA). Because of the large size of the actual containment structure, ful1scale simulation of a IOCA is impractical. Irstead, scale-model tests provide data that support inferences about the behavior of the full-scale system. (In fact, the small size of the apparatus and the indoor environment enable better control of test conditions and quicker, more speciallzed results than full-size physlcal testing.) The overail purpose of the main program $^{*}$ is threefold:

- Establishment of scaling laws.

\footnotetext{
*For details of the 1/5-scale factlity, the alr test program, and related activities, see Refs. 1-5.
}

- Design and fabrication of a three-dimensional 1/5-scale test facility.

- Conduct of a comprehenstve test program.

This report summarizes table-top investigations that were initiated prior to the 1/5-scale tests. These investigations were designed to provide detailed phenomenological and theoretical understanding of key features of the dynamic behavior of the system. The purpose of this summary is to relate the results predicted by scaling and modeling the Vertical Load Function (VLF) to results from the $1 / 5$-scale torus experiment (whose facilfty incorporates both a three-dimensional $90^{\circ}$ and a $7.5^{\circ}$ torus sector).

Substantial portions of the text of this summary re either extracts from or paraphrases of our own ear1Ler reports, as $w \in 11$ as those of other tnvestigators. To avold a surfeit of footnotes and quotation marks, we have exercised the editorial prerogative of presenting a relatively unblemished text with only Inited author citation for specific contributions. Nevertheless, to 
ensure that authors are given appropriate credit for their work, we wish to acknowledge the contributions our cclleagues have made to these pages:

In Section 3, we use material from a report co-authored by John Meier (Ref. 17) for results of the cinenatographic investigation of rectangular. pool dynamics and from a report by John Pitts (Ref. 18) for the discussion of the 1/64-scale torus model.

In Section 4, we rely on the results of air-scaling experiments designed and initiated by Frank Morrison (Ref. 19). The discussions of benchmark experiments, characterization of the VLF, and the effect of downcomer fill level on the response vel rical load function (RVLF) are based on three reports of our own (Refs. 22, 23, and 25).

Readers will find that Section 2 provides a useful perspective on Sections 3 and 4; it presents what we feel are the highlights of the scaling and modeling studies, along with new information and a discussion of how well (or poorly) the results from modeling match the data from the largescale experiments.

Our debt to our colleagues is evident throughout this report; we trust we have represented their work accurately and must assume responsibility for any errors of interpretation that result from the compression necessary for this compilation. 


\section{ABSTRACT}

Results of table-top model experiments performed to investigate pool dynamics effects due to a postulated loss-of-coolant accident (LOCA) for the Peach Bottom Mark I boiling water reactor containment systen guided subsequent conduct of the 1/5-scale torus experiment and provided new insight into the vertical load function (VLF).

Pool dynamics results were qualitatively correct. Experiments with a 1/64-scale fully modeled drywell and torus showed that a $90^{\circ}$ torus sector was adequate to reveal threedimensional effects; the 1/5-scale torus experiment confirmed this. Table-top scaling-law studies showed (and 1/5-scale torus experiments also confirmed) that the VLF is insensitive to the enthalpy fiux parameter. Additionally, table-top experiments produced data suitable for computer code verification.

Table-top, 1/5-scale torus, and other scaled experiments show an oscillatory VLF; the maximum dotrload is typically double-spiked, whereas the maximum upload is more gradual. The load function contains a high frequency oscillation superimposed on a low frequency one; evidence from measurements and from momentum modeling with a computer indicates that the oscillations have hydrodynamic origins.

The maximum download diminishes with initial downconer fill level. When the downcomer is initially empty, table-top experiments show that the maximum download degenerates to a sinusoidal shape. This leads to the possibility of decomposing the VLF into a low-frequency-damped sinusoidal load plus a higher frequency (w10 times the low frequency) damped sinusoidal load.

\section{INTRODUCTION}

The success of the pressure suppression contaimment system design of a light-water reactor is dependent on the capability of a water heat sink to provide rapid and stabie condensation of the released primary high-pressure steam coolant during a hypothetical LOCA. However, during the initial stage of the LOCA, significant vertical loads due to moncondensable air injection from the drywell are imposed on the toroidal wetwell (see Fig. 1). To gain a better understanding of this aspect of the dynamic behavior of the system, a $1 / 5-s c a l e$ three-dimensional pressure 


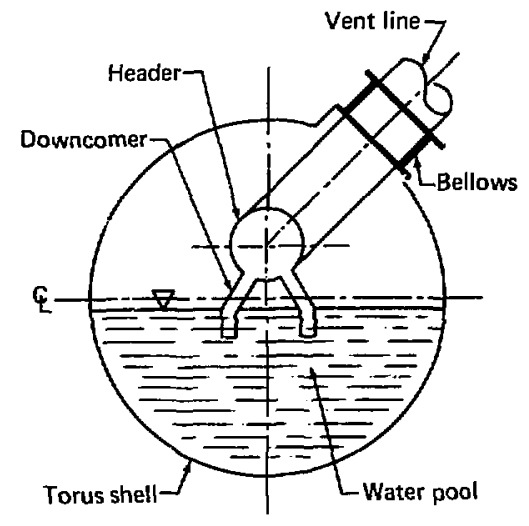

Fig. 1. Cross-section of Peach

Bottom BWR Mark I toroidal wetwell.

suppression experimental facility was daveloped for the Nuclear Regulatory Commission. Excensive testing was performed to quantify the hydrodynamic phenomena and associated forces.

Prior to the 1/5-scale tests, an inexpensive but extensive series of table-top experiments were conducted to investigate the fluid dynamics of the system. These smali-scale ( $1: 40)$ experiments provided detailed phenomenological and theoretical unaiers tanding of the key features of the dynamic behavior of the pressure suppression system. The results accurately predicted the transient hydrodynamically induced load function for the large-scale facility that was observed later.
PURPOSE OF THIS REPORT

This report summarizes the tablecop investigations initiated prior to the 1/5-scale tests. The objective of this summary, in addition to presenting results of the testing, is to relate the test results to those from the 1/5-scale torus experiment.

\section{ORGANIZATION OF THIS REPORT}

Major conclusions from scaling and modeling studies, supported by data putlished elsewhere and by results from the $1 / 5-s c a l e$ experiment are presented in Section 2. In addition, Section 2 contains a more complete discussion of the characteristics of the VLF than has previously been published. It also recapitulates the findings, strengthening some on the basis of new data, and presents a new conclusion regarding the components of the VLF. Sections 3 and 4 summarize the results of the modeling studies; each covers four areas of interest: objective, test apparatus, results and discussion, and conclusions.

Cinematographic investigations are presented in Section 3, which focuses on studies of a rectangular pool, a cylindrical pool, and a 1/64-scale torus model. (The cylindrical pool study has not been reported elsewi... ..) 
Instrumented experiments are presented in Section 4. Included are results from experiments in four areas: air scaling, generation of benchmark data, characterization of the response vertical load function * (RVLF), and the effect of downcomer fill level on the RVLF.

Three appendices give details of some of the work reported in Section 4.

\section{HIGHLIGHTS AND IMPLICATIONS}

The table-top modeling studies provided useful results in the attempt to broaden our understanding of pressure suppression system dynamic behavior. Summarized in this section are the more significant conclusions from studies detailed in Sections 3 and 4. Also presented are further analyses of results. Whenever possible, the presentation is supported by results from larger scale experiments, particularly from the Lawrence iivermore Laboratory (LLL) 1/5-scale experiment.

THREE-DIMENSIONAL EFFECTS

The 1/64-scale torus experimental results (Section 3) indicated that significant three-dimensional (3-D) effects should be expected in the 1/5-scale $90^{\circ}$ torus sector. Significantly, the 1/64-scale model showed major bubble action and pool swell in regions of closely spaced downcomers, which Implied that pool pressures

\footnotetext{
* The RVLF is the VLF measured with a load cell.
}

should be higher in these regions.

Pressure measurements made in the vetwell of the 1/5-scale experiment confirmed the 1/64-model predictions. Representative of this 3-D effect are the peak pressures measured at the bottom of the wetwell along the axis of the $90^{\circ}$ torus (Figs. 2 and 3 ) $;^{6-7}$

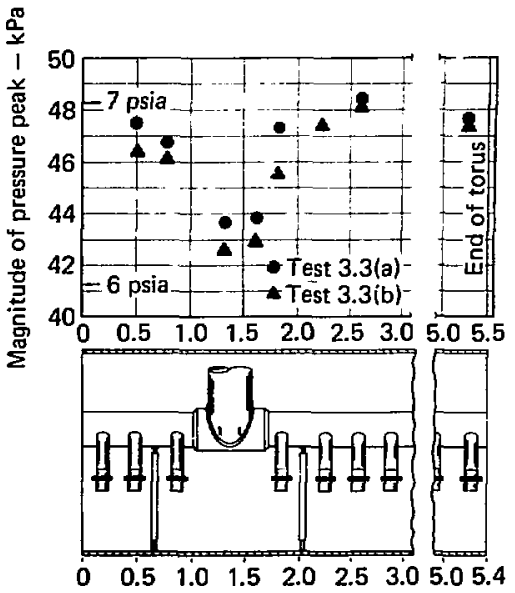

Distance along bottom dead center from left end of the toroidal wetwell $-m$

Fig. 2. Spatial variation of the pressure peak along the botton dead center of the $90^{\circ}$ toroidal wetwell [Tests $3.3(a)$ and $3.3(b)$ ]. 


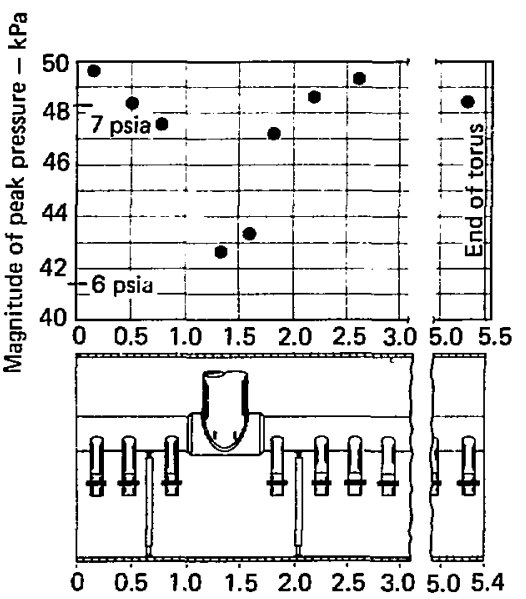

Distance along bottom dead center from left end of the toroidal wetwell - $m$

Fig. 3. Spatial variation of the pressure peak at bottom dead center of the $90^{\circ}$ toroidal wetwell (Test 2.8).

note the occurrence of maximum and minimum pressures in the expected regions.

\section{EFFECT OF ENTHALPY FLUX}

An important aspect of the airscaling studies (Section 4) was to evaluate the relevance of the enthalpy flux group $\left[\left(\mathrm{RT}_{\mathrm{o}}\right] /[\mathrm{gL}]\right.$ or $\left[\mathrm{h}_{\mathrm{o}} \dot{\mathrm{m}}\right] /$ $\left.\left[\rho_{g} g^{3 / 2} L^{7 / 2}\right]\right)$. The enthalisy $f 1 u x$ was varied by a factor of 2 ath a vent line orifice. The results show that the maximum download and upload remained essentially unchanged.
The 1/5-scale RVLF i esults confirmed the behavior of the maximum upload and also showed that the maximum download was insensitive to the enthalpy flux group. ${ }^{8-9}$ In general, the maximum upload for the hydrodynamic VLF (HVLF) showed a larger variation for the range of parameters studied. Except for a single case, the results for the $90^{\circ}$ torus sector showed $\leqslant 10 \%$ change; the results for the $7.5^{\circ}$ torus sector showed $\leqslant 18 \%$ change. ${ }^{8-9}$ The pertinent data are summi: : ized in Tables 1-5.

CHARACTER OF THE VLF

The results of the table-top VLF characterization study (see Section 3) are summarized in Fig. 4. The general distinguishing features of the VLF from table-top experiments are also observed in the RVLF and HVLF from the $1 / 5-s c a l e$ experiments (Figs. 5-7). This is not proof, however, that identical mechanisms are operative in all experiments. For instance, the most visible effect at the maximum upload for the 1/5-scale VLF is pool impact of the header; this component obviously does not exist for our bench-top experiments.

The pressure measurements in Ref. 11 exhibit an oscillatory behavior (Fig. 8). The HVLF is obtained by integration of pressure measurements so that it exhibits the same type of 
Table 1. Summary of actual test conditions ${ }^{a}$ for orifice-effect tests.

\begin{tabular}{|c|c|c|c|c|c|c|}
\hline \multirow{3}{*}{$\begin{array}{l}\text { Test } \\
\text { No. }\end{array}$} & \multirow{3}{*}{${ }_{\text {dw }}^{o}}$, & \multirow{3}{*}{$\begin{array}{c}\dot{\mathrm{p}}, \\
\mathrm{psi} / \mathrm{s}\end{array}$} & \multirow{3}{*}{$\begin{array}{c}\text { Drywel1 } \\
\text { volu } \\
\text { fte } \\
\text { is }\end{array}$} & \multicolumn{3}{|c|}{ Vent line orifice diameter, in. } \\
\hline & & & & \multicolumn{2}{|c|}{$90^{\circ}$} & \multirow{2}{*}{$\frac{7.5^{\circ}}{\text { Vent }}$} \\
\hline & & & & Left vent & Right vent & \\
\hline 1.3 & 2.946 & 25.96 & 348 & 9.5 & 9.5 & 3.63 \\
\hline 1.3 .1 & 3.084 & 27.24 & 296 & 9.5 & 9.5 & 3.63 \\
\hline 2.4 & 2.994 & 24.31 & 296 & $9 . j$ & 9.5 & 3.63 \\
\hline 3.5 & 3.044 & 25.63 & 348 & 9.5 & 9.5 & 3.63 \\
\hline 3.1 & 2.897 & 28.90 & 296 & 10.58 & 10.58 & 4.08 \\
\hline 3.2 & 2.9415 & 25.73 & 348 & None & None & 4.08 \\
\hline $3.3 a$ & 2.984 & 24.90 & 348 & 9.5 & 0.0 & 3.63 \\
\hline $3.3 b$ & 2.975 & 24.90 & 348 & $0.0^{c}$ & 9.5 & 3.63 \\
\hline $3.4 a$ & 2.859 & 25.00 & 348 & None & 0.0 & None \\
\hline $3.4 \mathrm{~b}$ & 2.953 & 22.61 & 348 & 0.0 & None & None \\
\hline
\end{tabular}

${ }^{a}$ During all tests, the initial torus water level was $0.2 \mathrm{ft}$ below torus centerline, the downcomer submergence set at $0.8 \mathrm{ft}$, and drywell ovirpressure was zero.

bWater was inadvertently sucked into the dxywe11 during tests $1.3 .1,2.4,3.1$, thereby slightly reducing the drywell volume.

The value 0.0 indicates a blocked vent line.

oscillations (Figs. 9 and 10). The observed frequencies appear to be apparatus-dependent, suggesting, at first, structural vibrations as the cause. However, phase relationships for our flask tests between independent measurements of RVLF, bottom pressure, and support acceleration substantiate the thesis that these oscillations are excited by hydrodynamic phenomena (see this section and Section 3); it was also shown that the oscillations in the 1/5- scale pressure and load data originated from hydrodynamic phenomena. 2

The double-spiked download peaks are clearly evident in Figs. 4-7. The less abrupt upload is also easily observed. The second download peak, or high frequency pulse (HFP), seems to signal the beginning of the high frequency oscillations. The HFP has also been observed in scale studies from General Electric (GE). ${ }^{12}$ The low frequency oscillations are also distinguishable in Figs. 4-7. 
Table 2. Effect of $\dot{m}$ on selected peak parameters.

\begin{tabular}{|c|c|c|c|}
\hline & Test 2.4 & Test 3.1 & Test 3.2 \\
\hline $\begin{array}{l}\text { Actual initial drywe } 11 \\
\text { pressurization rate }\end{array}$ & $\begin{array}{l}167.5 \mathrm{kPa} / \mathrm{s} \\
(24.3 \mathrm{psi} / \mathrm{s})\end{array}$ & $\begin{array}{l}189.6 \mathrm{kPa} / \mathrm{s} \\
(27.5 \mathrm{psi} / \mathrm{s})\end{array}$ & $\begin{array}{l}160.0 \mathrm{kPa} / \mathrm{s} \\
(23.2 \mathrm{psi} / \mathrm{s})\end{array}$ \\
\hline \multicolumn{4}{|c|}{ Load cell 4 (main outboard): } \\
\hline Peak download & $\begin{array}{l}70.7 \mathrm{kN} \\
(15,900 \mathrm{Ibf})\end{array}$ & $\begin{array}{l}71.6 \mathrm{kN} \\
(16,100 \mathrm{bf})\end{array}$ & $\begin{array}{l}64.5 \mathrm{kN} \\
(14,500 \mathrm{lbf})\end{array}$ \\
\hline Peak upload & $\begin{array}{l}26.7 \mathrm{kN} \\
(6,000 \mathrm{ft}-\mathrm{tb})\end{array}$ & $\begin{array}{l}26.7 \mathrm{kN} \\
(6.000 \mathrm{fc}-1 \mathrm{~b})\end{array}$ & $\begin{array}{l}29.4 \mathrm{kN} \\
(6.600 \mathrm{ft}-1 \mathrm{~b})\end{array}$ \\
\hline \multicolumn{4}{|c|}{ Load cell 5 (main inboard): } \\
\hline Peak download & $\begin{array}{l}120.3 \mathrm{kN} \\
(23,000 \mathrm{ft}-1 \mathrm{~b})\end{array}$ & $\begin{array}{l}113.4 \mathrm{kN} \\
(25,500 \mathrm{ft}-1 \mathrm{~b})\end{array}$ & $\begin{array}{l}112.5 \mathrm{kN} \\
(25,300 \mathrm{ft}-1 \mathrm{~b})\end{array}$ \\
\hline Peak upload & $\begin{array}{l}52.0 \mathrm{kN} \\
(11,700 \mathrm{ft}-1 \mathrm{~b})\end{array}$ & $\begin{array}{l}52.0 \mathrm{kN} \\
(11,700 \mathrm{ft}-1 \mathrm{~b})\end{array}$ & $\begin{array}{l}56.9 \mathrm{kN} \\
(12,800 \mathrm{ft}-1 \mathrm{~b})\end{array}$ \\
\hline \multicolumn{4}{|l|}{ Peak pressure at $180^{\circ}$ : } \\
\hline $7.5^{\circ}$ Torus & $\begin{array}{l}48.3 \mathrm{kPa} \\
(7.0 \mathrm{psia})\end{array}$ & $\begin{array}{l}48.3 \mathrm{kPa} \\
(7.0 \mathrm{psia})\end{array}$ & $\begin{array}{l}47.6 \mathrm{kPa} \\
(6.9 \mathrm{psia})\end{array}$ \\
\hline $90^{\circ}$ Torus, plane 9 & $\begin{array}{l}46.9 \mathrm{kPa} \\
(7.2 \mathrm{psia})\end{array}$ & $\begin{array}{l}48.3 \mathrm{kPa} \\
(7.0 \mathrm{psia})\end{array}$ & $\begin{array}{l}47.6 \mathrm{kPa} \\
(6.9 \mathrm{psia})\end{array}$ \\
\hline
\end{tabular}

Figure 11 shows measurements made with table-top equipment to determine the effects of downcomer fill level on the RVLF (Section 4). Even though the load function changed shape with downcomer fill level, the HFP persists.

The increased relative magnitude of the HFP when downcomer fill level is reduced to $80 \%$ is shown clearly in Fig. 11a. The RVLF for progressively lower intial downcomer fill levels Is show in Fig. 11b; the trace for $80 \%$ full is repeated to provide an index for comparison. Note that the time between the first and second
HFP download peaks remain constant at $21.5 \mathrm{~ms}$, even as the HFP becomes dominant (note the trace for $60 \%$ ). Figure 1lc exhibits the sane trends at a lower pressure ratio.

The high frequency oscillations in the traces in Fig. $11 \mathrm{~b}$ seem to be moving left in a path defined by the low frequency envelope. Careful inspection shows that the peak pulse for the initially empty downcomer case is the fourth pulse; the first pulse ts just disappearing into the left baseline. The time between pulses has not changed. 
Table 3. Varlation in the peak hydrodyramic loads due to the vent-line orifice - standard tests.

\begin{tabular}{|c|c|c|c|c|c|c|c|c|}
\hline \multirow[b]{2}{*}{ Test } & \multicolumn{4}{|c|}{$90^{\circ}$ Sector } & \multicolumn{4}{|c|}{$7.5^{\circ}$ Sector } \\
\hline & $\mathrm{L}_{\mathrm{dn}}{ }^{a}$ & $E-\%$ & $\mathrm{I}_{\text {up }}$ & $E-\%$ & $\mathrm{~L}_{\mathrm{dn}}$ & $E-\%$ & $\mathrm{~L}_{\mathrm{up}}$ & $\varepsilon-z$ \\
\hline Group A & 39.8 & - & 17.7 & - & 3.04 & - & 1.12 & - \\
\hline 3.1 & 37.4 & -6.0 & 17.7 & 0.0 & 2.74 & -9.9 & 1.08 & -3.6 \\
\hline 3.2 & 35.6 & -10.6 & 22.5 & +27.1 & 2.82 & -7.2 & 1.26 & +12.5 \\
\hline
\end{tabular}

$a_{L}$ in $k l b$.

Table 4. Variation in the peak hydrodynanic loads due to the vent-line orifice - blocked vent line.

\begin{tabular}{|c|c|c|c|c|c|c|c|c|}
\hline \multirow[b]{2}{*}{ Test } & \multicolumn{4}{|c|}{$90^{\circ}$ Sector } & \multicolumn{4}{|c|}{$7.5^{\circ}$ Sector } \\
\hline & ${ }^{L_{d n}}{ }^{a}$ & $\varepsilon-\%$ & $\mathrm{~L}_{\text {up }}$ & $\varepsilon-\%$ & $\mathrm{~L}_{\mathrm{dn}}$ & $\varepsilon-\%$ & $\mathrm{~L}_{\mathrm{up}}$ & $\varepsilon-\%$ \\
\hline Group A & 39.8 & - & 17.7 & - & 3.04 & - & 1.12 & - \\
\hline $3.3 a$ & 18.9 & - & 7.95 & - & 2.90 & -4.6 & 0.958 & -14.5 \\
\hline $3.3 \mathrm{~b}$ & 18.8 & - & 9.75 & - & 2.90 & -4.6 & 0.968 & -13.6 \\
\hline 3.3 sum & 37.7 & -5.3 & 17.7 & 0.0 & - & - & - & - \\
\hline $3.4 \mathrm{a}$ & 20.2 & - & 9.40 & - & 2.99 & -1.6 & 1.30 & +16.1 \\
\hline $3.4 b$ & 20.6 & - & 9.35 & - & 3.14 & $\div 3.3$ & 1.32 & +17.9 \\
\hline 3.4 sum & 40.8 & +2.5 & 18.8 & +6.2 & - & - & - & - \\
\hline
\end{tabular}

$\mathbf{a}_{\mathrm{L}}$ in $\mathbf{k I b}$.

Table 5. Vent-Iine resistance coefficients for the $1 / 5$-scale torus experiment. 10

\begin{tabular}{cccc}
\hline & \multicolumn{2}{c}{$45^{\circ}$ Sector } & $7.5^{\circ}$ Sector \\
\cline { 2 - 4 } Tests & Left & Right & \\
\hline Nominal & 24.1 & 22.4 & 21.6 \\
3.1 & $12.9^{\mathrm{a}}$ & $12.9^{\mathrm{a}}$ & $12.9^{\mathrm{a}}$ \\
3.2 & 5.1 & 4.7 & $4.3^{\mathrm{a}}$ \\
\hline
\end{tabular}

${ }^{a}$ Calculated values. 


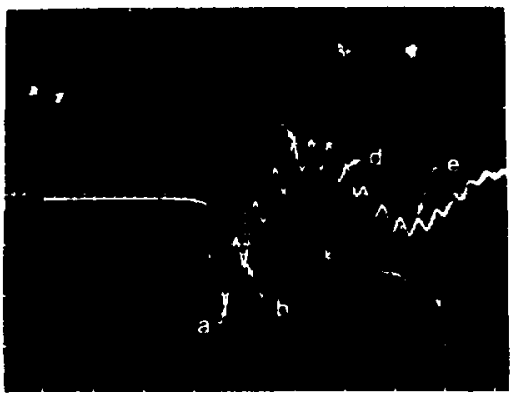

Fig. 4. Origin of VLF characteristics. (a) Hydrodynamic origin: peak downforce results from ejection of water slug into the pool. (b) Hydrodynamic origin: second peak of downforce becomes dominant as downcomer initial fill level is reduced. (c) hydrodynamic origin: maximum upforce given by average, results from combination of pool levitation and compression due to pool swell. (d) Hydrodynamic origin: low frequency carrier wave due to vertical oscillations of the expanding air bubble. Frequency increases will ullage pressure. Oscillations are in phase with pressure oscillations at bottom of pool. (e) Hydrodynamic origin: high frequency on carrier wave not fully characterized; slight reduction with increase in ullage pressure, oscillations in phase with pressure oscillations at the bot tom of the pool.

The characteristic sharp maximum download has changed to a less abrupt sinusoidal download for the initially empty downcomer. Note that the pulse relationship observed in these flask tests

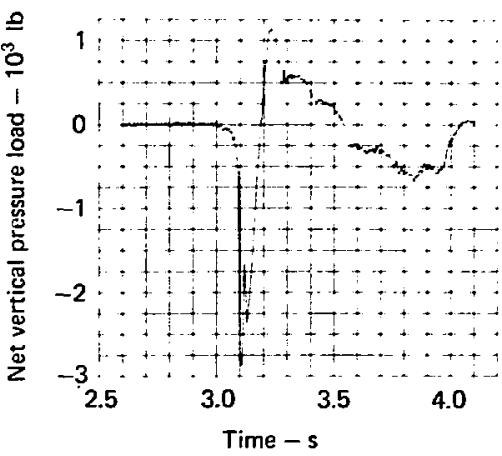

Fig. 5. Typical HVLF ${ }^{\circ}$ or the $7.5^{\circ}$ torus secotr. (Test 1.3.1)

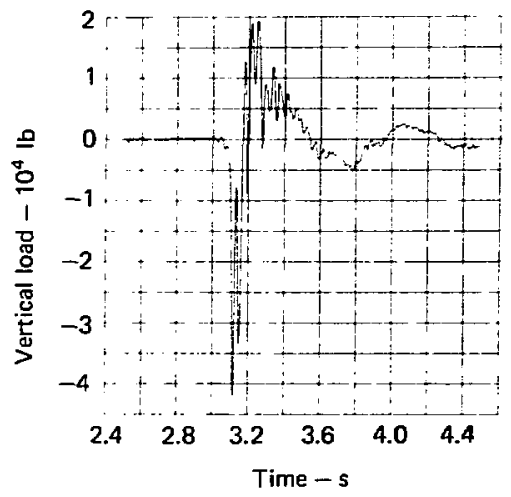

Fig. 6. Typical RVLF for the $90^{\circ}$ torus sector. (Test 1.3.1)

between load peaks and accleration of the center of the flask support beam is that of the load driving the beam and this is maintained regardless of the downcomer fill level (Figs. 12-14). 


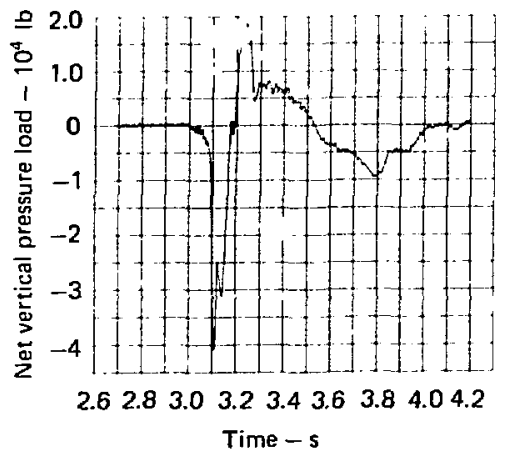

Fig. 7. Typical HVLF for the $90^{\circ}$ torus sector. (Test 1.3.1)

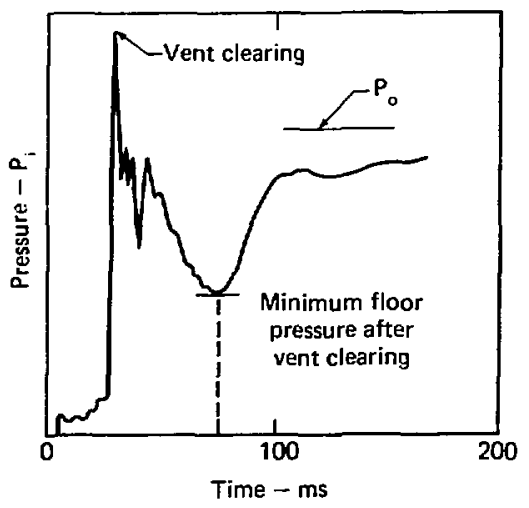

Fig. 8. Typical pressure trace at the bottom of the pool for a cylindrical tank (Ref, 11).

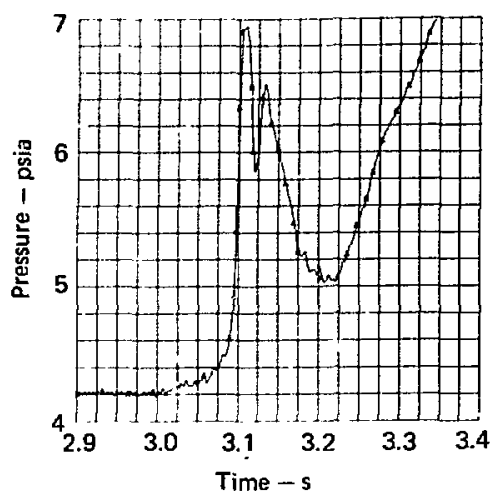

Fig. 9. Typical pressure trace at the bot of the pool for the $7.5^{\circ}$ torus sector. (Test 1.3.1)

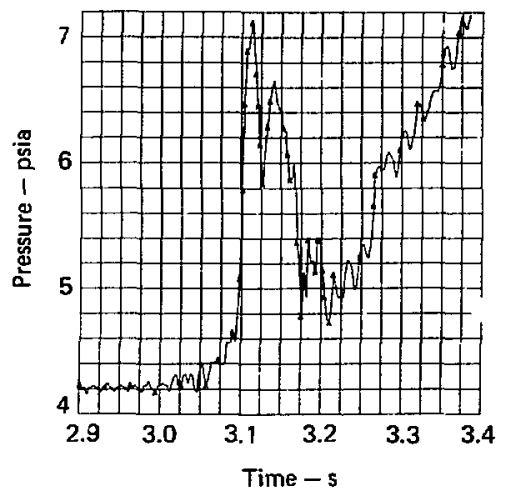

Fig. 10. Typical pressure trace at the bottom of the pool for the $90^{\circ}$ torus sector. (Test 1.3.1) 


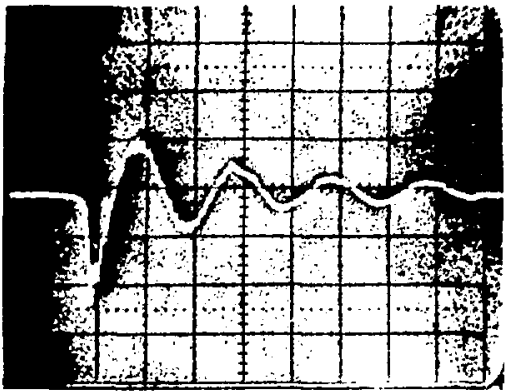

i. Downcomer initially full

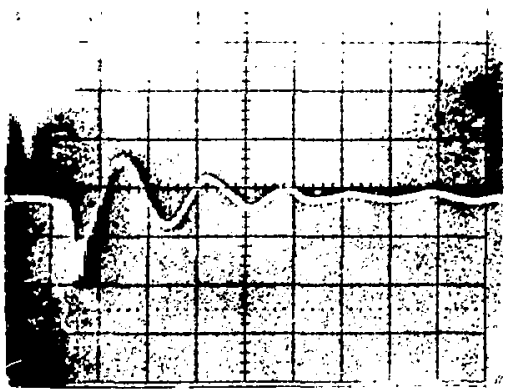

ii. Downcomer initiaily $80 \%$ full

Fior. 11. Change of tha RVLF as a function of jinitial downcomer fill level (5-litre flask, single downcomer, 2.51 itre water, all vercical scales $=501 \mathrm{bf} / \mathrm{cm})$.

a) Nominal pressure ratio $3: 1$, timescale $=10 \mathrm{~ms} / \mathrm{cm}$.

Figure 11 reveals two additiona]. characteristics. The first is that the download starts earlier as the downcomer fill level decreases. The difference in download starting time for the full downcomer (Fig. 1la) and the empty downcomer (Fig. I.lb) is 'lo ms, which is of the order of the clearing time of the full downcomer. The second is that the time duration of the download (measured by wotrapulating the initial baseline) remains essential'y constane at 8 ms, regardless of the initial downromor fill level.

The additional data fros the downfonter fill fovel study suggest that the blf charareteristics summari ged in Fis. a ran be decemposed into the two simpler parts illustrated i.. Fig. 1\%, This decomposition is consistent with the freliminary indicaLions found by Dav

FFFECT OF DOWNCOMER FILL LEVEL ON THE VLF

Both maximum download and maximum upload rea ces sith the initial downcomer fill level. (see Section 4). The download results for flask tests conducted with an initial pressure ratio of $15: 5$ (3:1) (from Fig. 61) are replotted in Fig. 16.

Also shown in Fig. 16 are the MAITAI code calculations for a vertical cylindrical flat-bottomed contalnrr with the same geonetric ratios as the LLL flask experiments; the initial pressure atio was $5.8: 1,15,16$ General Electric data derived from $1 / 12-s c a l e$ experiments conducted in a short (essentially two-dimensional) 


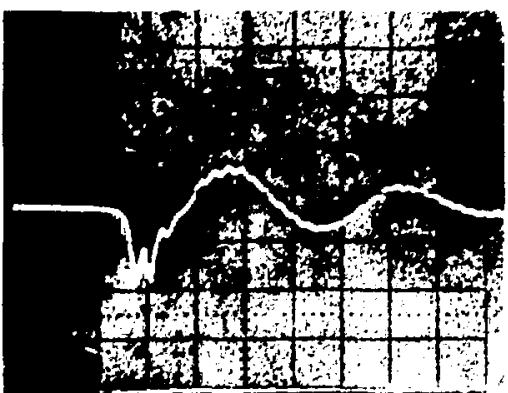

i. Downcomer initiaily $80 \%$ full

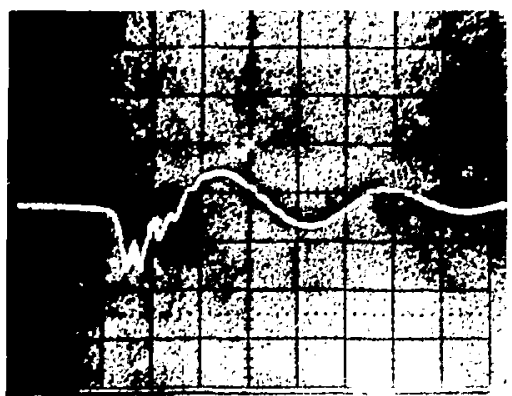

ii. Downcomer initia!ly $60 \%$ full

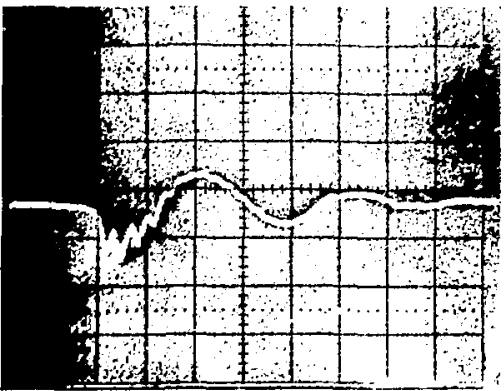

iii. Downcomer initially $40 \%$ full

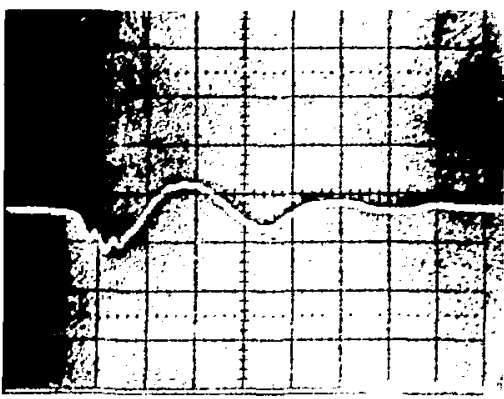

Iv. Downecsmer ismtiall' $20^{\prime \prime}$, fulf

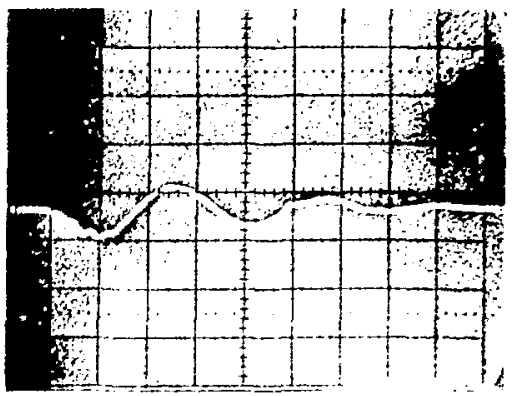

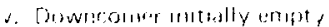

b) Noninal pressure ratio 3:1, tia., it 


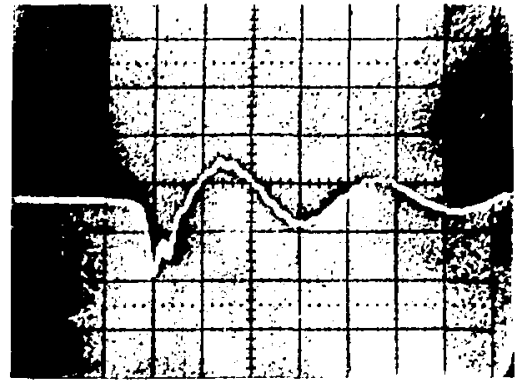

i. Downcomer initially $100 \%$ full

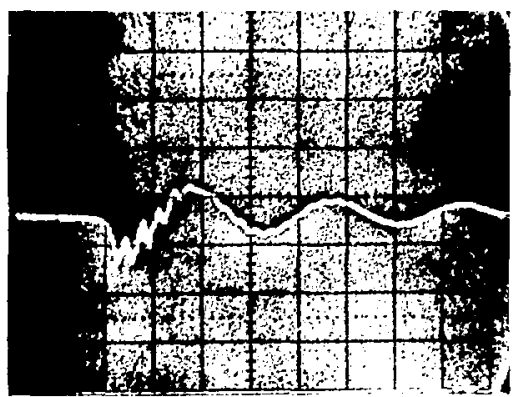

ii. Downcomer initially $40 \%$ full

() Nominal pressure ralio $2: 1$, timescalo $=5 \mathrm{~ms} / \mathrm{cm}$.

hor izonlal cylinder also show the same trend; clie jnilial pressure rate wo was 12:1. The curves in Fig. If show a comunutl trend toward smal ler download witi Jower initial downomor fijl level.
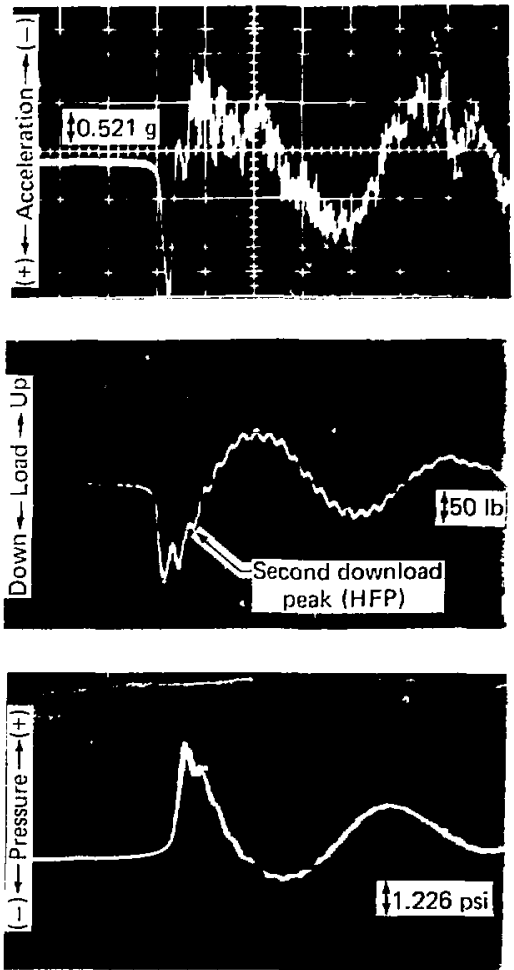

Fig. 12. Dynamic response of a typical. blowdown test conducted with an initially full downcomer (run 1/14-1, 5-1itre flask, nominal a tmosphere, ullage $=15: 5$, timescale $=5 \mathrm{~ms} / \mathrm{cm}$ ) . 

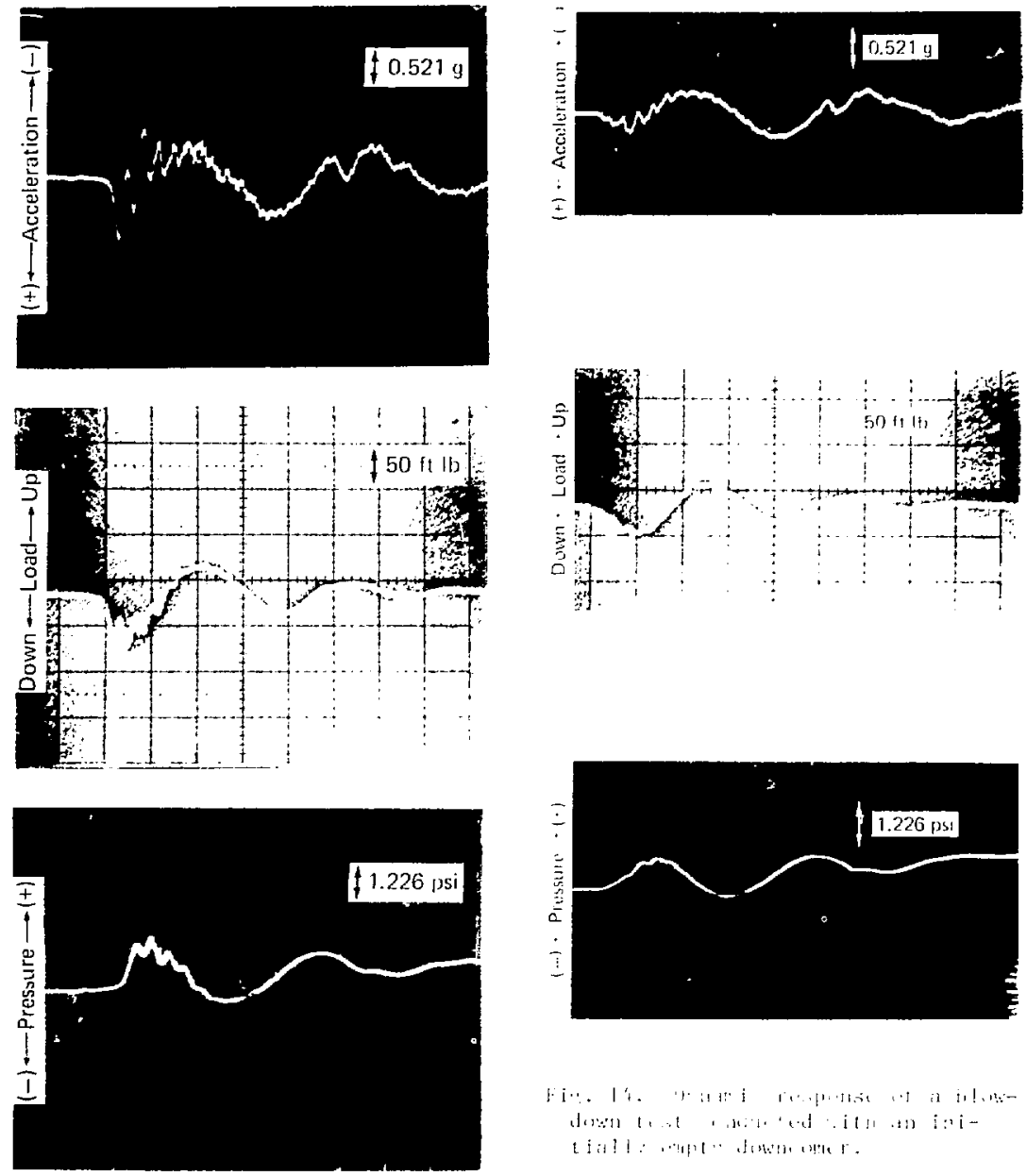

Fig. 13. Dynamic response of at blnwlown test conducted with an initially partially $(40 \%)$ filled downcomer (run 1/21-8, 5-1itre flask, nominal atmosphere, ullage $=15: 5$, nominal. pressture ratio $3:\rfloor$, Limescale $=5 \mathrm{~ms} / \mathrm{cm}$ ). 


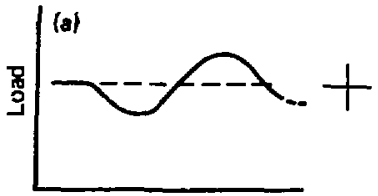

Time

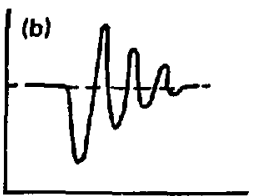

Time

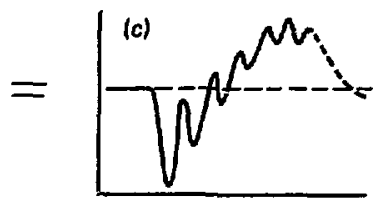

Time

Fig. 15. Suggested composition of the VLF.

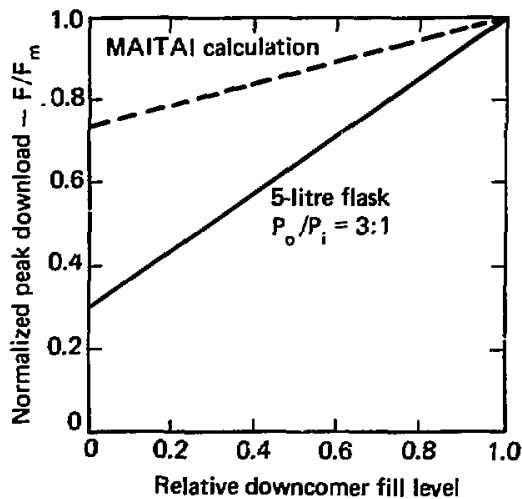

Fig. 16. Effect of initial downcomer f111 level on the maximum download.

\section{CINEMATOGRAPHIC STUDIES}

Bubble and pool dynamics resulting from clearlng of downcomers in enclosures configured to simulate the Mark I pressure suppression system were studied using high speed motion pictures, primarily. Three container shapes were investigated: rectangular, cylindrical, and 1/64-scale torus.
RECTANGULAR POOL ${ }^{17}$

The primary purpose of these tests was to study the effect of downcomer spacing on growth characteristics of bubbles following air injection. The effect of initial downcomer fill level was also Investigated. 


\section{Test Apparatus}

The test apparatus ised for these experiments consisted of a pair of partially submerged downcomers located in a rectangular tank of water (see Fig. 17). Most of the important dimensions on the test apparatus were linearly scaled from a BWR Mark I torus in a ratio of $1: 38,4$. The space between plates $A$ and $B$ (the axial dimension in the torus), was varied to represent the effects of different spacing of downcomer pairs within the torus on the bubble-formation dynamics.

The alr injected into the downcomers was supplied by a shop air supply via $10 \mathrm{ft}$ of 3/8-in.-i.d. plastic tubing. The flow resistance of this tubing was not scaled to the flow resistance between drywell and the torus in a $B^{\prime}$ plant, nor was an attempt made to scale the air supply uld ullage pressures. Ilowever, ' nature of the bubbles developed in the experiment and the results of

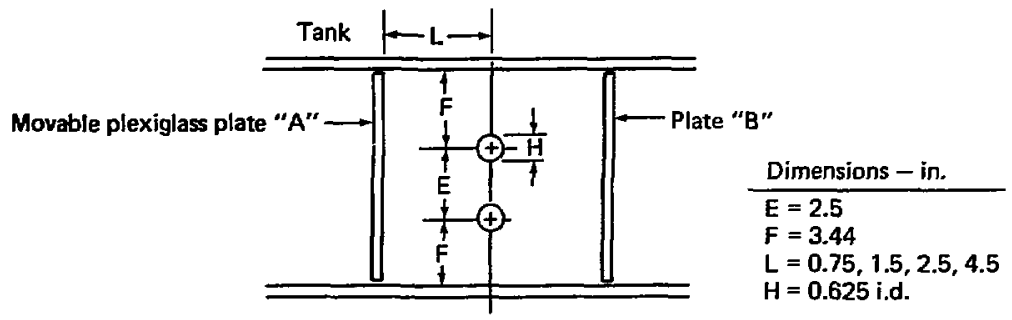

Plan view

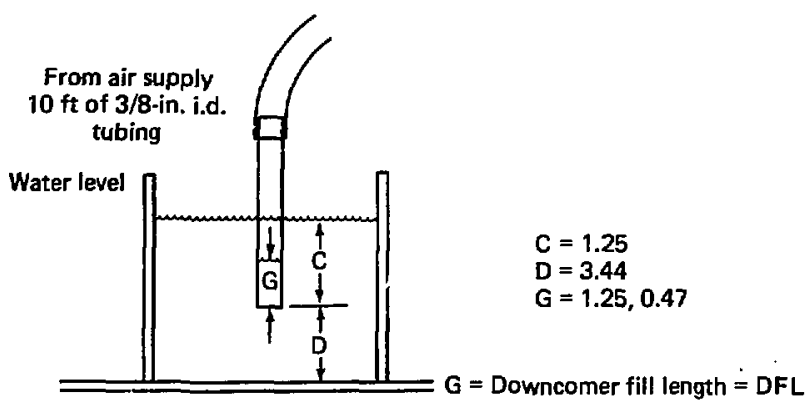

Elevation

Fig. 17. Geometry of the single downcomer pair experiment. 
this experiment provide useful information about the effect of downcomer spacing on bubble growth dynamics. With the pool exposed to atmospheric pressure, inlet pressures were varied in ratios up to $25: 1$. Tests were initiated by a manual, quick-opening valve.

Visualization of the air/water dynamics was provided by two Hycam* cameras that operated at 400 framcs per second, viewing simultaneously perpendicular to and parallel to the downcomer pair. Camera focus was centered on the exit of the downcomers. Conscquently, initial measurements of the water surface in the figures include approximately 0.2 in. of parallax error.

Results and Discussion

$\Lambda$ Vanguar $\mathrm{d}^{*} 16-\mathrm{mm}$ motion analyzer was used to determine the pool and bubble movement as a function of time from the high speed films. The various points considered are indicated in Fig. 18 (which also illistrates a typical bubble-pool swell configuration). The pool-surface rise rate, which is an indicator of impact

\footnotetext{
*Reference to a company or product name does not imply approval or recommendation of the product by the University of California or the U.S. Energy Research \& Development Administration to the exclusion of others that may be suitable.
}

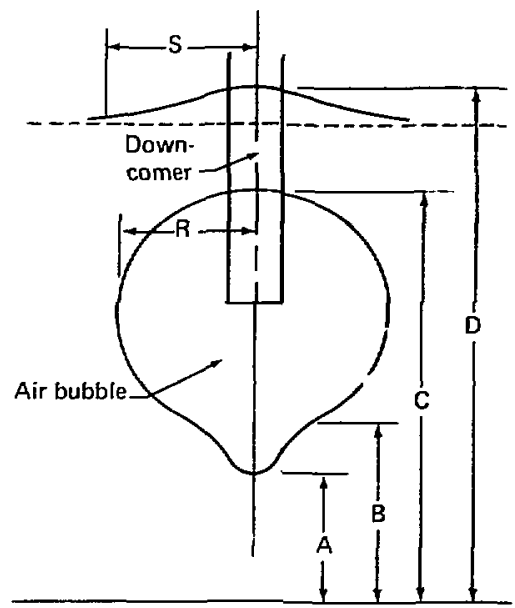

Fig. 18. Dimensions selected to represent pool dynamics.

load on the header (Fig. 1), was computed (see Table 6).

Conclusions

Although the apparatus used in these experiments was only partially scaled geometrically, the results indicate the following:

- A close spacing of downcomer pairs is likely to lead to an increase in the momentum of the water thrown up by the air bubble.

- An increase in dxiving pressure will increase the momentum of the water.

- Lowering the initial water level in the downcomer may lead to an increase in the momestum of the water surface. 
Table 0. Summary of results for pool-dynamics tests conducted in a rectangular pool.

\begin{tabular}{rcccc}
\hline Run No. & $\begin{array}{c}\text { Plate } \\
\text { spacing } \\
\text { in. }\end{array}$ & $\begin{array}{c}\text { Downcomer } \\
\text { 1evel-DFL, } \\
\text { in. }\end{array}$ & $\begin{array}{c}\text { Supply } \\
\text { pressure, } \\
\text { psig }\end{array}$ & $\begin{array}{c}\text { Pool surface } \\
\text { rise rate, } \\
\text { ft/s }\end{array}$ \\
\hline 1 & 9.0 & 1.25 & 40 & 1.49 \\
2 & 9.0 & 1.25 & 60 & 1.91 \\
3 & 1.5 & 1.25 & 60 & 2.65 \\
4 & 1.5 & 0.47 & 60 & 3.22 \\
5 & 1.5 & 1.25 & 40 & 2.15 \\
6 & 1.5 & 0.47 & 40 & 2.56 \\
7 & 3.0 & 1.25 & 40 & 1.54 \\
8 & 3.0 & 1.25 & 60 & 1.66 \\
9 & 5.0 & 1.25 & 60 & 1.81 \\
10 & 5.0 & 1.25 & 40 & 1.74 \\
11 & 5.0 & 0.47 & 40 & 2.06 \\
12 & 5.0 & 0.47 & 60 & 2.15 \\
\hline
\end{tabular}

${ }^{a_{S}}$ caled Peachbottom downcomer spacings range from 1.406 in. to $4.95 \mathrm{in}$. The scaled average spacing is $2.28 \mathrm{in}$.

CYLINDRICAL POOL

The objectives of these tests were threefold:

- Io compare the effects of : $r$ and $\mathrm{N}_{2}$ on vent clearing and bubble growth.

- To obtair data for comparison with MAITAI code predictinns. 15,16

- To compare back- and frontlighting cinematography.

Test Apparatus

Available materials and equipment were adapted to these experiments. As shown in Figs. 19 and 20, the cylindrical container is a closedend glass pipe. The downcomer is a piece of acrylic tubing. The geometry was scaled linearly from the MAITAI model (Fig. 21, see Ref. 16), which was scaled approximately linearly from the Peach Bottom Mark I BINR. The MAITAI model dimeisions, scaled dimensions, and actual dimensions are 1isted in Table 7. A standard $1.61-\mathrm{cm}-i . d$. acrylic tube was used for the downcoiner instead of the actual scaled dimension of 1.69 cm i.d. The line resistance and drywell volume were not scaled. Dynamics of the pool resulting from 


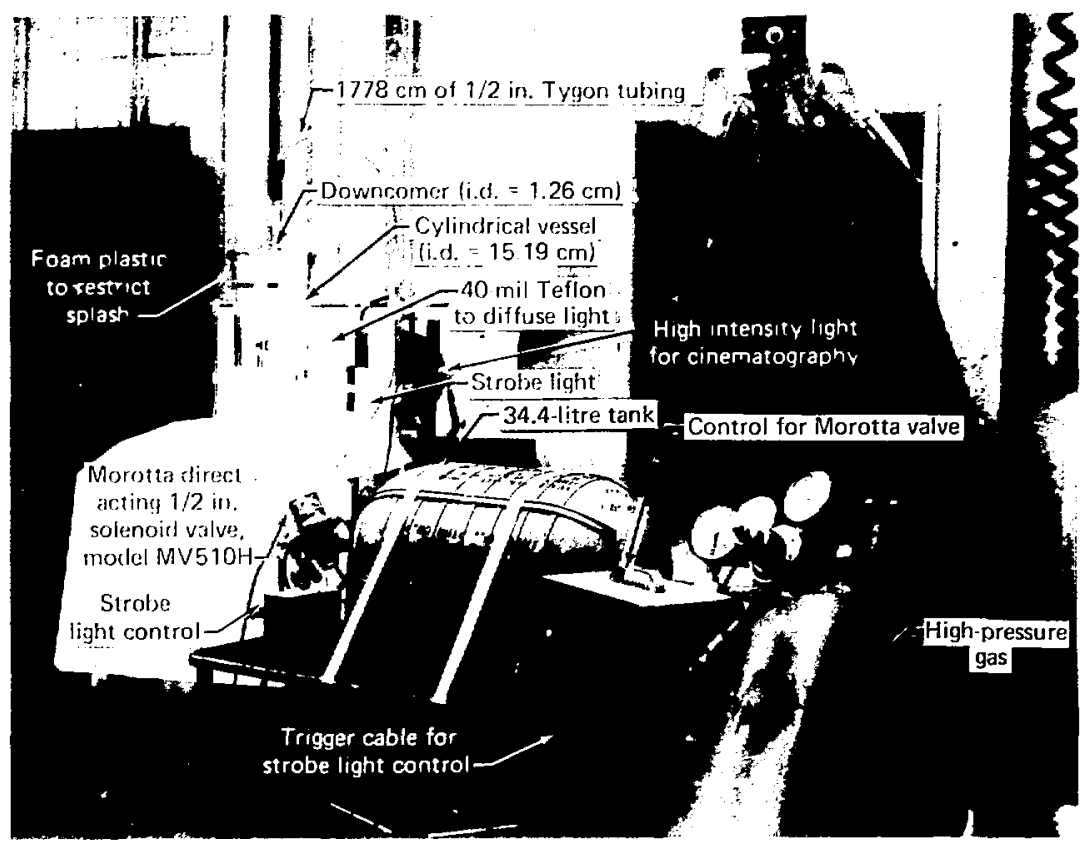

Jin. 19. Cylindrical puml wporiant showing balk I ighting arrangement.

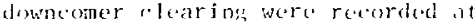

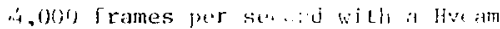

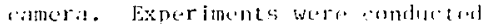
with both air and nitrogen la drival bis.

Kesults and Discussian

Parameters for the six tosts are listed in lable 8 . The presstur. ranges for the tests were selested as a compromise between desired and attajnable. The desired pressure was omputed from the pressure used in the ihTh valdations using the acreptod scaling law, which states that pressisure is proportional to limar swale.* The MATAl input or source pressure is $5.81 \times 10^{5} \mathrm{~Pa}$; bence, this series of tests should be conducted at

$$
\begin{aligned}
\mathrm{P}_{0} & =\frac{15.19}{12.91} \cdot 5.81=6.84 \times 10^{5} \mathrm{~Pa} \\
& =100.1 \mathrm{psig}
\end{aligned}
$$

* See Section 4 for a discussion of scaling laws 


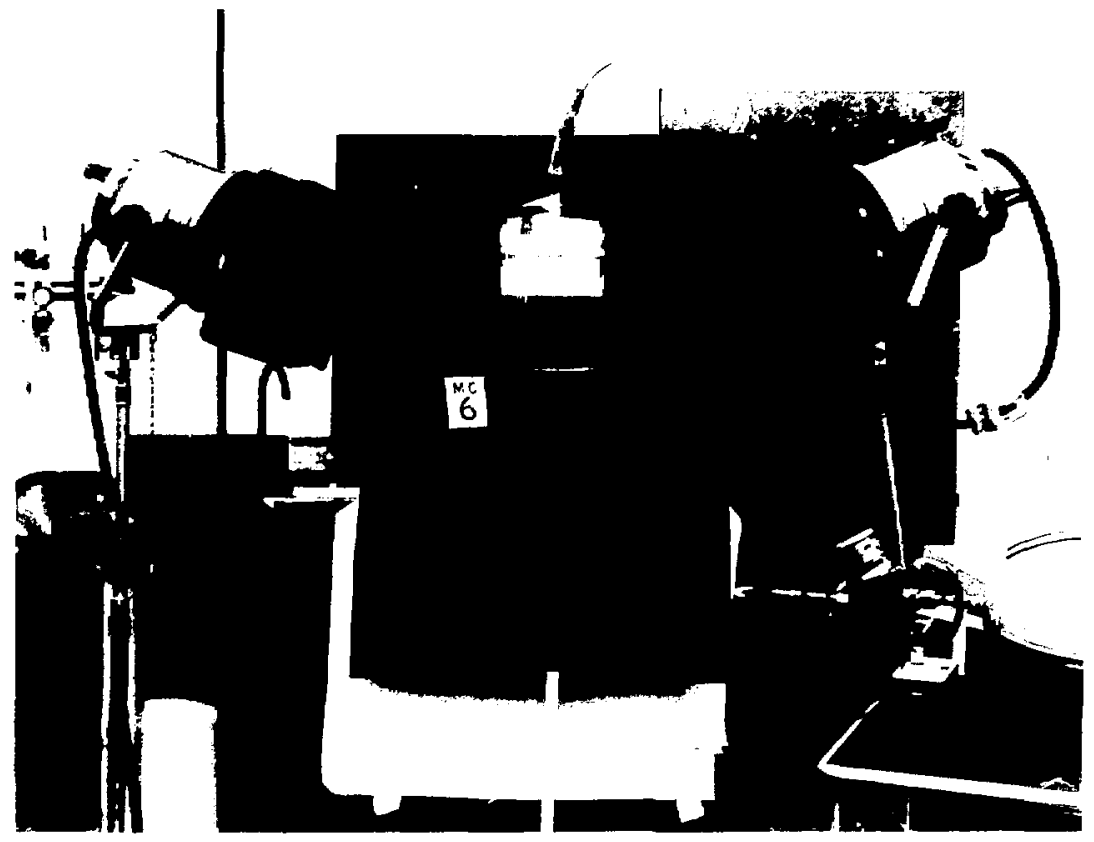

Fig. 20. Front-lighting arrangement for cylindricial pool test.s.

A maximum of 90 psig was used iu iimit the effect of pool splash (pool splash caused the vented foam plastic. plug to be ejected from the container when the source pressure was greater than $90 \mathrm{psig}$ ). The high speed films provided the data comparison for the MAITAI calculations.

The downcomer clearing times decermined from the high speed films were $0.0043 \mathrm{~s}$ for Test MC3 and $0.0047 \mathrm{~s}$ for MC4. As shown in Table 8 , these two tests differed only in

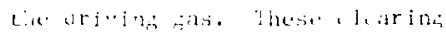
times may be comsidered idencicial within the at lainable accurary of measurcinents. Figure's 22 and 23 are frames from the high speed films of tests $\mathrm{MC} 3$ and $\mathrm{MC}_{4}$. Nite the approsimately $1: 1$ correspondence in lubble growth and pool shape. It is evident from Figs. 22 and 23 tilat, within the limitations of observation, air and $N_{2}$ sources produce essentially the same initial bubble in rowth. 


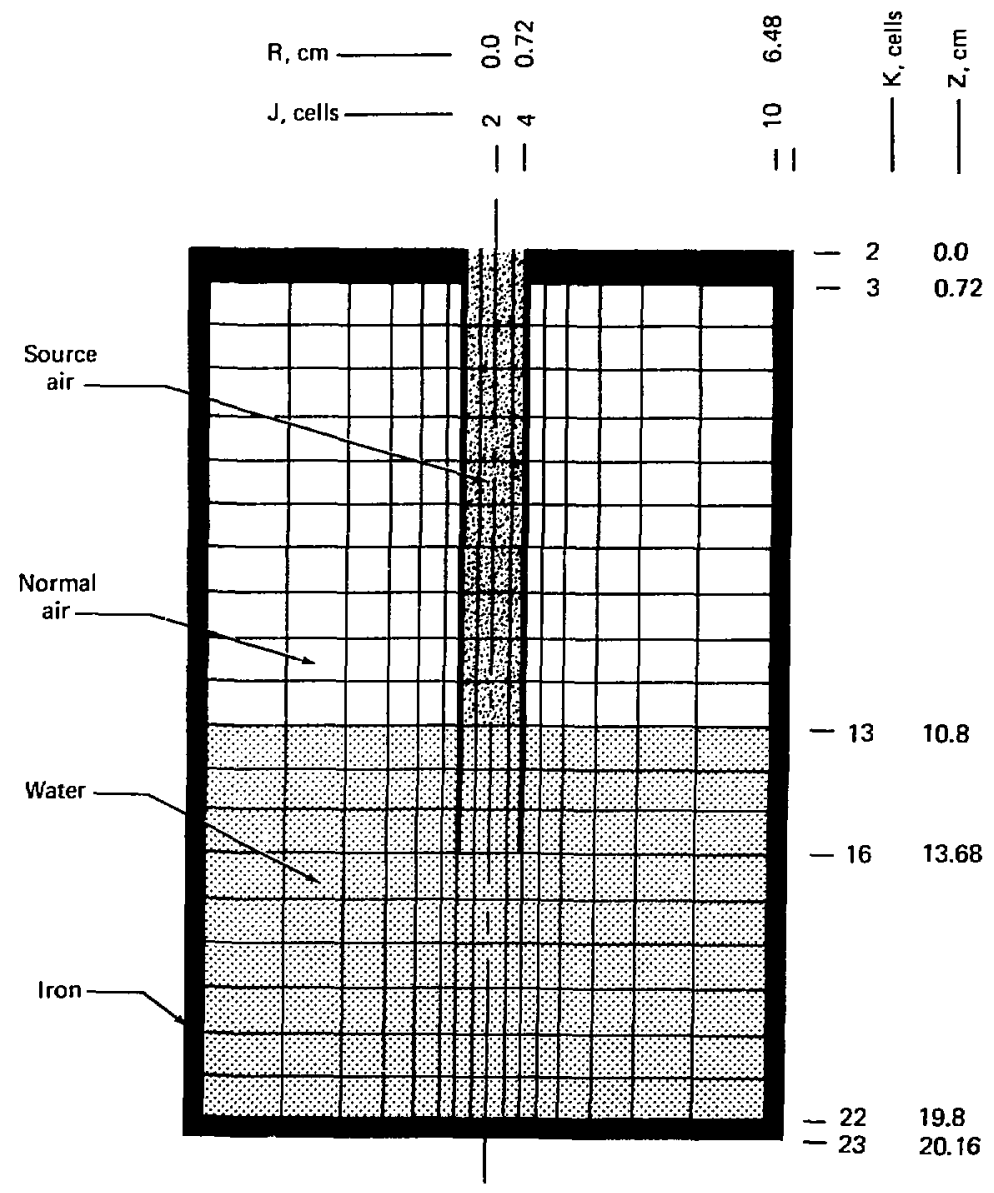

Fig. 21. Single downcomer geometry, on-axis. 
Table 7. Dimensions of cylindrical pool test apparatus.

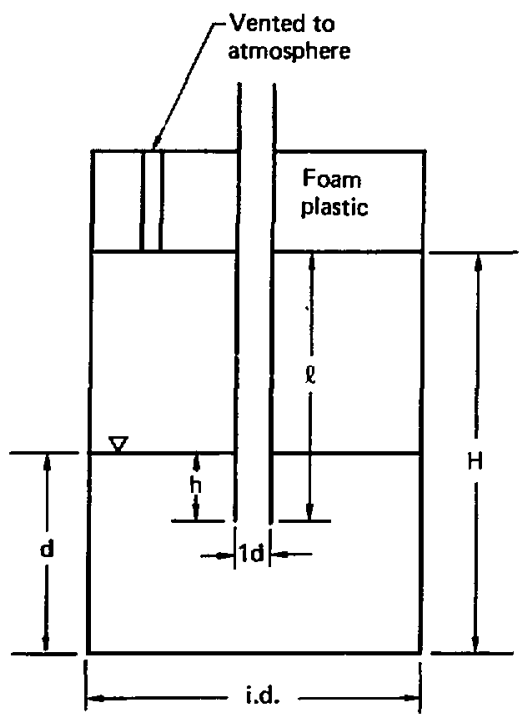

\begin{tabular}{cccc}
\hline Dimensions, cm & MAITAI & Scaled & Actual \\
\hline Id & 1.44 & 1.69 & 1.61 \\
i.d. & 12.96 & 15.19 & 15.19 \\
H & 19.08 & 22.36 & 22.36 \\
d & 9 & 10.55 & 10.55 \\
h & 2.88 & 3.38 & 3.38 \\
\& & 12.96 & 15.19 & 15.19 \\
\hline
\end{tabular}

According to the scaling laws (discussed in Section 4), time is proportional to the square root of a linear dimension. The times for the MAITAI-computed events (Fig. 24) scaled to the size of cylindrical pool experiments are summarized in
Table 9. Comparing FIg. 24 with Figs. 22 or 23 shows that actual bubble growth and pool surface breakthrough is slower than MAITAI predictions. Figures 22 and 23 also show that the actual shape of the bubble assumes the arrow-head-like 


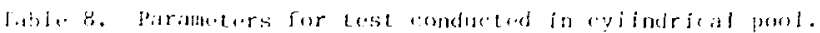

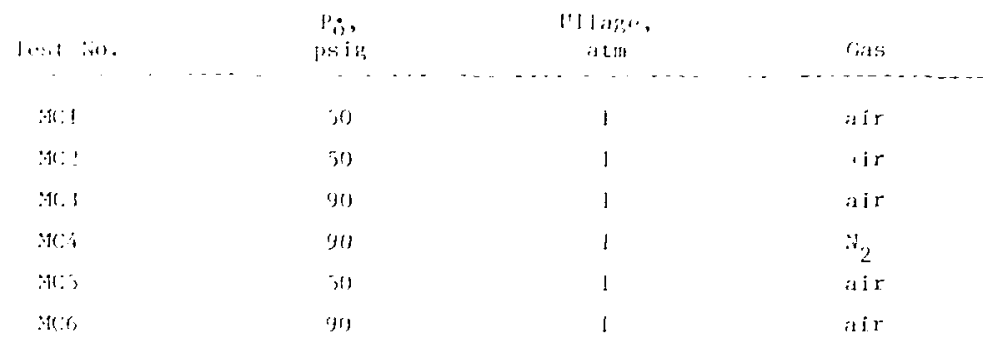

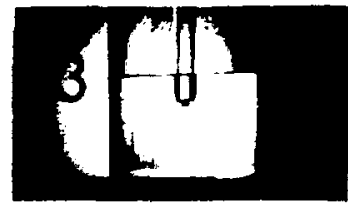

$0 \mathrm{~ms}$

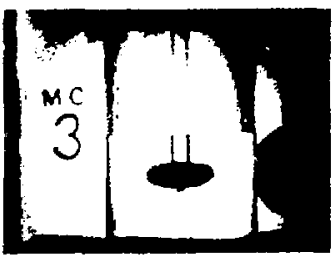

$3 \mathrm{~ms}$

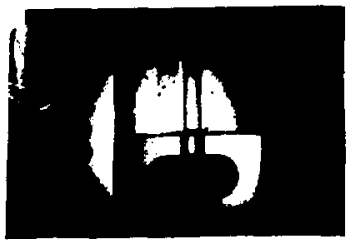

$7 \mathrm{~ms}$

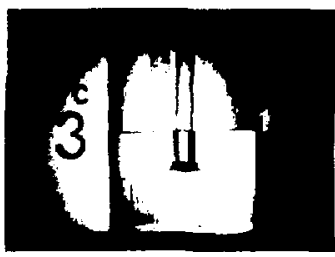

$1 \mathrm{~ms}$

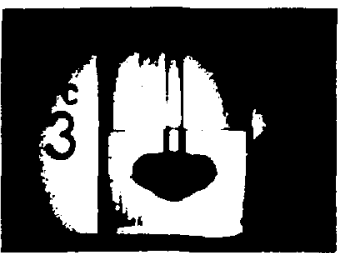

$5 \mathrm{~ms}$

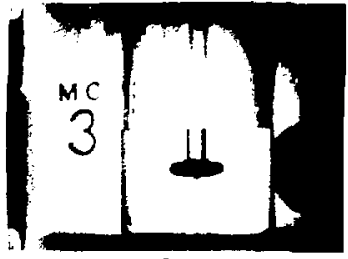

$2 \mathrm{~ms}$

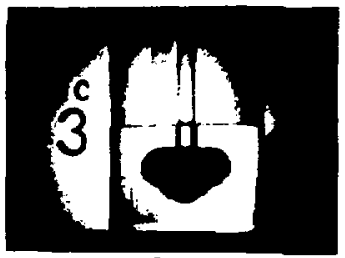

$6 \mathrm{~ms}$

Fig. 22. Selected frames from high speed motion pictures of Test NC3 (aii source). 
cross-section predicted by the computer code for tine $\geq 7 \mathrm{~ms}$. Although MAITAI code predictions are tailored more for the pressure and time range of a safety relief valve discharge than for a postulated LOCA, it is evident that they are qualitatively correct.

Both back-1ighting and frontlighting provided sufficient illumination for cinematography at $\checkmark 4,000$ frames per second: the bubble is dark with back-1ighting and bubble surface phenorena are accentuated. For this reason, flufd velocities on the surface of back-lighted bubbles are easier to measure than those from front-lighted bubbles.

\section{Cunclusions}

The results of these experiments indicate the following:

- Within the limitations of observation, air and $\mathrm{N}_{2}$ sources produce identical vent clearing and bubble growth.

- Although event times and magattudes are not predicted accurately, pool dynamics behavior computed with the MAITAI code agrees qualitatively with observed behavior.

- For the test configuration, both front- and back-1ighting produce satisfactory movies at $\checkmark 4,000$ frames per second.
1/64-SCALE TORUS MODEL STUDY ${ }^{18}$

The primary purpose of this study was to determine the adequacy of modeling the wetwell with a $90^{\circ}$ torus sector.

\section{Test Apparatus}

Figure 25 is a photograph of the 1/64-scale model. The transparent acrylic construction provides total viewing. The model was fabricated to permit selective positioning of vertical barriers in the wetwell and to block off selected vent I1nes. Selective insertion of barriers permitted evaluation of the effect of several sizes of torus segments and of blocked vent 1 ines.

The pressure history in the drywell and wetwell was recorded with oscilloscopes; Table 10 lists the location of measurements and type of transducers. Typica1 transducer data sheets are found in Appendix A.

To prepare for a test, the drywe11 dome was sealed with a burst disk. The apparatus was evacuated to the desired pressure and the burst disk was ruptured. Rupture of the disk triggered the oscilloscope to record the pressure history.

The pressures used were not scaled, due to the limits imposed by the water and the model. The minimum pressure 


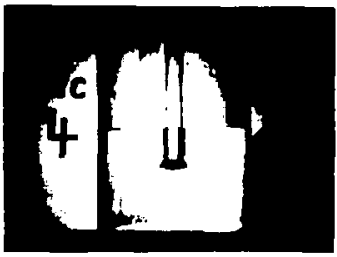

$1 \mathrm{~ms}$

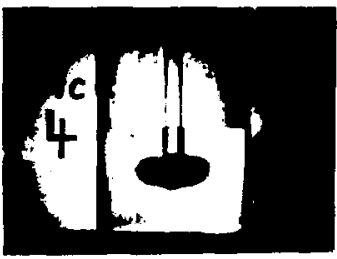

$4 \mathrm{~ms}$

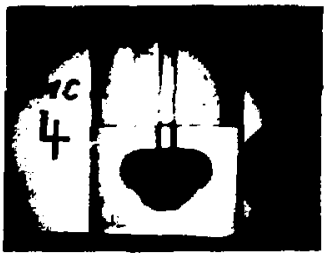

$7 \mathrm{~ms}$

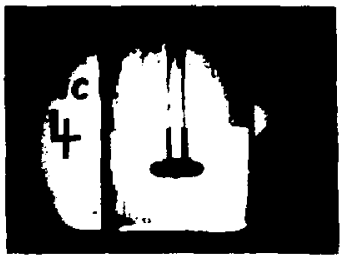

$2 \mathrm{~ms}$

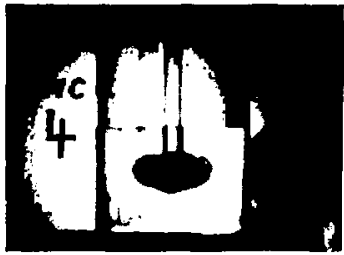

$5 \mathrm{~ms}$

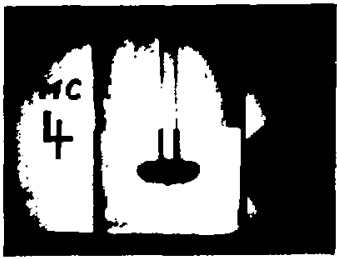

$3 \mathrm{~ms}$

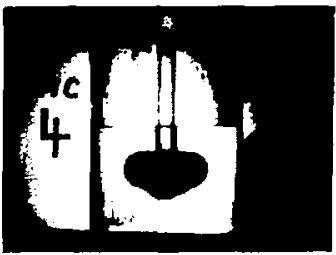

$6 \mathrm{~ms}$

Fig. 23. Selected frames from high speed motion pictures of Test IIC4 $\left(\mathrm{N}_{2}\right.$ source).

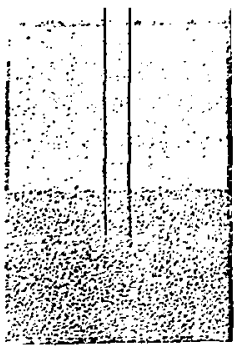

$\mathrm{t}=\mathbf{0} \mathrm{ms}$

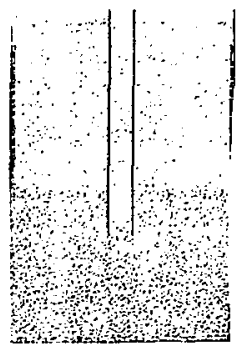

$\mathrm{t}=1 \mathrm{~ms}$

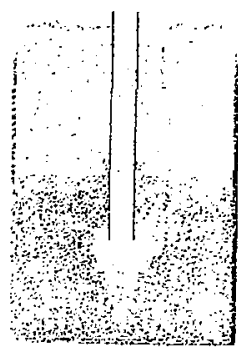

$\mathrm{t}=2 \mathrm{~ms}$

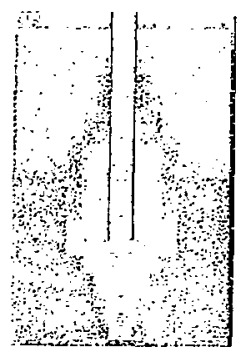

$\mathrm{t}=3 . \mathrm{s} \mathrm{ms}$

Fig. 24. Sequential bubble growth (density dot plot), single downcomer, on-axis, fiom MAITAI calculations. 


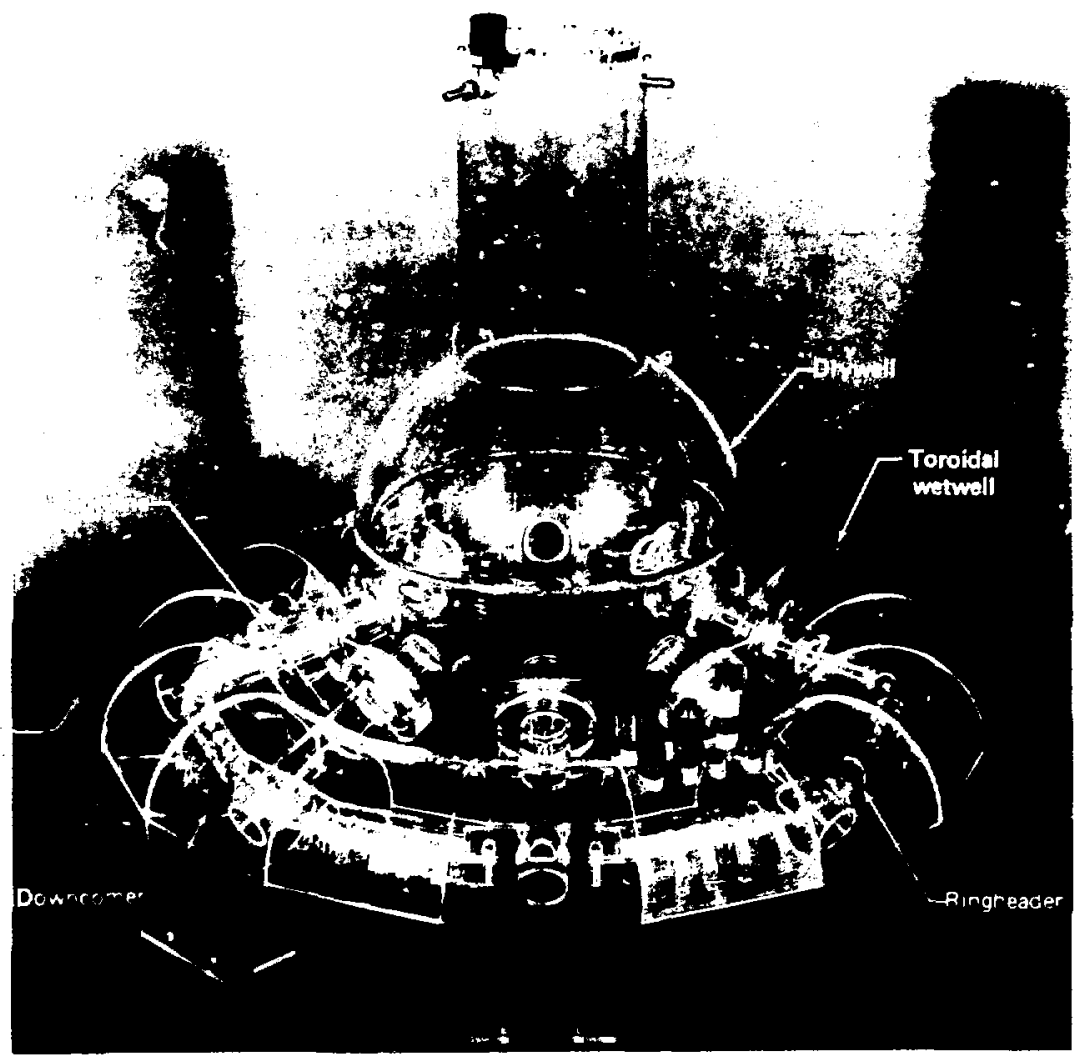

Fig. 25. Photograph of the 1/64-scale torus model.

was determined by the boiling point of the water. The maxinum pressure was determined by the burst pressure of the model. A Hycam camera provided cinematography at 400 frames per second.
Results and piceussion

Three seri.s totaling 100 tests were conducted. The first series was conducted with the torus consisting only of the bottom half. The sacond and third series were conducted with 
Table 9. Scaled times of MAITAIcomputed events.

\begin{tabular}{cc}
$\begin{array}{c}\text { MAITAI predicted } \\
\text { times, } \\
\mathrm{ms}\end{array}$ & $\begin{array}{c}\text { Cylindrica1 poo1 } \\
\text { experimental } \\
\text { times, } \\
\mathrm{ms}\end{array}$ \\
\hline 1 & 1.08 \\
2 & 2.17 \\
3.5 & 3.79 \\
\hline
\end{tabular}

the complete torus; the initial pressures in the drywell and wetwell were subatmospheric. A11 series tested the effects of barriers and blocked vent 1ines.
The toroidal wetwell was designed with $22-1 / 2^{\circ}$ between planes of symmetry. There are eight evenly spaced vent lines connecting the drywell to the wetwell in the complete torus. Tests were conducted with barriers placed at the planes of symmetry. Evaluation of asymetric flow due to blockage requires a minimum of two vent lines, i.e., a $50^{\circ}$ torus sector.

Critical examination of the high speed films showed that bubble dynamics and pool surface motion were independent of the torus segments size; the minimum size rested was

Table 10. Transducer characteristics for the $1 / 64$ th-scale model tests. ${ }^{a}$

\begin{tabular}{|c|c|c|}
\hline Location & Transducer & $\begin{array}{l}\text { Manufacturer's } \\
\text { stated accuracy }\end{array}$ \\
\hline $\begin{array}{l}\text { Top of drywel1 } \\
\text { test series } \# 2\end{array}$ & $\begin{array}{l}\text { Kulite, Model } \\
\text { HKMS-375-50A } \\
(0-50 \text { psia) }\end{array}$ & \pm 1.50 psia \\
\hline Test series $\$ 3$ & $\begin{array}{l}\text { Bel1 \& Howell, Model } \\
4-312 \text { (0-5 psid) }\end{array}$ & $\pm 0.05 \mathrm{psid}$ \\
\hline $\begin{array}{l}\text { Top of toroidal wetwell } \\
\text { test series } \|_{2}\end{array}$ & $\begin{array}{l}\text { Kulite, Model } \\
\text { HKMS-375-25A (0-25 psia) }\end{array}$ & \pm 0.75 psia \\
\hline Test series $\# 3$ & $\begin{array}{l}\text { Bel1 \& Howel1, Model } \\
4-312 \text { (0-5 psid) }\end{array}$ & $\pm 0.05 \mathrm{psid}$ \\
\hline $\begin{array}{l}\text { Bottom of toroidal wetwell } \\
\text { test series } \# 2\end{array}$ & No transducer & -- \\
\hline Test series \#3 & $\begin{array}{l}\text { Kulite, Model } \\
\text { HKMS-375-25A } \\
(0-25 \text { psia) }\end{array}$ & \pm 0.75 psia \\
\hline
\end{tabular}

${ }^{a}$ In test series, \#1 only photographic records were obtained. 
22-1/20 (Fig. 26). The films also showed most vigorous bubble action in regions of closely spaced downcomers; pool swell was also more prominent in these regions. The pressure traces show the delay in pressurization of the drywell and the wetwell (Figs. 27 and 28).

Pool dynamics action was not affected when one yent line was blocked. However, changes were noticeable as successfvely nore vent lines were blocked. These results suggest that the minimm, two-ventline $90^{\circ}$ sector was necessary for the 1/5-scale torus.

\section{Conclustons}

- Comparions of pressure-time traces and high speed motion pictures of the 1/64-scale apparatus reveal no difference between results with a full $360^{\circ}$ sector of the toroidal wetwell and those with a $90^{\circ}$ sector.

- Comparison of pressure-time traces and high speed motion pictures of the 1/64-scale apparatus reveal no difference between results with a full $360^{\circ}$ and with a $90^{\circ}$ sector of the toroldal wetwell.
- Tests on the 1/64-scale apparatus show no difference in the phenomena between tests with a $360^{\circ}, 45^{\circ}$, or $22-1 / 2^{\circ}$ sector of the toroidal wetwell. However, a $90^{\circ}$ sector ts required as a minimu for tests associated with vent-line asymetry for the 1/5-8cale apparatus.

- Three-dimensional effects were observed on tests with the 1/64-scale apparatus. Bubble action and pool swell were largest in regions where the downcomers were closely spaced. Little bubble action or pool swell were observed where the vent lines attach to the ringheader.

- The major hydrodynamic phenomena that exist in the pressure suppression system following a LOCA were observed in tests of the 1/64-scale apparatus.

- Results when one of efght vent lines was blocked indicated no difference from tests when all elght vent lines were open. However, if more than one vent line was blocked, decreases did occur in both the pool swell and in the magnitude of the structure of the pressure-time traces in the toroldal wetwell. 
(a)

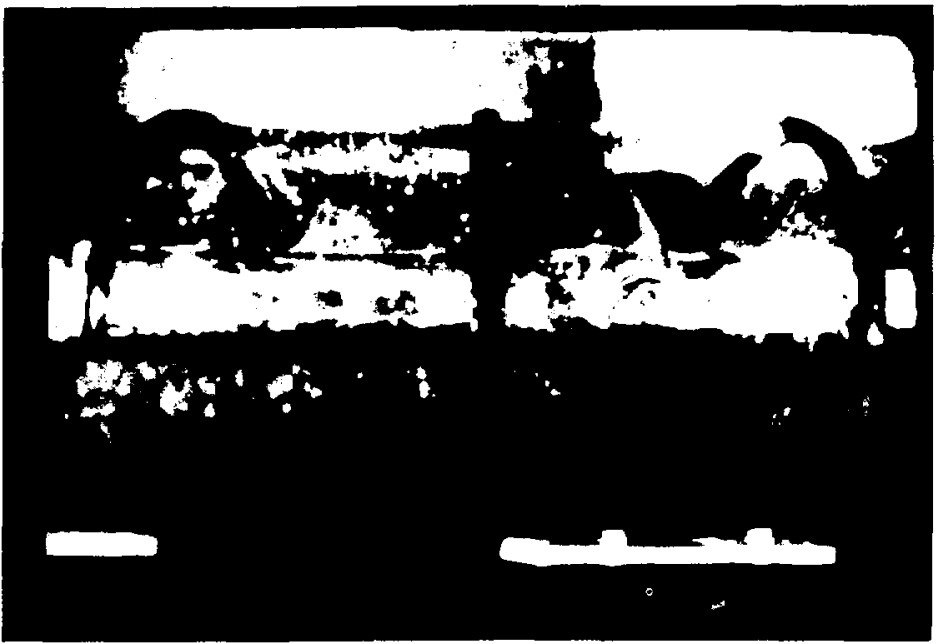

(b)

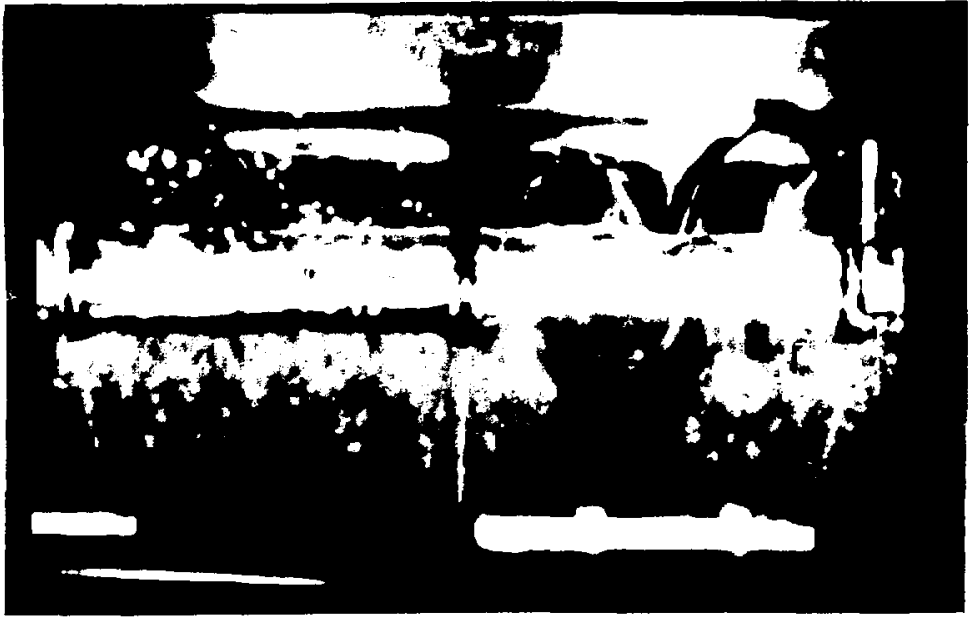

Fig. 26. Comparison of photographic results: (a) $360^{\circ}$ and (b) $90^{\circ}$ torus sector. 
(a) $360^{\circ}$ Sector

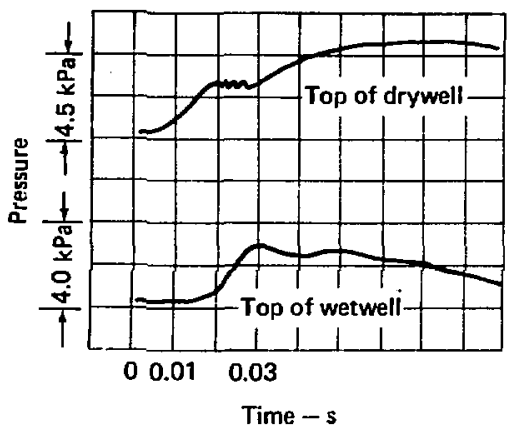

(b) $90^{\circ}$ Sector

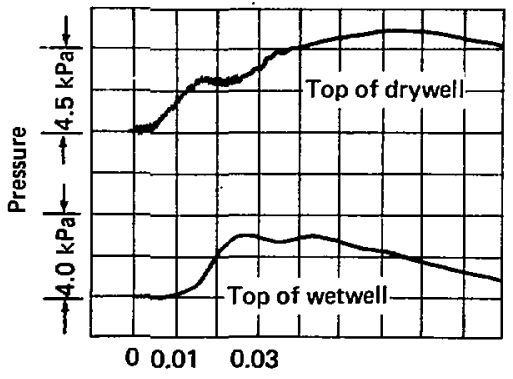

Time $-\mathrm{s}$

Fig. 27. Comparison of pressure traces for the top of the drywell (initial pressure $=8.6 \times 10^{4} \mathrm{~Pa}$.) (a) $360^{\circ}$ sector, (b) $90^{\circ}$ sector.
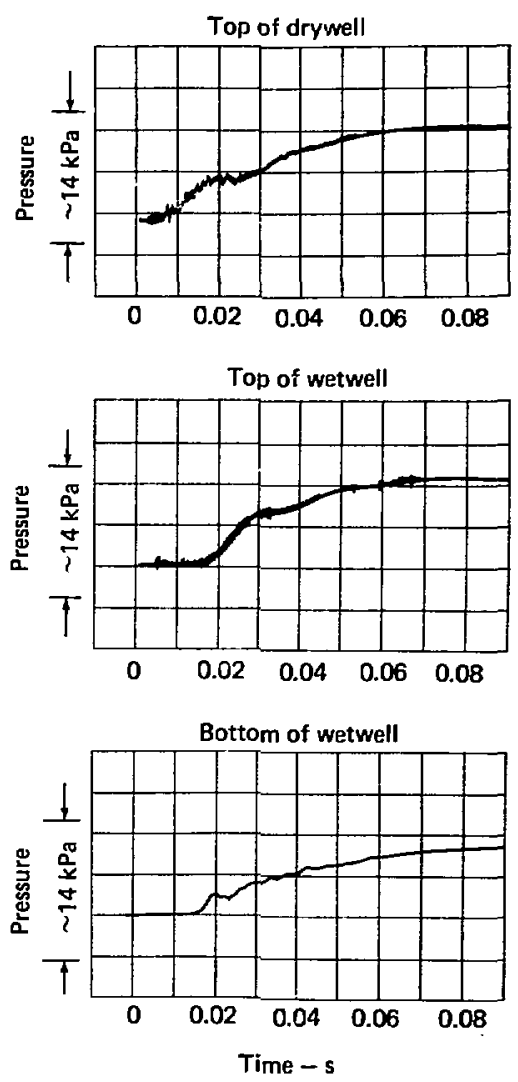

Fig. 23. Comparison of pressure traces for the top of the toroidal wetwell (initial pressure $=8.6 \mathrm{i}$ $\left.10^{4} \mathrm{~Pa}\right)$. 


\section{INSTRUMENTED STUDIES}

Scaling laws, developed to predict plant loads from loads measured with scaled models, were studied with instrumented table-top experiments. Fully instrumented benchmark experiments were conducted to establish a set of reference data suitable for computer code verification. Tests were also conducted to charricterize the VLF and to investigate the effect of downcomer fill level on the VLF.

SCALING LAW EXPERIMENTS ${ }^{19}$

This limited study was conducted to experimentally establish the poo1dynamics modeling or scaling law to ensure that the $1 / 5-$ scale results could be applied to actual plants. Earlier, Moody ${ }^{20}$ derived a law that is generally accepted in industry for predicting plant loads from measurements made with geometrically reduced models. In terms of dimensionless groups, the scaling law may be expressed ${ }^{*}$ as

$\frac{E}{\rho_{\ell} g L^{3}}=\phi\left(\frac{P I}{\rho_{\ell} g L}, \frac{P o}{\rho_{\ell} g L}, \frac{R T o}{g L}, f, \gamma, \frac{t^{2} g}{L}\right)$ (1)

(Eq. (I) is hereafter designated Model A.) The factor (RTo/gL) was shown to be equivalent to the enthalpy

\footnotetext{
*The Glossary of Terms identifies the varlables.
}

fIux parameter of Moody when $\gamma$ is constant ${ }^{13,19,20}$ :

$$
\frac{h_{o} \dot{m}}{\rho_{g} g^{3 / 2} L^{7 / 2}} \times \frac{y \text { RTo }}{g L(\gamma-1)^{3 / 2}}
$$

ilethod and Test Apparatus

Modeling laws apply to physical phenomena and are not restricted to specific hardware. To test the validity of scaling pool dynamics phenomena, it is suffjcient to focus on pool-dynamics phenomena generated in geometrically scaled apparatus; the apparatus need not be faithful reproductions of the full-sized plant nor of plant operating parameters. The resulting measurements (e.g., peak forces) will not be applicable to the full-sized plant; to be applicable, data must be generated with models configured and parameters sized after the full-sized plant. The observed phenomena are, however, those representative of the large-scale or prototype systems.

Tests were conducted with two sizes of bolling flasks and downcomers (Fig. 29). In this manner, the scaling of the measured forces resulting from pool dynamics may be compared for similar systems. Figure 30 shows the basic equipment. (The Hycam camera for cinematographic 


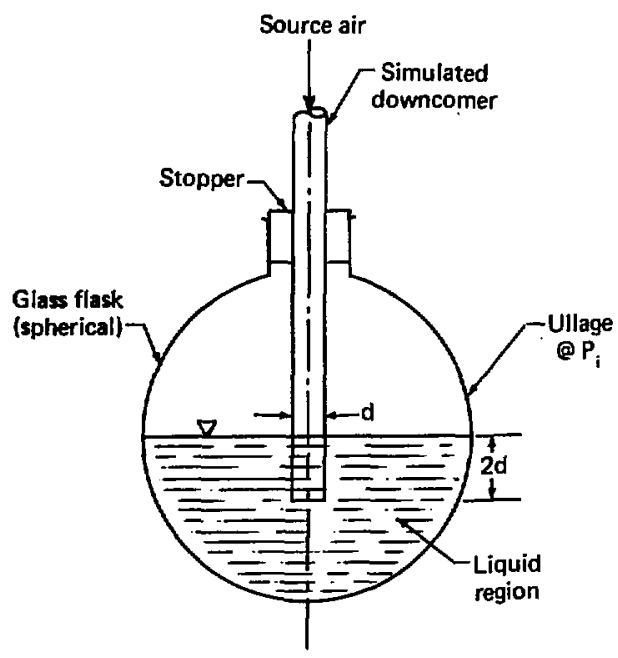

FIg. 29. Basic experimental flask configuration.

coverage at $\mathbf{9 0 0}$ frames per second is in the foreground.) Figure 31 is a schematic of the experimental apparatus. Figure 32 is a block diagram showing the instrumentation and controls (see Appendix A for typical. transducer data sheets). Tests with other sizes of flasks and with other fluids than water were planned. Time and funding constraints, however, permitted only a portion of the planned experiments to be conducted.

The canera is started prior to the test. When the framing rate becomes constant, a zero-crossing switch is closed and the valve opens a few ms later to initiate flow. An amplified signal from the pressure transducer near the valve triggers a strobotac and fires a flashbulb. The strobotac pulse duration is so short - only about one $\mu s$ - that it may be missed on the film; the strobotac pulse was, however, observed on $\mathrm{film}$ in approximately $40 \%$ of the experiments. The flashbulb (AGlB) light lasts several ms but peaks about 2 ms after initiation, due to thermal inertia.

The signal from the pressure transducer also triggers the oscilloscope. The voltage output of the load cell is recorded for about $45 \mathrm{~ms}$ using a single sweep on the oscilloscope display. This period is sufficient to obtain the response through the time of Interest. Since the start of 


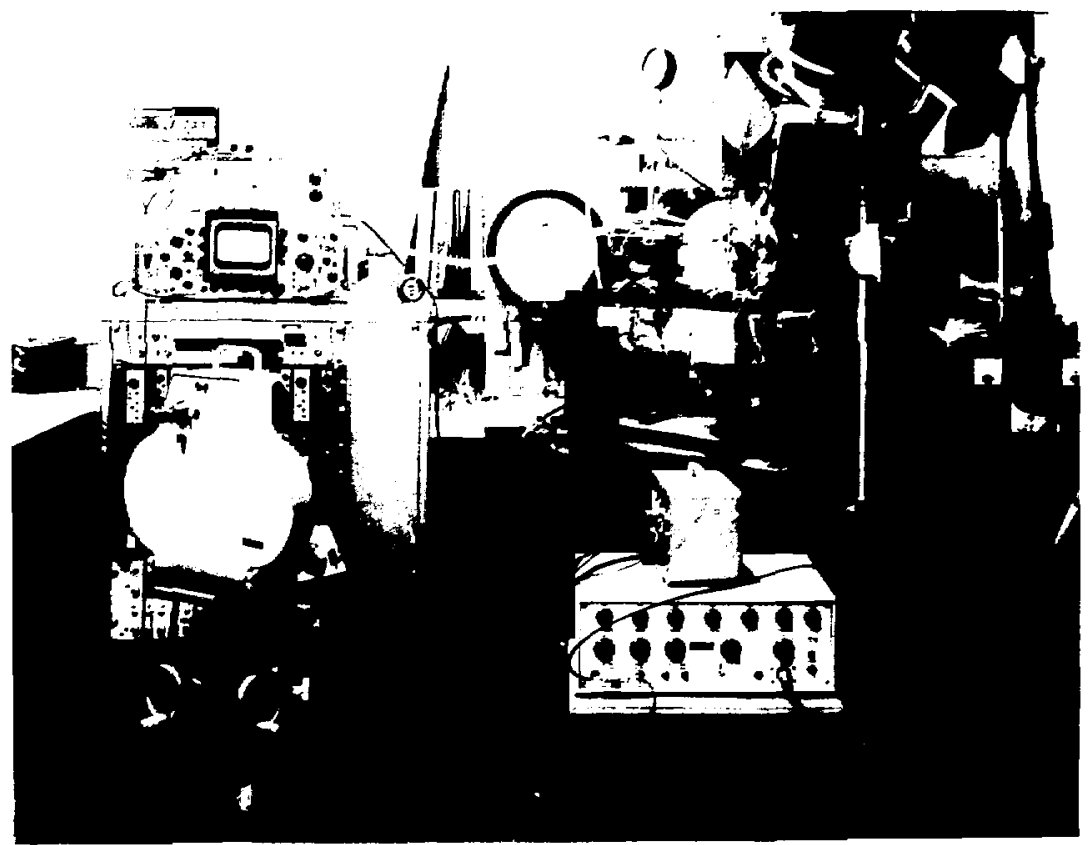

Fig. 30. Test apparatus.

the osc: lloscope trace is practically simultaneous with the strobotac Iight signal recorded on filtn, the oscilIoscope recorded load cel] trace and the high speed movie has a common fiducial.

Four safe, transparent liquids of widely different densities and proportional scaling pressures were used in these experiments to allow perfect scaling (according to any of: the four scaling models considered by us) at room temperature.
Experiments were conducted with variations in length scale, liquid density, driving pressire $\left(P_{0}\right)$, and initial pressure $\left(\mathrm{P}_{\mathrm{i}}\right)$. Additionally, deliberate exploration of distortions by varying temperatures was also planned; however, the time available was too short to accomplish this.

Results and Discussion

Figure 33 shows a typical RVLF for these tests. The existence of low and higher frequency oscillations is 
(a) Plan view

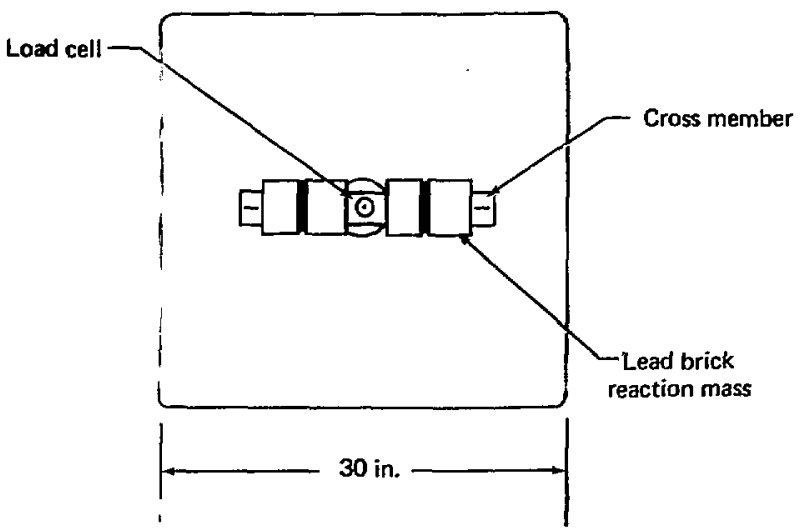

(b) Elevation

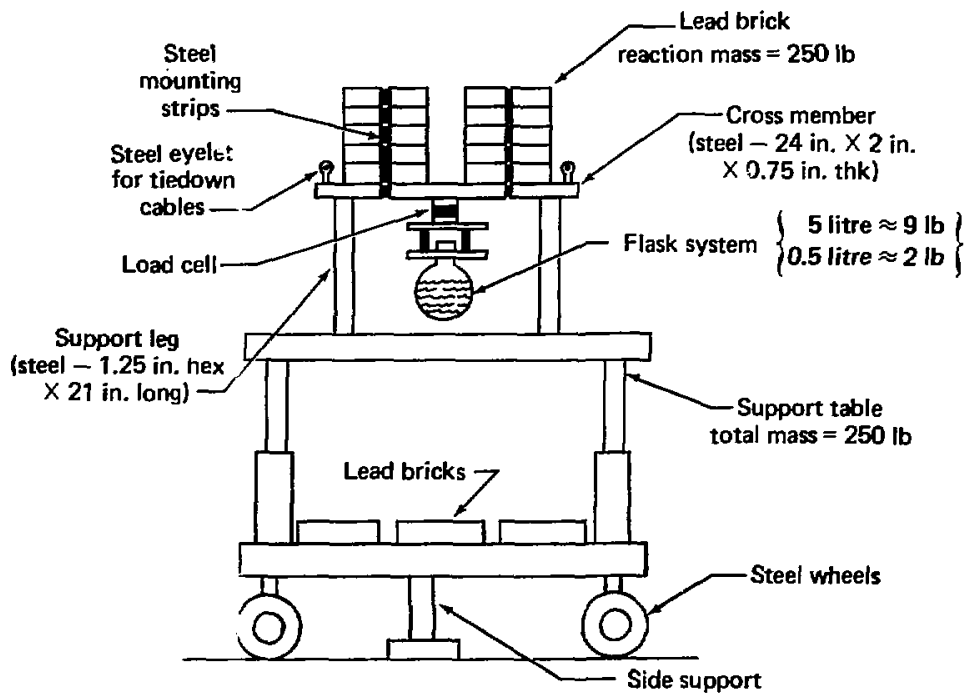

Fig. 31. Schematic of load-cell support system. 


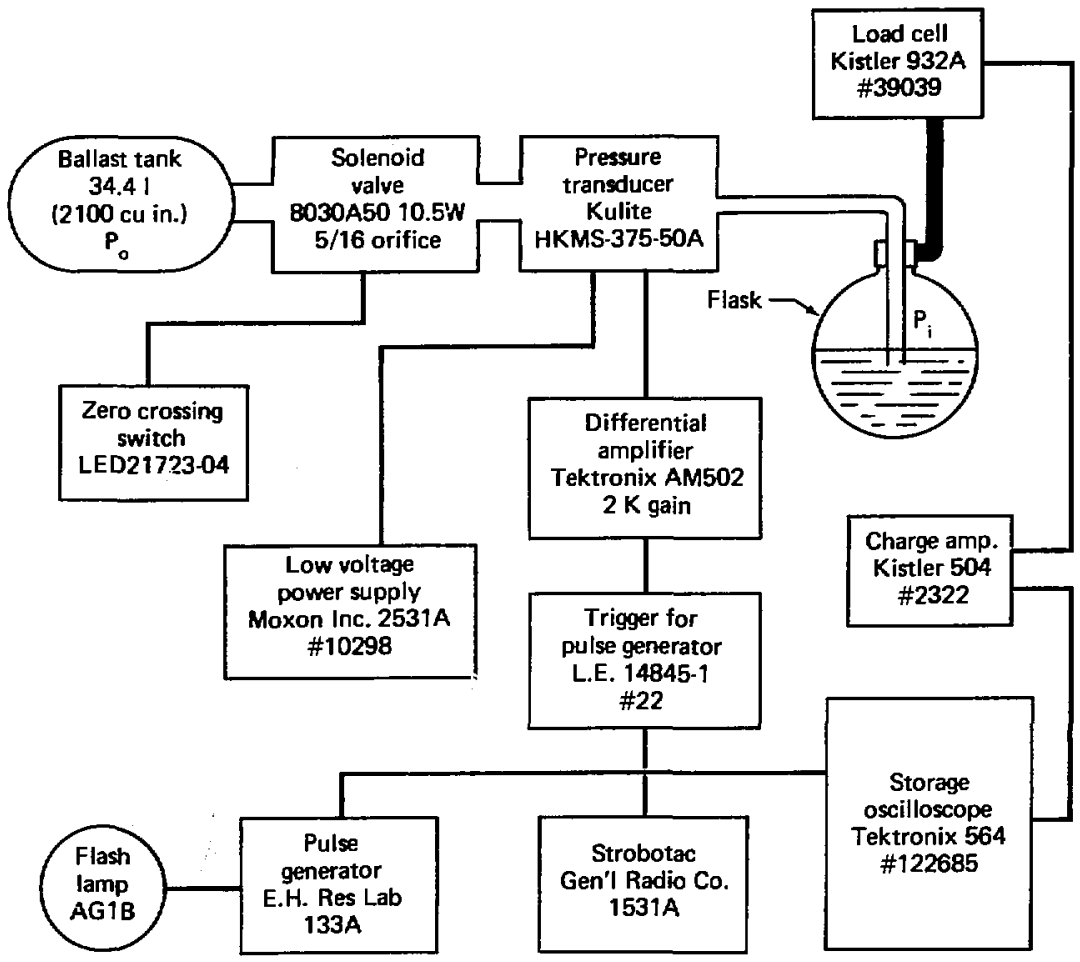

Fig. 32. Block diagram of scaling test equipment.

evident. The shorter duration of the maximum download spike compared with the upload is prominently displayed. The upload is significant, even though the test geometry does not have a header. The labels in Fig. 33 define the quantities used in this section.

The restricted range of variables studied, coupled with the limited number of tests, prohibited application of customary dimensionless group correlation procedures. Instead, more fundamental approaches were used that involved testing the effect of parameters as dictated by the scaling law and testing simplified scaling laws derived by neglecting parameters of minor significance. 


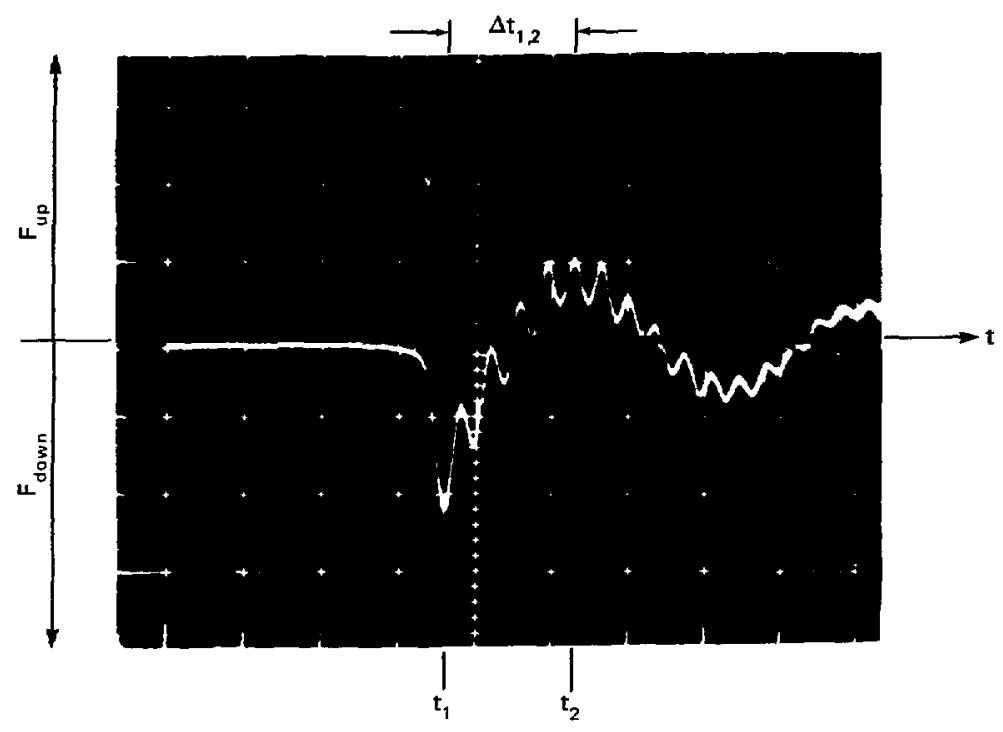

Fig. 33. Typical oscilloscope load trace.

The experiments can be grouped into four series based on the values of the dimensionless groups. The parameters of these serie., based on water, are shown in Table 11. The length $L$ is arbitrarily chosen to be the downcomer submergence. Series I and II were conducted with a 5-litre flask and four fluids (Table 12). Series III and IV used a 0.5-1itre flask. All four liquids were used in Series III, but only water was used in Series IV. (Series III and IV are identical except for the flow restriction in Series IV tests.)
In all series, water was the basis fluid. For Series I, the basis source pressure $p_{0}$ was set at 15 psia and the initial drywell and ullage pressure $p_{i}$ at 5 psia. The corresponding pressure sets for the other working fluids were calculated from the dimensionless group $\mathrm{p} / \mathrm{\rho}_{\ell} \mathrm{gL}$. The pressure sets for test Series II, III, and IV were computed from the Series I pressures using the geometric scale factor $\sqrt[3]{10}$. Test Series II, conducted with the 5-1itre flask, used the same pressures as the Series III (0.5-1iter flask) to explore the 
Table 11. Summary of dimensionless groups (Series I-IV).

\begin{tabular}{|c|c|c|c|c|}
\hline \multirow[b]{2}{*}{ Quantity } & \multicolumn{2}{|c|}{ 5-litre flask } & \multicolumn{2}{|c|}{0.5 -11tre flask } \\
\hline & Series I & Series II & Series III & Series IV \\
\hline$p_{o} / \rho_{l} g L$ & 332 & 154 & 332 & 332 \\
\hline $\mathrm{p}_{\mathbf{i}} / \rho_{\ell} \mathrm{gL}$ & 110 & 51 & 110 & 110 \\
\hline$R T_{0} / g L$ & $2.7 \times 10^{5}$ & $2.7 \times 10^{5}$ & $5.8 \times 10^{5}$ & $5.8 \times 10^{5}$ \\
\hline $\mathrm{K}$ & 89.6 & 89.6 & 91.5 & 193.9 \\
\hline$\gamma$ & 1.4 & 1.4 & 1.4 & 1.4 \\
\hline$p_{0} / p_{i}$ & 3 & 3 & 3 & 3 \\
\hline
\end{tabular}

implications of the Model $\mathrm{C}$ scaling law discussed below.

Effect of Pool Fluid Density

The maximum downward force, the maximum upward force, and the time elapsed between the force maxima were selected for comparison. According to Model A, tests employing different liquids with different densities will scale together, provided the pressures

Table 12. Working fluids used in scaling experiments.

\begin{tabular}{ll}
\hline \multicolumn{1}{c}{ Fluid } & $\begin{array}{c}\text { Specific } \\
\text { gravity, } \\
\text { gm/cm }\end{array}$ \\
\hline Dow Corning 200 & 0.761 \\
Water & 1.000 \\
$1,1,1-t r i c h l o r o e t h a n e$ & 1.325 \\
$1,1,2-t r i c h l o r o e t h a n e$ & 1.4432 \\
\hline
\end{tabular}

are varied in proportion, other variables remaining constant. Thus, $p_{i} / \rho_{\ell} g L$ and $p_{o} / \rho_{\ell} g L$ are each fixed. Then, as in Eq. (1), the resultant hydrodynamic forces will scale in proportion to the density. That is,

- $F / \rho_{\ell} \mathrm{gL}^{3}$ should have the same value in each test within a series.

- The timescale should be unaffected by the density and pressure changes.

- Corresponding values of $F / \rho_{\ell} g \mathrm{~L}^{3}$ should be observed at corresponding values of $t^{2} g / L$.

Results of exploring the validity of the first two statements above are shown in Figs. 34-38, Figure 34 demonstrates that maximum downward force scales as predicted. Figures 35-37 verify that the scaling also describes the upward force. In each figure showing force versus density, the resultant force is proportional 

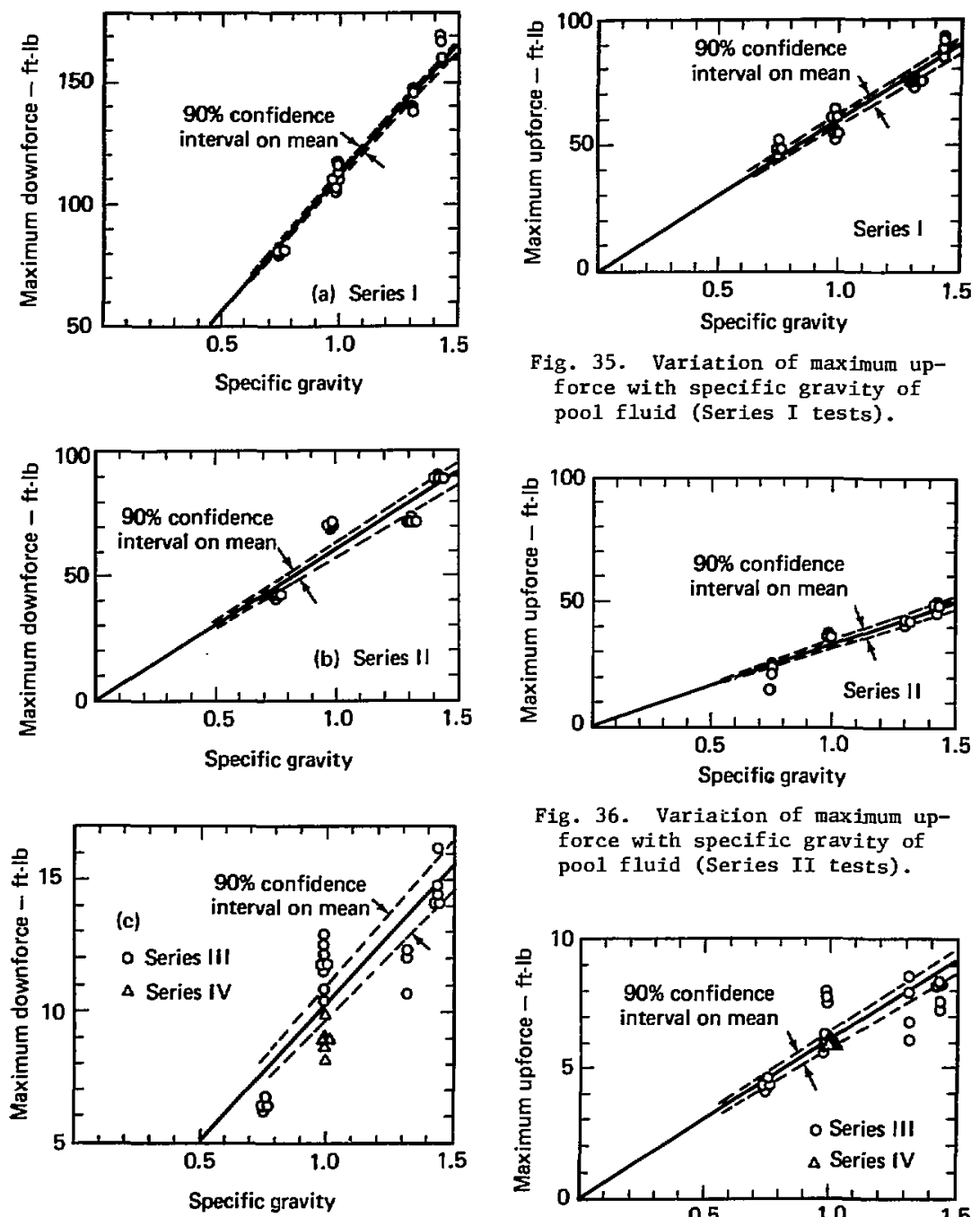

Fig. 34. Variation of maxtmum downforce with specific gravity of pool fluids: (a) Series I tests, (b) Series II tests, and (c) Series III and IV tests.

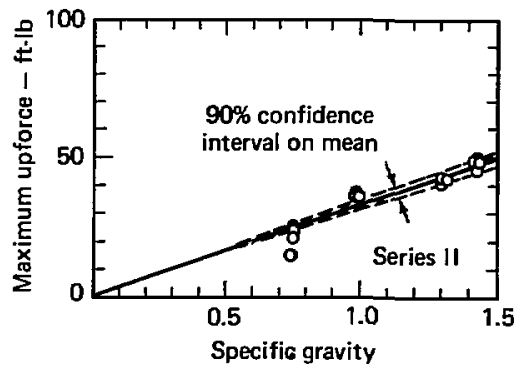

Fig. 36. Variation of maximum upforce with specific gravity of pool fluid (Series II tests).

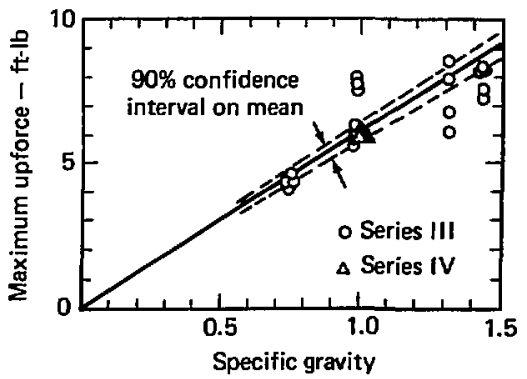

Fig. 37. Variation of maximum upforce with specific gravity of pool fluid (Series III and IV tests). 


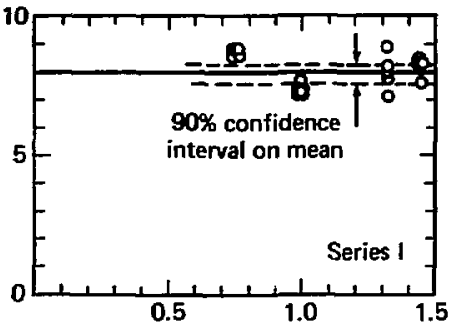

Specific gravity

Fig. 38. Effect of specific gravity of pool fluid on time interval between maximum forces.

to density. FIgure 38 shows that the timescale is independent of density, as predicted. The data scale within acceptable errors, according to Model A.

Testing Significance of Groups

The number of grouss in Eq. (1) may be reduced if nearly constant parameters are dropped. If the temperature dependence is assumed to be small (as though the flow were essentially barotropic), the temperature and gas constant can be removed from the parameter set. This leaves nine variables, three dimensions and, consequently, six groups, thus reducing Model A to llodel B:

$\frac{F}{\rho_{\ell} g L^{3}}=\phi\left(\frac{P_{t}}{\rho_{\ell} g L}, \frac{P_{o}}{\rho_{\ell} g L}, f, \gamma, \frac{t^{2} g}{L}\right)$

If thermal effects are significait and we ignore gravitational effects, we have ten varlables, four dimenstons, and, again, six groups. Under these conditions, Model A reduces to Hode1 C:

$\frac{F}{P_{i} L^{2}}=\phi\left(\frac{P_{i}}{P_{0}}, \frac{P_{i}}{\rho_{\ell} R T_{0}}, f, \gamma, \frac{\tau^{2} P_{i}}{\rho_{\ell} L^{2}}\right)$

If we assume that the temperature group $R T_{o} / g L$ can be compensated for by changing (increasing) the flow resistance $(K=f L / D)$ of the model over that of the reference system, then Model $A$ may be written as Mode1 D:

$$
\begin{aligned}
& \frac{F}{\rho_{\ell} g L^{3}}=\phi\left(\frac{P_{i}}{\rho_{\ell} g L}, \frac{P_{o}}{\rho_{\ell} g L}, K, \gamma, \frac{t^{2} g}{L}\right) . \\
& K=f \frac{L}{D} \text { is defined by } \\
& \left(f \frac{L}{D}\right)_{m}=\frac{L r}{L m}\left[1+\left(f \frac{L}{D}\right)_{r}\right]-1 .
\end{aligned}
$$

The modification is developed in terms of enthalpy flux by Moody. 20a

The predictive capability of each model can be tested by comparing experfmental results among the test serles. The mean values of these comparisons for all fluids tested are shown in Tables 13-16. Examination of the tabulated data permits evaluation of the scaling models. 
Table 13. Maximum downforce comparison.

\begin{tabular}{cllccccc}
\hline Model & Function & Reference & Series & Model & Series & $\begin{array}{r}\text { Difference } \\
\text { between means, \% }\end{array}$ & $\begin{array}{c}\text { Is difference significant } \\
\text { at } 0.05 \text { conf Idence level? }\end{array}$ \\
\hline B & $F / \rho_{\ell} \mathrm{LL}^{3}$ & $1563 \pm 22$ & I & $1467 \pm 84$ & III & -6 & No \\
C & $F / \rho_{1} L^{2}$ & $16.72 \pm 0.79$ & II & $13.25 \pm 0.76$ & III & -21 & Yes \\
D & $F / \rho_{\ell} \mathrm{gL}^{3}$ & $1563 \pm 22$ & I & $1283 \pm 68$ & IV & -18 & Yes \\
\hline
\end{tabular}

岁

Table 14. Maximum upforce comparison.

\begin{tabular}{|c|c|c|c|c|c|c|c|}
\hline Model & Function & Reference & Series & Model & Series & $\begin{array}{l}\text { Difference } \\
\text { between means, \% }\end{array}$ & $\begin{array}{l}\text { Is difference significant } \\
\text { at } 0.05 \text { confidence level? }\end{array}$ \\
\hline B & $F / \rho_{\ell^{g L}}{ }^{3}$ & $855 \pm 24$ & I & $846 \pm 46$ & III & -1 & No \\
\hline C & $F / p_{i} L^{2}$ & $9.03 \pm 0.39$ & II & $7.64 \pm 0.41$ & III & -15 & Yes \\
\hline $\mathrm{D}$ & $F / \rho_{\ell} g L^{3}$ & $855 \pm 24$ & I & $856 \pm 21$ & IV & +0.1 & No \\
\hline
\end{tabular}


Table 15. Comparison of times to maximum downforce.

\begin{tabular}{cccccccc}
\hline Model & Function & Reference & Series & Model & Series & $\begin{array}{c}\text { Difference } \\
\text { between means, \% at } 0.05 \text { confidence level? }\end{array}$ \\
\hline B & $t \sqrt{\mathrm{g} / \mathrm{L}}$ & $0.2400 \pm 0.0038$ & I & $0.1787 \pm 0.0055$ & III & -25 & Yes \\
$\mathrm{C}$ & $t \sqrt{\mathrm{g}_{\mathrm{i}} / \rho_{\ell} \mathrm{L}^{2}}$ & $2.098 \pm 0.054$ & II & $1.880 \pm 0.058$ & III & -10 & Yes \\
$\mathrm{D}$ & $\mathrm{t} \sqrt{\mathrm{g} / \mathrm{L}}$ & $0.2400 \pm 0.0038$ & I & $0.1720 \pm 0.0084$ & IV & -29 & Yes \\
\hline
\end{tabular}

t)

Table 16. Comparison of time intervals between load maxima.

\begin{tabular}{|c|c|c|c|c|c|c|c|}
\hline Mode1 & Function & Reference & Sertes & Model & Series & $\begin{array}{c}\text { Difference } \\
\text { between means, \% }\end{array}$ & $\begin{array}{l}\text { Is difference significant } \\
\text { at } 0.05 \text { confidence level? }\end{array}$ \\
\hline B & $t \sqrt{g / L}$ & $0.1407 \pm 0.0042$ & I & $0.225 \pm 0.011$ & III & +64 & Yes \\
\hline C & $t \sqrt{\frac{1}{2}}$ & $1.841 \pm 0.086$ & II & $2.369 \pm 0.113$ & III & +29 & Yes \\
\hline D & $t \sqrt{g / L}$ & $0.1407 \pm 0.0042$ & I & $0.2168 \pm 0.0111$ & IV & +57 & Yes \\
\hline
\end{tabular}


In each comparison, we make the nulZ hypothesis that the means* are equal. We use the Student's $t$ test to establish whether the differences in these means are significant. Rejection of the nuZZ hypothesis is, consequently, a reasonable position to take when rejection is indicated. If rejection is not indicated, we reserve judgment, but any differences between means may well be solely due to chance.

As shown in Table 13, the maximum downward force is predicted most closely by Model B (i.e., when the model flow resistance is the same as that of the reference system). Model $\mathrm{C}$, the gravity-free model, and Model D, the modified flow-resistance model, both underestimate this force by a considerably larger margin.

As Table 14 demonstrates, the maximum upward force is closely predicted by both Model $\mathrm{B}$ and Model $\mathrm{D}$, independently of the model flow resistance. Again, Model C underestimates the forces. Because the maximum downward force nearly coincides with downcomer clearing, it appears that the additional flow restriction introduced in Mode 1 D to simulate the post-peak-download bubble formation reduces the early forces below the scaled values wlthout significantly

\footnotetext{
*The $90 \%$ confidence Ievel was selected.
}

affecting the peak upload. The agreement for the maximum upward forces most likely results from the fact that the flow at this later stage is largely governed by the postinjection liquid response. This relative independence of maximum upload from maximum download has been observed in the loss of fluid test (LOFT) experiments. 21

Models $B$ and $D$ fail to predict the observed times; time does not scale as predicted by these models (see Tables 15 and 16). Time is more closely scaled by Model $\mathrm{C}$, although significant differences remain between computation and observation. Since gravity must certainly have little effect on the gas motion prior to significant liquid motion in the downcomer, it seems entirely reasonable that Model $\mathrm{C}$ should better scale the time to maximum download. (See Benchmark Experiments, below, for additional discussion of the scaling of time.)

\section{Conclusions}

The results of the air-scaling tests conducted suggest the following conclusions:

- The predictability of peak download in the reference system is best obtained from the model whose flow resistance $K$ is the same as trat of the reference system. 
- The predictability of peak download in the reference system is impaired by introduction in the model of the increased flow resistance of Model D or the gravity-free modeling of Model C.

- The reference-system peak upload is equally well predicted by models having either a flow resistance equal to that of the reference system (Model B) or a flow resistance inrreased as indicated by Eq. (7) (Nodel D).

- Failure to scale the temperature group of Lodel A does not significantly distort the peak load scaling.

- Time or time intervals are not we1l scaled by the models.

\section{BENCHMARK EXPERTMENTS 22}

The primary purpose of this experiment was to produce quantitative data to validate various air-water dynamic computations; the experiments were performed because relevant benchmark data were not $: a i l a b l e$ from outside sources. The secondary purposes of this study was to provide a test bed for instrumentation and postexperiment data processing techniques to be used in the 1/5-scale pressure suppression experiment to provide additional measurements for the alr-water scaling study.
Test Apparatus

Tests were performed with the same basic apparatus used in the air-water scaling studies ${ }^{19}$ (Figs. 30 and 31 ). The experiment was designed to correlate the load on the flask due to vent-clearing-induced pool dynamics with the transient gas velocity and gas pressure in the downcomer. The gas temperature, the strain on the flask, and the pressure at the bottom of the flask were also determined for collaborative data. To make the required measurements, four modifications were made to the basic apparatus :

- An orifice was inserted immediately upstream of the downcomer to measure the mass flow rate. (The gas velocity was calculated from the mass flow rate.)

- The bottom of the flask was modified to accept a pressure transducer.

- A thermocouple was installed in the downcomer to measure the temperature of the entering air.

- Strain gages were located on the flask exterior to determine wall response (Fig. 39).

\section{Measurements}

A11 measurements were recorded simultaneously. The instrumentation and their locations axe summarized in 


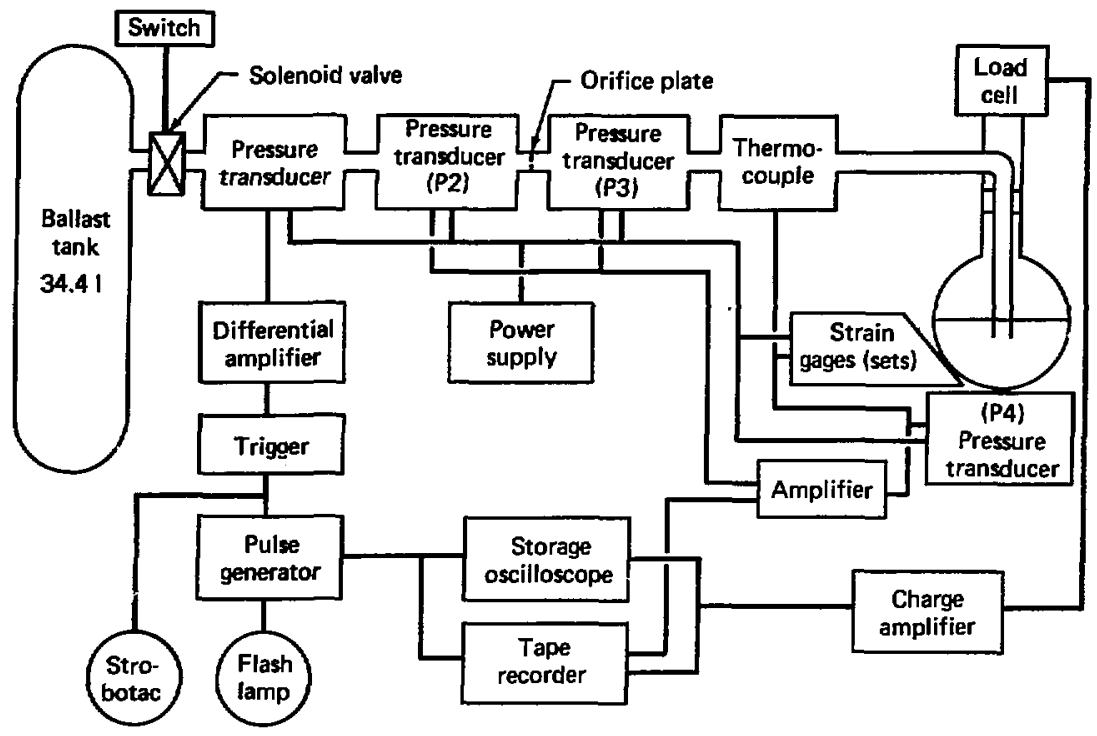

Fig. 39. Block diagram of benchmark test instrumentation.

Table 17 and Fig. 40. (See Appendix A for typical trangducer data sheets.) Tests were performed in a 5-1itre flask half-filled with water and with two sets of initial pressure (SET $X$ : driving pressure $P_{0}=1 \mathrm{~atm}$, pressure above the pool $P_{1}=1 / 3$ atm; and Set Y: $P_{0}=2$ atm, $\left.P_{i}=1 \mathrm{~atm}\right)$. The first set is a repeat of one condition used in the scaling studies; in this way, the scaling studies also were further quantified. -

The measurements were recorded on an analog tape recorder, Ampex Hodel CP-100, digitized at a sampling rate of 53,580 points per second, and computer-reproduced in analog form. The vertical force history was also recorded with a Tektronics Hodel 564 oscilloscope on Polaroid film for immediate examination. In addition, a film record of the pool dynamics for selected runs was made with a Hycam camera at a rate of 2900 frames per second. Individual fiduclals were provided in the taped record and the high speed film with an electrical signal and a flashbulb, respectively. Later study showed that thermal delay of the flash bulb caused the movie fiducial to lag that on the tape by $2 \mathrm{~ms}$. 
Table 17. Summary of benchmark experiment instrument characteristics.

\begin{tabular}{|c|c|c|c|}
\hline Transducer & $\begin{array}{l}\text { Excitation } \\
\text { voltage }\end{array}$ & Sensitivity & Remarks \\
\hline \multicolumn{4}{|l|}{ Rig } \\
\hline $\mathrm{P}-3$ & 6.45 & $0.155 \mathrm{MV} / \mathrm{V} / \mathrm{PSIA}$ & Kulite, S/N 2778-1-57 \\
\hline $\mathrm{P}-2$ & 6.10 & $0.164 \mathrm{MV} / \mathrm{V} / \mathrm{PSIA}$ & Kulite, s/N 2778-1-59 \\
\hline$P-4$ & 6.13 & $0.0816 \mathrm{MV} / \mathrm{V} / \mathrm{PSIA}$ & Kulite, S/N 2596-7-9-B1-83 \\
\hline $\mathrm{L}-1$ & - & $2501 \mathrm{~b} /$ volt & $\begin{array}{l}\text { Kistler load cell. } \\
\text { Range Switch }=500 \text { Black }\end{array}$ \\
\hline$T-1$ & - & -- & $\begin{array}{l}\text { Ch/Const. 0.001 dia. wire } \\
\text { 0"C Ref. Temp. BLH }\end{array}$ \\
\hline s-1 & 6.667 & $120^{\mathrm{a}}$ & Factor $96.4 \%-116 \mu \varepsilon /$ volt \\
\hline$s-2$ & 6.667 & $120^{a}$ & Factor $95.8 \%-115 \mu \varepsilon / v o l t$ \\
\hline$s-3$ & 6.667 & $120^{a}$ & Factor $94.3 \%-113 \mu \varepsilon /$ volt \\
\hline$s-4$ & 6.667 & $120^{\mathrm{a}}$ & Factor $95.8 \%-115 \mu \varepsilon / v o 1 t$ \\
\hline$s-5$ & 6.667 & $120^{a}$ & Factor $96.9 \%-116 \mu \varepsilon /$ volt \\
\hline$s-6$ & 6.667 & $120^{a}$ & Factor $96.2 \%-115 \mu \varepsilon /$ volt \\
\hline
\end{tabular}

assumed gage factor of 120 . Reduce by factor in remarks column.

Test Procedure

The test apparatus was prepared for a selected test condition by setting the initial pressures. When the instrumentation, conditioning equipment, and recording equipment were ready, a master switch was activated to start the camera. When the camera reached the selected steady-framing rate, the following events were initiated: tape recorder started, ballast tank solenoid valve opened to inftiate air flow through the downcomer, mag tape and film were indexed with a fiducial mark, and oscilloscope triggered. The air flowed continuously for more than 50 ms; the precursor scaling experiments had shown that 50 ms was sufficient to contain the period of primary interest. During this flow time, the supply air pressure maintained a constant value.

Results and Discussion

A total of nine tests were conducted. Table 18 presents the test conditions and selected results. The results were the first from experiments performed with the modifled 


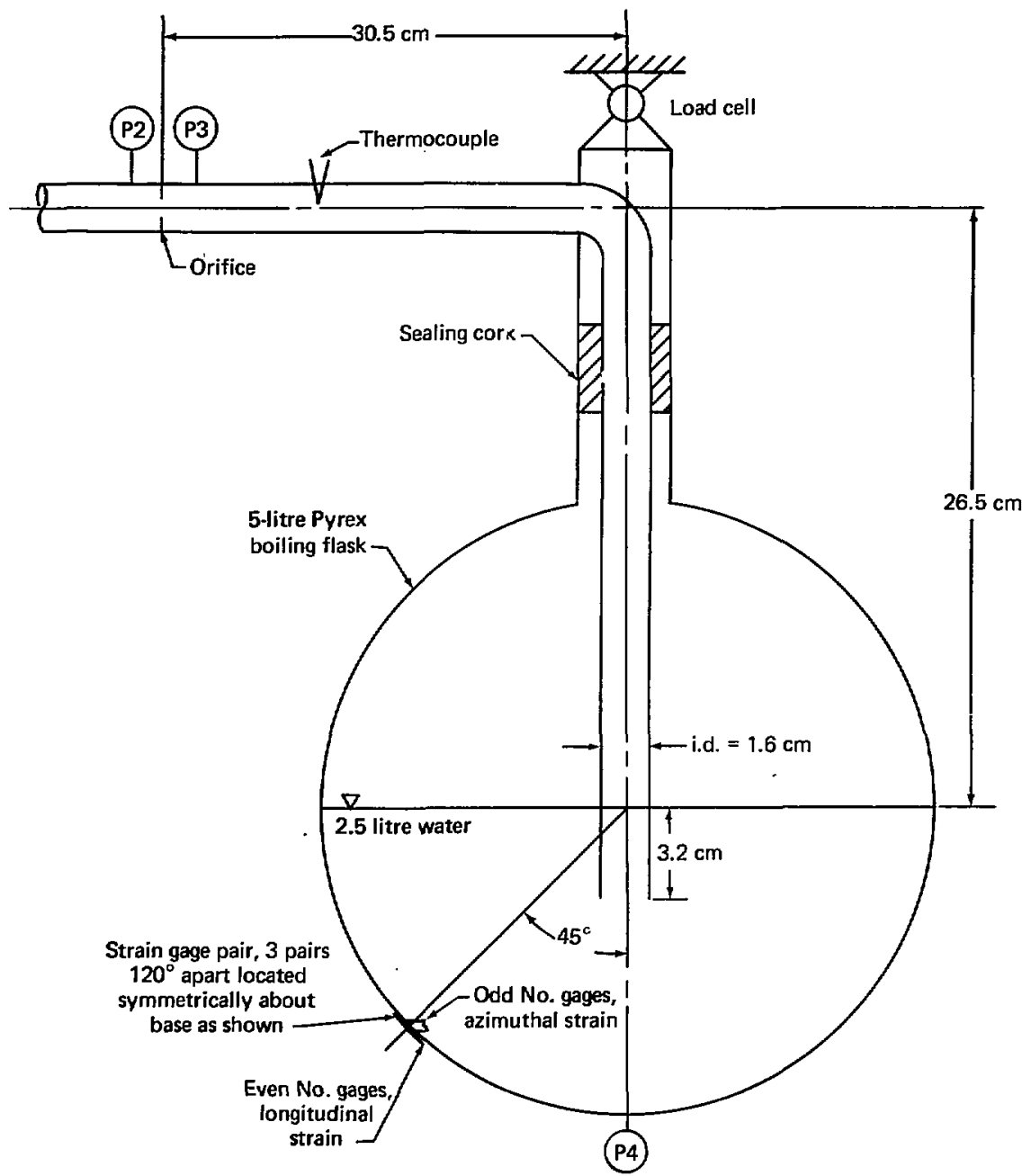

F1g. 40. Location of transducers for the benchmark experiment. 
Table 18. Selected results from benchmark experiments.

\begin{tabular}{|c|c|c|c|c|c|c|c|c|c|c|}
\hline \multirow[b]{3}{*}{ Test } & \multirow[b]{3}{*}{$\begin{array}{c}\text { Initial } \\
\text { press } \\
\text { ratio, } \\
\mathrm{P}_{\mathrm{i}} / \mathrm{P}_{\mathrm{o}} \\
\end{array}$} & \multicolumn{4}{|c|}{ Maximum loads } & \multirow{2}{*}{\multicolumn{2}{|c|}{$\begin{array}{l}\text { Press flask } \\
\text { bottom }\end{array}$}} & \multirow[b]{3}{*}{$\underset{{ }^{\circ} \mathrm{F}}{\text { Temp., }}$} & \multirow{2}{*}{\multicolumn{2}{|c|}{$\begin{array}{l}\text { Average strain } \\
\text { at max. download } \\
\end{array}$}} \\
\hline & & \multicolumn{2}{|c|}{ Taped data } & \multicolumn{2}{|c|}{ Oscilloscope data } & & & & & \\
\hline & & $\begin{array}{c}\text { Down } \\
\text { If }\end{array}$ & $\begin{array}{l}\text { Up } \\
\sharp \mathbf{f}\end{array}$ & $\begin{array}{c}\text { Nown } \\
\# \mathrm{~F}\end{array}$ & $\begin{array}{l}\text { Up } \\
\text { If } F\end{array}$ & $\begin{array}{l}\text { At max } \\
\text { download, } \\
\text { psig }\end{array}$ & $\begin{array}{l}\text { At max } \\
\text { upload, } \\
\text { psig }\end{array}$ & & $\begin{array}{l}\text { long. } \\
\text { (even " } \\
\text { gages), } \\
\text { pin./in. }\end{array}$ & $\begin{array}{l}\text { Trans. } \\
\text { (odd } \\
\text { gages), } \\
\text { Min./in. }\end{array}$ \\
\hline $\mathrm{x} 1$ & $1 / 3$ & 124 & 40 & 105 & 40 & 3.4 & +0.5 & 78.8 & 6 & 1 \\
\hline $\mathbf{x} 2$ & $1 / 3$ & 116 & 42 & 100 & 40 & 0.4 & 0.5 & 82.4 & 7 & 0 \\
\hline $\mathrm{x} 3$ & $1 / 3$ & 112 & 34 & 100 & 40 & 2.8 & -1.5 & 81.9 & 8 & 2 \\
\hline$x 4$ & $1 / 3$ & 120 & 45 & -- & - & 0.5 & -0.5 & 83.3 & 8 & 1 \\
\hline $\mathbf{Y 1}$ & $1 / 2$ & 155 & 47 & -- & - & 6.5 & -0.5 & 79.2 & 8 & 0 \\
\hline Y2 & $1 / 2$ & 153 & 43 & 140 & 40 & 4.0 & -0.8 & 80.1 & 10 & 0 \\
\hline Y3 & $1 / 2$ & 160 & 43 & 145 & 40 & 4.7 & -0.1 & 79.7 & 11 & 1 \\
\hline $\mathbf{Y 4}$ & $1 / 2$ & 150 & 44 & 140 & 40 & 6.0 & -0.5 & 78.8 & 10 & 1 \\
\hline Y5 & $1 / 2$ & $16 !$ & 48 & -- & -- & 4.6 & 0.9 & 83.8 & 10 & 1 \\
\hline
\end{tabular}

flask apparatus and with the measurements tape recorded. Under normal circumstances, the data would have been replaced by new data after improvements were made on the instrumentation. However, due to circunstances beyond our control, suggested improvements could only be recorded for posterity.

Notwithstanding the shortcomings, this initial set of data contained new information that helped to explain the forces arising from pool dynamics. Each measurement was examined critically to provide significant physical insights.

The load or force experienced by the load cell has a shape reminiscent of a damped vibration curve (Figs. 41-43). Figure 43b is included to show repeatability. The short duration of the initial download peak, compared with that of the subsequent gross load durations, indicates different causative phenomenon. The high speed film shows that the initial downforce occurs near the moment of downcomer clearing (Fig. 44). Essentially simultaneously, a pressure spike of the same duration as the initial downward force appears at the bottom of the flask (Fig. 45). In other words, vent clearing and arrival of the pressure pulse at the bottom of the flask occur nearly simultaneously.

If we postulate that the pressure pulse results from a pressure disturbance initiated by vent clearing that travels downward at sound speed, 


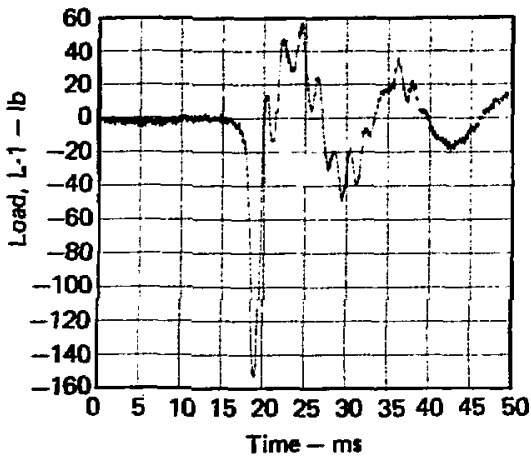

Fig. 41. Typical RVLF for benchmark tests (Test Y4).

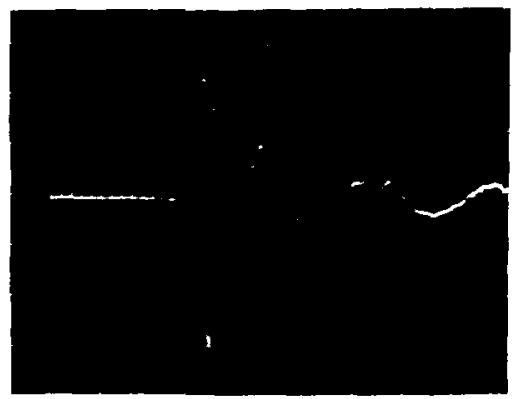

Fig. 42. Typical oscilloscope trace of RVLF for benchmark tests (Test Y4).

the travel time or delay time will be 260 Hs. This short a time is not distinguishable with current instrumentation. Hence, the nearly simultaneous occurrence of events is reasonable. (a)

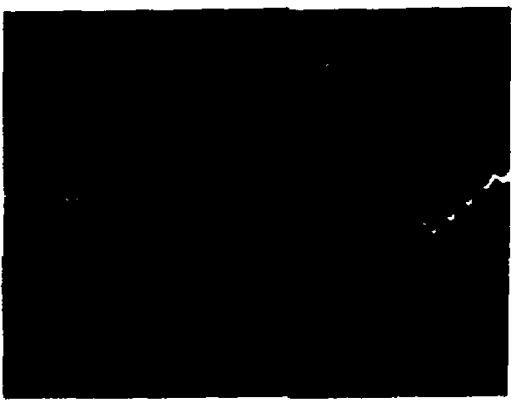

(b)

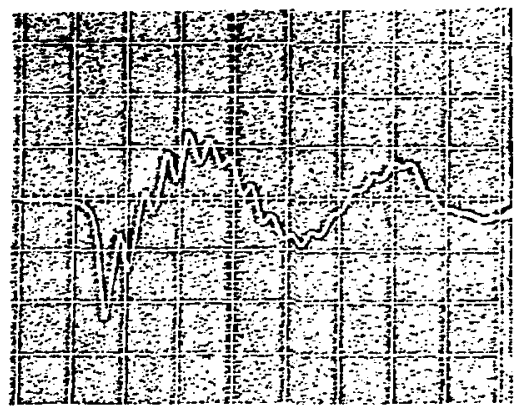

Fig. 43. Oscilloscope traces for benchmark Test No, $\mathrm{X} 3(\mathrm{a})$ and $\mathrm{air}$ scaling Test No. $3(b)$ under identical conditions.

The inftial downforce inparts a downward acceleration to the flask. Since the water is neither rigid nor integral with the flask, but can move independently, the downward acceleration imparted to the flask leaves the water momentarily.suspended. Thus, the bottom transducer will experience a momentary reduction of pressure 


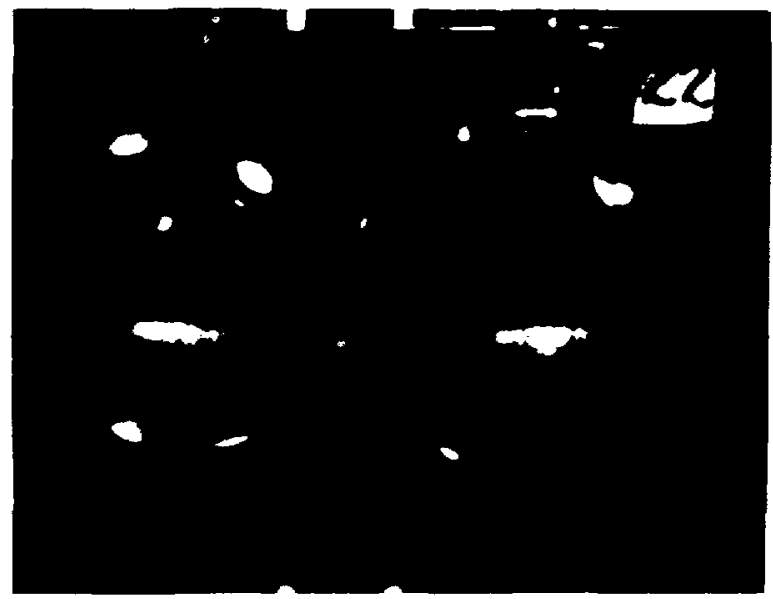

Fig. 44. Pool configuration at maximum download.

(Fig. 45). In effect, the flask experiences a net increase in pressure resulting in an upward force (Fig. 41). Once initiated by the first downforce, the flask support system, water, and

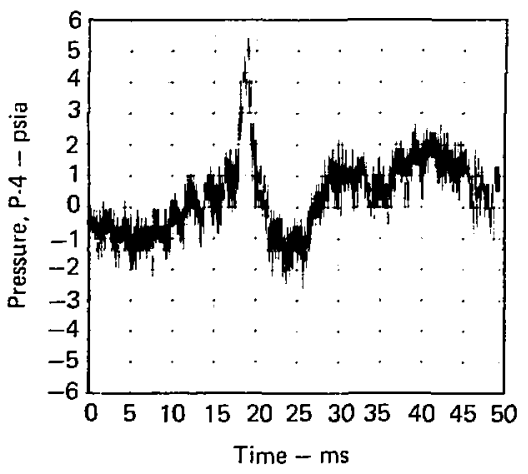

Fig. 45. Pressure variation at the bottom of the flask (Tests Y4, $\mathrm{P}_{4}$ ). air system seems to oscillate as a damped-spring mass unit. For Test Y4, the damped-spring mass system oscillated at $280 \mathrm{~Hz}$. This means that after the initial downforce, appiication of the remaining load curve to predict time of events in similar systems requires inclusion of vibration characteristics. (Appendix $B$ is a reanalysis of scaling results for the time lapse between maximum download and maximum upload. The reanalysis shows that a substantial reduction of percent difference from the mean value is achieved by inclusion of mass and spring constant, the two parameters that characterize undamped vibrating spring-mass systems. The minor movement of the flask during acceleration should have negligible 
effect on the magnitude of the first download.)

Further confirmation of the springmass behavior is exhibited by pressures observed at P3 and P4 (Figs. 45 and 46). The observed pressures are in phase with the force trace. In addition, P3 should lead P4 by $260 \mu \mathrm{s}$, a time that is not distinguishable. We note that P3 tracks the pressure as the air clears the downcomer. Therefore, P3 should (and does) show maxima at downloads followed by minima in pressure as the air in the bubble adjusts to the external environment. Corresponding1y, P4 measures the pressure at the bottom of the flask and shows maxima and minima corresponding to downloads and uploads respectively.

The high speed films show the bubble touching the bottom of the

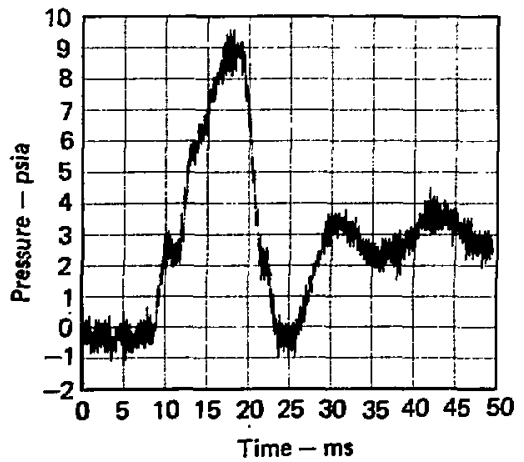

Fig. 46. Pressure variation downstreal fron the orifice (Tests Y4, P3). flask at approximately the time of the maximum upload (at $224 \mathrm{~ms}$ in Fig. 41). The bubble remains near the bottom of the flask and continues to grow in size to the end of the force trace at $250 \mathrm{~ms}$. No visual evidence appears to indicate the higher frequency oscillations superimposed on the primary load trace originate from visible macroscopic behavior of the bubble, but may be derived from other coupling mechanisms; other possibilities include high frequency oscillations of the bubble, transverse or longitudinal vibration of the frame securing the flask to the load cell, and transverse vibration of the flask and water.*

\section{Gas Velocity}

The gas velocity in the downcomer was calculated from the volume flow rate. The volume floz rate was determined fron the measured differential pressure across a statically calibrated orifice. The static calibration of the orifice is given in Fig. 47. The average velocity and flow rate in the downcomer for test Y4 are plotted in Figs. 48 and 49.

\footnotetext{
*In the characterization of the VLF below, the low frequency oscillations are traced to vertical oscillations of the bubble. Also, the high frequency oscillations seem to be initiated by the second pulse of the double-peak download.
} 


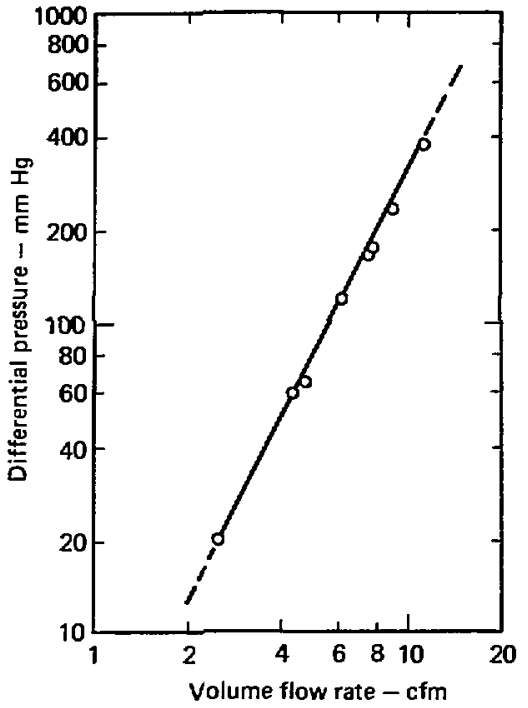

Fig. 47. Static calibration of orifice.

Because of the noise level exhibited by the $\Delta \mathrm{P}$ data (Fig. 50), the reduction of $\Delta \mathrm{P}$ to volume flow rate and velocity are based on average values. Zero time for these curves was determined by the intersection of the time axis with the extrapolation of $\Delta P$ to zero pressure; $\Delta \mathbf{P}=0$ corresponds to no flow.

The positions of the lown and up loads (transferred from Fig. 41) are Indicated In Figs. 48 and 49 . A qualitative chronology of events may be constructed for the essentially four-step injection process of compression, downcomer clearing,

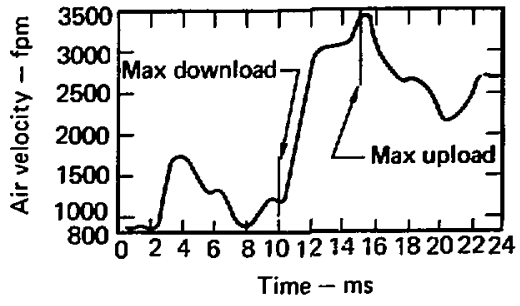

Fig. 48. Average air velocity in downcomer for Test Y4.

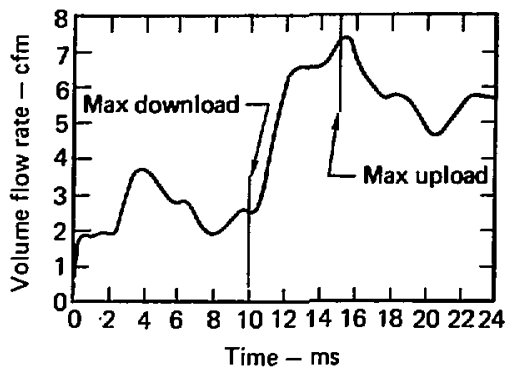

Fig. 49. Average air volume flow rate in downcomer for Test $\mathrm{Y} 4$.

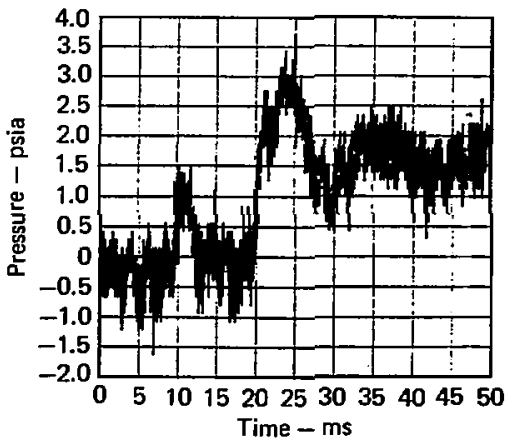

Fig. 50. Pressure differentia1 across the orifice (Test Y4). 
bubble growth, and pool swell (Table 19).

\section{Gas Temperature}

Although the gas should remain close to room temperature during the test, the gas temperature actually increased during injection, probably because of heating by the flood lights.

\section{Flask Rigidity}

The flask rigidity was checked by measuring the strain on the external surface both transverse and parallel to the downcomer. The neasurements show negligible surface strain, indicating that the flask behaved essentially in a rigid manner. The even-numbered gages, oriented parallel to the downcomer, show the expected maximum strain coinciding approximately with the time of the initial maximum download (Table 18).

\section{Conclusions}

The followlng may be concluded:

- The maximum download results from a pressure pulse generated when the downcomer clears.

- The maximum upload and subsequent low frequency load fluctuations seem to result from oscillation of a damped spring-mass system.

- Scaling the time for the load curve to similar flask systems requires inclusion of vibration characteristics of the air-water flask or container system.

- The air injection velocity history in the downcomer may be separated into four phases that are controlled by the dynamics of the system:

Table 19. Qualitative chronology of events during air injection for Test Y4.

$\begin{array}{ccc}\begin{array}{c}\text { Approximate time, } \\ \text { ms }\end{array} & \text { Step } & \text { Event } \\ 0-44 & 1 & \begin{array}{c}\text { Compression of air space in downcomer above the } \\ \text { water level }\end{array} \\ 9.5 & 2 & \begin{array}{c}\text { Clearing of water in downcomer, } \\ \text { maximum download }\end{array} \\ 9.5-416 & 3 & \begin{array}{c}\text { Essentially unimpeded growth of bubble, possibly } \\ \text { over expansion of bubble, pool is levitated }\end{array} \\ >216 & 4 & \begin{array}{c}\text { Interaction of compressibility of gases internal } \\ \text { and external to bubble }\end{array}\end{array}$


Step (1): The air space in the downcomer is compressed.

Step (2): The water is driven from the downcomer into the pool.

The downcomer is cleared. The velocities are relatively low. Maximum download occurs during this step. The sharpness of the average ervelope is a function of fill level in the downcomer. Step (3): The bubble forms. The air velocity in the downcomer is higher than in Step (2). The maximum upload occur during this step. Levitation of the pool and compression of the ullage occur. Step (4): The gases internal and external to the bubble interact to cause an unsteady velocity and subsequent pressure and load oscillations.

- The flask may be considered rigid for these experiments.

\section{CHARACTERIZATION OF THE VERTICAL LOAD FUNCTION 23}

This study was conducted to define the mechanisms that give rise to the observed loads and oscillations in the VLF following the maximum download. To assure adequate experimental control, vibration characteristics of the experimental systems and support structure were investigated systematically (see Appendix C).

\section{Test Apparatus}

The experiment was performed with the same basic apparatus used in the air-water scaling study ${ }^{19}$ (Figs. 31 and 32). Measurements were made with an accelerometer, a load cell, and a pressure transducer along the axis of the downcomer (transducer data sheets are presented in Appendix A).

Results and Discussion

Severa1 blowdown tests were conducted with the 5-litre flask supported in the original high-inertia support system ${ }^{*}$ to provide a basic set of data to judge improvements (Table 20). Figure 51 shows a typical load trace transduced by the $50-\mathrm{kHz}$ piezoelectric load cell used in all scaling and model studies. Four features are of particular interest in the VLF:

- The maximum download.

- The maximum upload.

- The damped sinusoid carrier wave following the peak upload $\left(f_{1}\right)$.

- The damped high frequency sinusoid superimposed on the carrier wave $\left(f_{2}\right)$.

*Details of the different support systems are found in Appendix C. In essence, $250 \mathrm{1b}$ of lead bricks were strapped firmly to the support beam. This is called the high inertia support system. The support beam for the soft support system was a $24-b y-$ 2-by-3/4-in. steel bar. A 4-in. I-beam was firmly strapped to the support beam to form the stiff support system. 
Table 20. Maximum dynamic loads and average oscillaticns due to blowdown high inertia support system. ${ }^{a}$

\begin{tabular}{|c|c|c|c|c|c|}
\hline \multirow[b]{2}{*}{ Run } & \multirow{2}{*}{$\begin{array}{c}\text { Nominal pressure ratio, } \\
\text { atm/ullage }\end{array}$} & \multicolumn{2}{|c|}{ Force, 1b } & \multicolumn{2}{|c|}{ Frequency, $\mathrm{Hz}$} \\
\hline & & Down & Up & Low-f 1 & High-f 2 \\
\hline 1 & $15 / 5$ & 110.0 & 42.5 & 50 & 471 \\
\hline \multirow[t]{2}{*}{2} & $15 / 5$ & 98.0 & 43.0 & 50 & 444 \\
\hline & Mean & 104.0 & 42.8 & 50 & 457.5 \\
\hline 3 & $15 / 7.5$ & 95.5 & 42.0 & 62 & 465 \\
\hline \multirow[t]{2}{*}{4} & $15 / 7.5$ & 95.5 & 42.0 & 59 & 455 \\
\hline & Mean & 95.5 & 42.0 & 60.5 & 460 \\
\hline
\end{tabular}

Figure 52 shows typical load traces (three separate tests) when the flask is supported in the soft support system. These VLF's are obviously distorted; the download and upload maxima are essentially equal and the data are unusable. The responses for two of the three tests wer 2 identical and are superimposed in Fig. 52.

Listed in Table 21 are the data from tests with the 5-1itre flask supported in the wholly stiff support system. The peak up- and downloads in Tables 20 and 21 are in good agreement; the largest discrepancy is $220 \%$ between the averages for the download, for a nominal pressure ratio $\left(P_{0}: P_{i}\right)$ of $15: 7.5 .^{*}$ For most of the tests listed in Table 21, the crossbeam acceleration at midspan, the dynamic load, and the pressure at the bottom of the flask were simultaneously recorded. All transducers were coaxial with the downcomer. Figure 53 is a set of typical traces of the dynamic event; the reduced amplitude of high frequency oscillations in the VLF is obvious when compared with Fig. 51. The effect is evident of the stiff system in clarifying the second download peak, which occurs $1.5 \mathrm{~ms}$ af ter the maximum spike (Fig. 51). This second peak is discussed in the section on damped high frequency oscillations.

\footnotetext{
* The variation exhibited by the data in Tables 20 and 21 are attributable to inaccuracies in setting the initial conditions.
} 
Table 21. Maximum dynamic response and average oscillations due to blowdown stiff support system, ${ }^{a}$

\begin{tabular}{|c|c|c|c|c|c|c|c|c|c|}
\hline \multirow[b]{2}{*}{ Run } & \multirow{2}{*}{$\begin{array}{c}\text { Nominal press. } \\
\text { ratio, } \\
\text { atm/ullage }\end{array}$} & \multicolumn{2}{|c|}{ Force, 1b } & \multicolumn{2}{|c|}{ Pressure, psig } & \multicolumn{2}{|c|}{ Accel, $\mathrm{g}$} & \multicolumn{2}{|c|}{ Freq, $\mathrm{Hz}$} \\
\hline & & Down & $\mathrm{Up}$ & + & - & Down & Up & Low & High \\
\hline V41-2 & $15 / 5$ & 99.0 & 50.0 & $-b$ & $-b$ & 1.30 & 0.85 & 49 & 700 \\
\hline v43-4 & $15 / 5$ & 89.5 & 42.5 & - & - & 1.18 & 0.81 & 50 & 710 \\
\hline v45-6 & $15 / 5$ & 96.5 & 45.0 & - & - & 1.18 & 0.84 & 52 & 700 \\
\hline v53-4 & $15 / 5$ & 90.5 & 40.0 & - & - & 0.92 & 0.67 & 49 & 767 \\
\hline $1 / 14-1$ & $15 / 5$ & 102.5 & 47.0 & 2.94 & 0.47 & 1.45 & 0.62 & 50 & 679 \\
\hline $1 / 14-2$ & $15 / 5$ & 92.5 & 43.5 & 2.49 & 0.43 & 1.35 & 0.62 & 53 & 800 \\
\hline $1 / 14-3$ & $15 / 5$ & 94.0 & 42.5 & 2.71 & 0.29 & 1.35 & 0.62 & 53 & 800 \\
\hline $1 / 2 I-1$ & $15 / 5$ & 110.0 & 45.0 & 3.12 & 0.37 & $\sim^{b}$ & $-{ }^{b}$ & 51 & 750 \\
\hline $1 / 21-2$ & $15 / 5$ & 87.5 & 50.0 & 2.39 & 0.37 & - & - & 51 & 769 \\
\hline $1 / 21-3$ & $15 / 5$ & 97.5 & 44.0 & 2.51 & 0.43 & - & - & 56 & $-c$ \\
\hline $1 / 2 I-4$ & $15 / 5$ & 112.5 & 52.5 & 3.30 & 0.48 & 1.54 & 0.87 & 53 & 708 \\
\hline \multirow[t]{2}{*}{$1 / 24-1$} & $15 / 5$ & 89.5 & 44.0 & 2.46 & 0.36 & 1.25 & 0.62 & 54 & 700 \\
\hline & Mean & 96.8 & 45.5 & 2.75 & 0.40 & 1.28 & 0.72 & 51.8 & 734.8 \\
\hline V47-8 & $15 / 7.5$ & 79.0 & 40.0 & $-{ }^{b}$ & $-b$ & 1.09 & 0.92 & 59 & - \\
\hline$v 49-50$ & $15 / 7.5$ & 81.0 & 42,0 & - & - & 1.11 & 0.84 & 59 & 710 \\
\hline$v 51-52$ & $15 / 7.5$ & 79.0 & 43.0 & - & - & 1.21 & 0.73 & 57 & 700 \\
\hline v55-56 & $15 / 7.5$ & 79.0 & 41.0 & - & - & 1.17 & 0.73 & 61 & 741 \\
\hline $1 / 14-4$ & $15 / 7.5$ & 87.5 & 42.5 & 2.33 & 0.43 & 1.14 & 0.80 & 62 & - \\
\hline $1 / 14-5$ & $15 / 7.5$ & 80.0 & 45.0 & 2.51 & 0.53 & 1.20 & 0.75 & 59 & 714 \\
\hline \multirow[t]{2}{*}{$1 / 2 I-11$} & $15 / 7.5$ & 72.5 & 40.0 & 2.08 & 0.37 & 1.06 & 0.91 & 62 & 750 \\
\hline & Mean & 79.7 & 41.9 & 2.31 & 0.44 & 1.14 & 0.81 & 60 & 723.0 \\
\hline $1 / 14-6$ & $15 / 10$ & 55.0 & 22.5 & 1.65 & 0.31 & 0.76 & 0.85 & 69 & 700 \\
\hline \multirow[t]{2}{*}{$1 / 14-7$} & $15 / 10$ & 58.5 & 25.0 & 1.65 & 0.25 & 0.75 & $0.8^{7}$ & 67 & - \\
\hline & Mean & 56.8 & 22.8 & 1.65 & 0.28 & 0.76 & 0.84 & 68 & 700 \\
\hline
\end{tabular}

a Configuration: 5-litre flask, 2.5 litre water, downcomer $1 . \mathrm{d} .=1.6 \mathrm{~cm}$, downcomer submergence $=3.2 \mathrm{~cm}$.

${ }^{b}$ Data missing because transducers not available.

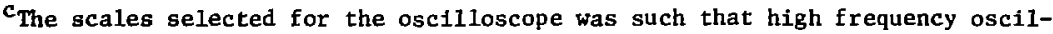
lations became indistinct. 


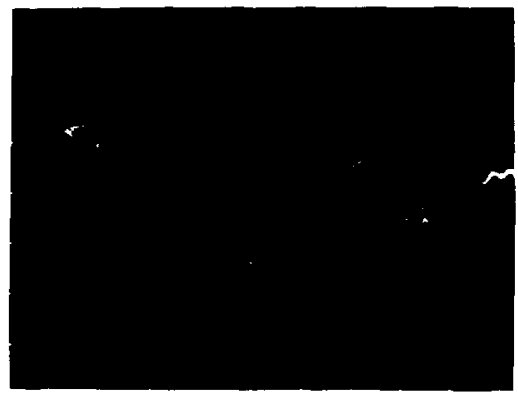

Fig. 51. Origin of VLF characteristics. (a) Hydrodynamic origin: peak downforce results from ejection of water slug into the pool. (b) Hydrodynamic origin: second peak of downforce becomes dominant as downcomer laftial fill level is reduced. (c) Hydrodynamic origin: maximum upforce given by average, results from combination of pool levitation and compression due to pool swell. (d) Hydrodynamic origin: low frequency carrier wave due to vertical oscillations of the expanding air bubble. Frequency increases with ullage pressure. Oscillations are in phase with pressure oscillations at bottom of pool. (e) Hydrodynamic origin: high frequency on carrier wave not fully characterized; slight reduction with increase in ullage pressure, osclllations in phase with pressure oscillations at the bottom of the pool.

The data listed in Tables 20 and 21 were obtained from Polaroid photographs cf oscilloscope traces. Average deflections were used to calculate the force, pressure, and acceleration. Where sizable oscillations exist, such as during the upload of a VLF for the high inertia system (FIg. 5I), the maxinum deflection is taken as that of the average curve through the high frequency oscillations. Additionally, the high and low frequencies were determined by favoring the earlier part of the VLF.

The Maximum Upload

The maximum upload is attributed to the combined effects of pool levitation and ullage compression due to pool rise. The force due to pool. levitation may be estimated (Fig. 54a); the pressure is assumed to vary IInearly to $85 \%$ of the maximum at the pool surface, as suggested by the G.E. 1/12-scale tests. The force due to ullage compression may also be estimated by calculating the isothermal pressure rise in the hemispherical volume of gas as the volume decreases (Fig. 54b).

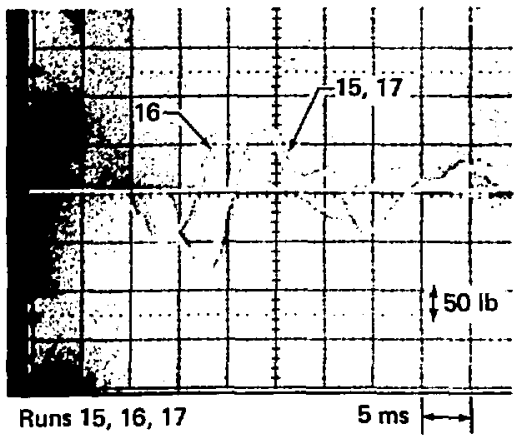

Fig. 52. Typical RVLF for blowdown in a soft support system. 

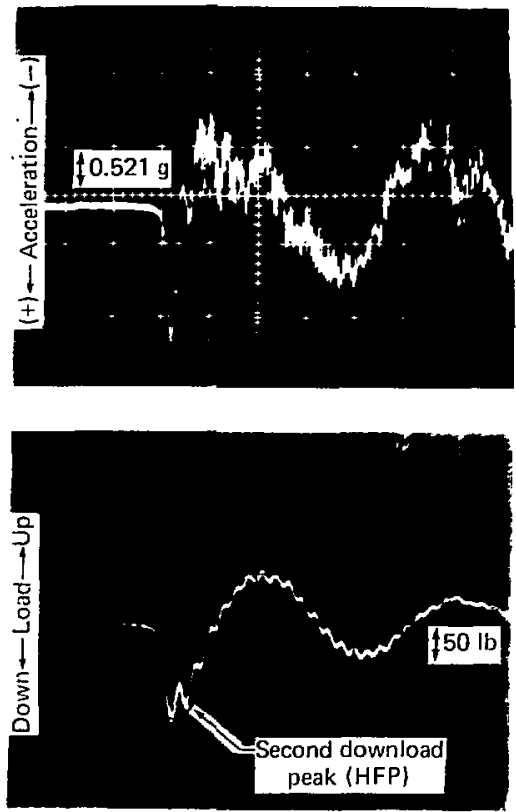

All time scales $5 \mathrm{~ms} / \mathrm{cm}$

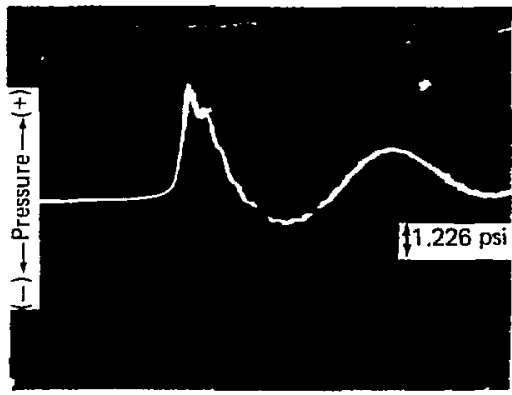

Fig. 33. Dynamic response of a typical blowdown test conducted with an initially full downcomer ( $r u n$ 1/14-1, 5-1itre flask, nominal. atmosphere, ullage $=15: 5$, timescale $=5 \mathrm{~ms} / \mathrm{cm}$ ) .
Assumed average of linear pressure profile

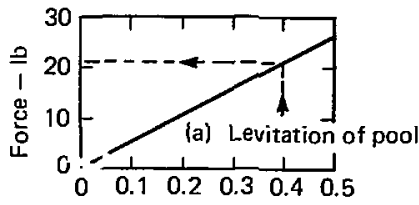

Pressure at pool bottom - psi

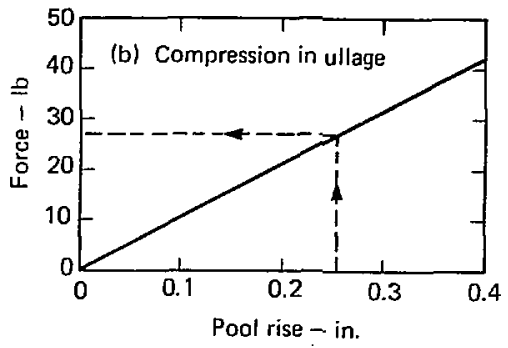

Fig. 54. Estimated forces due to

(a) levitation of the pool and

(b) compression of the ullage.

Careful analysis of high speed movies show that the average pool rise at maximum upload is betweer 0.2 and $0.3 \mathrm{in.}$ Figure 54 shows that this pool rise vill cause an upload of $\sim 27 \mathrm{lb}$. Table 21 shows that the pressure at the bottom of the flask at maximum upload varies between -0.29 and -0.53 psig. A change of -0.4 psig will result in an upforce of 21. 1b. The sum of these loads is 48 1.b, which is the same magnitude as that measured for the 15:5 tests. These calculations show that the 
maximum upload does result from a combination of pool levitation and u. Jage compression.

\section{Damped Carrier Wave}

Examination of the average carrier (or low) frequencies listed in Tables $2 n$ and 21. shows the following:

- The frequencies increase with ul lage pressure.

- The frequencies are essentially the same for the VLF's measured either with the high inertia or the stiff systems.

Compressing the limescale on the oscilloscope shows that these low frequency oscillations damp out rapidly (Fig. 55); except for the timescale, the test conditions for Figs. 53 and 55 are the same. These observed effects are consistent with air-water interactions (they were suggested at a Revien Group Meeting ${ }^{24}$ ).

Note in Fig. 55 that the accelerometer trace shows the beam still vibrating after the pressure and VLF have essentially dampeu out. The vibration of the beam after the pressure and VLF signals have damped out shows that structural interaction for the stiff support has no effect on the oscillatirg behavior of the pressure and VLF traces. Inscead, Fig. 55 shows that the crossbeam is reacting sympathetical. Iy to the dynamic loads.
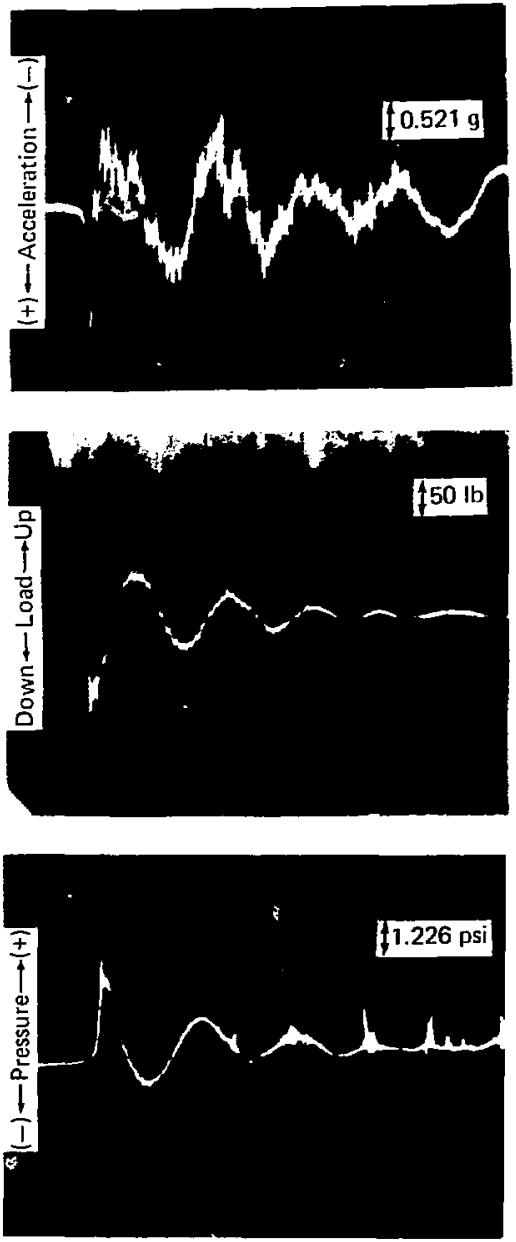

Fig. 55. Typical dynamic response traces showing the rapid damping of the ponl disturbances (run 1/14-2, 5-Iitre flask, nominal atmosphere, ullage $=15: 5$, ti.1escale $=10 \mathrm{~ms} / \mathrm{cm})$. 
Digruptions of the pool begin $220 \mathrm{~ms}$ after the maxinum download.

The distortions in the pressure trace from a ssooth sinusoid, especially in the tail portion, are attributed to pool splash. In addition to the pressure fluctuations, the pressure in the flask rises steadily due cio continuous flow of gas into the flask. This effect is exhibited in the pressure trace by the gradual positive shift in the base pressure line with time.

The magnitude of the low frequency oscillations resulting from the dynamic events suggest that the causative disturtances should be observable. With this in mind, the high speed filns ( $i 900$ frames per second) of air-water scaling tests were examined. The results confirmed that the oscillating carrier wave results from airwater interactions arising from vertical oscillations of the bubble. During expansion, the bubble dynamically adjusts to the pool confinement and continuing air injection by osclllating vertically, much as a piston. Plotting the motion-picture frame numbers (equivalent to time) corresponding to the high and low positions of the bubble onto the VLF shows a $1: 1$ correlation between bubbie position and load (Fig. 56); the slight mismatch results primarily from the discrete frames available $(900$ frames per second).

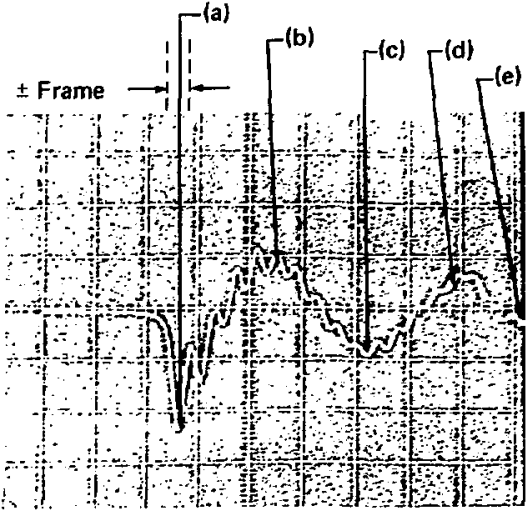

Fig. 56. Correspondence between bubble position and carrier oscillations: (a) Frame 11, downcomer cleared (indexed arbitrarily to maximum download. (b) Frame 21, bubble at high position. (c) Frame 31, bubble at low position. (d) Frame 39 , bubble at high position. (e) Frame 47, bubble at low position. (A11 frames are relative to frame 11.)

Vertical oscillations of the bubble have also been observed for a lower test pressure ratio. The results tabulated in Table 21 and plotted in Fig. 57, shows that the carrier wave frequency increases with ullage pressure. Tris is the expected trend for air-water interaction.

Damped High Frequency Oscillations

It is evident that the amplitude of the high frequency oscillations in the VLF for the stiffer flask strut support system was diminished by a factor of at least 3 from that for 


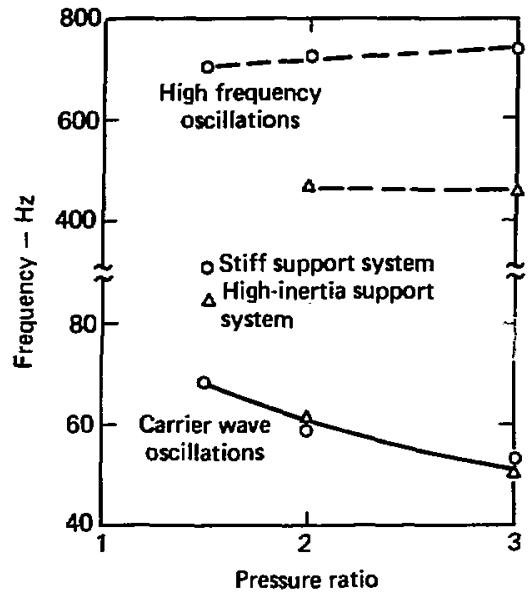

Fig. 57. Effect of ullage pressure on oscillation frequencies.

the high inertia system (compare Figs. 51 and 53). Nevertheless, the persistence of these oscillations suggests further investigation.

Especially interesting is the ever-present second download peak, which seems to signal the beginning of the high frequency oscillations; the pressure trace suggests a second impact $a:$ the bottom of tine flask. This high frequency peak (HFP) arrives $\sim 1.5$ ms after the maximum download for the high inertia system and has been observed in G.E. scaling studies (both 1/12- and 1/4-scale), but on a different timescale. Also, as noted in Section 2, this first HFP becomes dominant as the downcomer fill level decreases (Figs. 58 and 59).

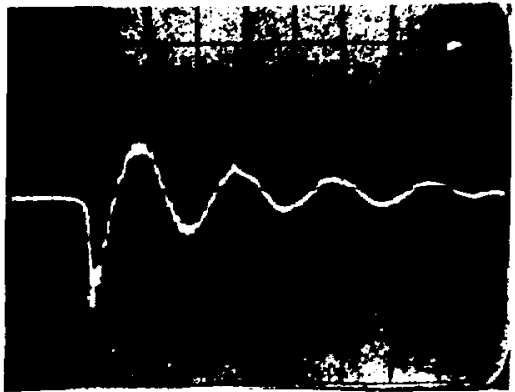

Downcomer initially full

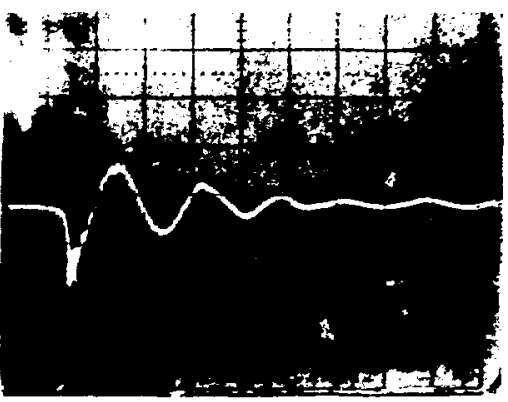

Downcomer initially $80 \%$ full

Fig. 58. Change of the VLF as a function of downcomer fill level (5-litre flask, single downcomer, 2.5 litre water, vertical scales $=50 \mathrm{ft} / \mathrm{lb} /$ $\mathrm{cm}$, nominal pressure ratio $3: 1$, timescale $=5 \mathrm{~ms} / \mathrm{cm}$ ).

In addition to the decreased magnitude, the stiffer flask strut support system has increased the high frequency oscillations from $460 \mathrm{~Hz}$ to $2700 \mathrm{~Hz}$ (Tables 20 and 21). Also, Table 20 (high inertia system) shows the average high frequencies are approximately independent of ullage pressure; however, Table 21 (stiff 

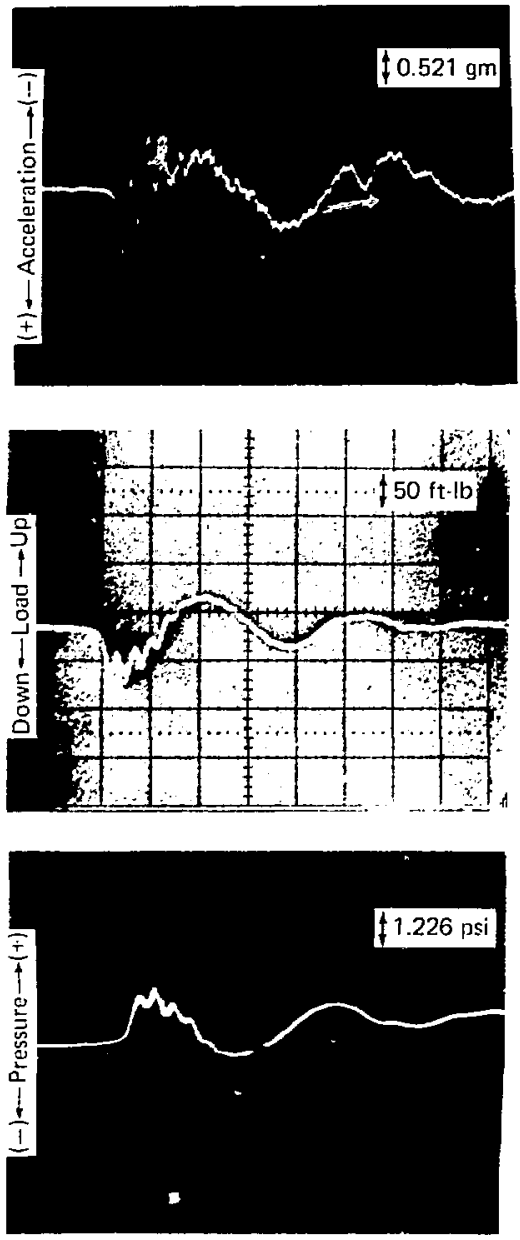

Fig. 59. Dynamic response of a blowdown tost conducted with an initially partialiy $(40 \%)$ [i]led downcomer (run 1/21-8, 5-litre flask, nomi..1 atmosphere, ullage $=15: 5$, nominal pressure ratio $3: 1$. Ejmrscale $=$ $5 \mathrm{~ms} / \mathrm{cm}$. support) shows the averase high fregutenceises tend to roduce with ul lage pressure (ploteed in Fis. 57).

Gareful examination af the three dynamir: response traces follch as Fig. 53) shows nearly perfect correspondence ariong high fremuency oscillations. The events are - Iso phasced properly, i.e., a domnload gives rise lo a down acceleration and an increasc in presisure linfortunately, ateceleration trace after the second peak contuins high-amplitude kHz-level oscillations that inide the lower frequeney conponent of interest.

Although attributing high frequency oscillations to structural support interaction is teripting, it is difficult to conceive or an interaretion that would result in synersistic, in-phase response between load and pressure at the bottom of the flask. Identification of the mechanisms responsible for the high requency oscillations will require further investigation.

Conclusions

The results of this study show that pool dynamics phenomena account For oscillations observed in the typical VLF for LLL bench-top tests. Specifically,

- The average loads are not affected by the high frequency oscillation; i.e., identical loads are 
obtaine $\rfloor$ with the averaget trace frem the high intertia suppert system and from libe stiff support sysilorit.

- The maximann uplatad is calsced by the coupled phonomena of pool levitation and pool swel] [rad the babble arowtin.

- Ihe law freruency damped carricer wave ascillations following the thaximun uplond result from arotiont oscillations of the bubble as it ad justs lo its surroundings.

- Jhe mazinum dounload originates from logdrudynamian and is dotubletpuakcod.

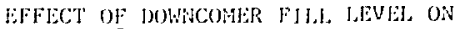
THE VIF'S

Thus $j_{\text {is }}$ an experingntal study of tine affert of demecomer fill level (DFI.) on the VL.T.

Test Apparatus

Jhis study was conducted with the stiffened support system used in the experiments to characterize the VLF. The dynamic load and the pressure at the bottom of the flask were simuIlaneously recorded; the lood cell and pressure transducer were coaxial with the downcomer. The acceleration at the middle of the support beam was also recorded; these data are presented in Section 2. The transducer data sheets are presented in Appendix A.

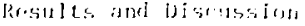

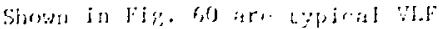
and prosiare Lranes for the rald inonand preasere trated for the fall dow-

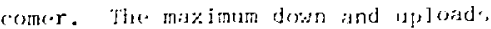
ind line eorresponding positive and nesative pressures at the botern of the f lask are tabulated in fabl: 22 . mhe daca in lable 22 are plotered in Fig. 61 and 6.?.

(a)

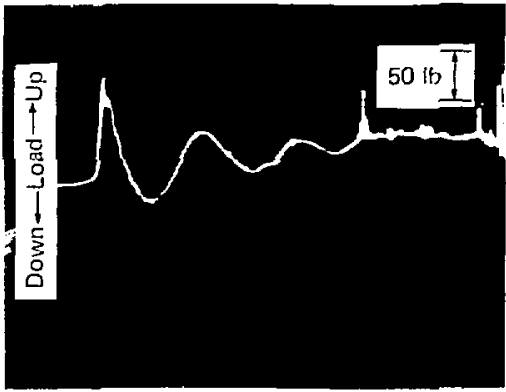

(b)

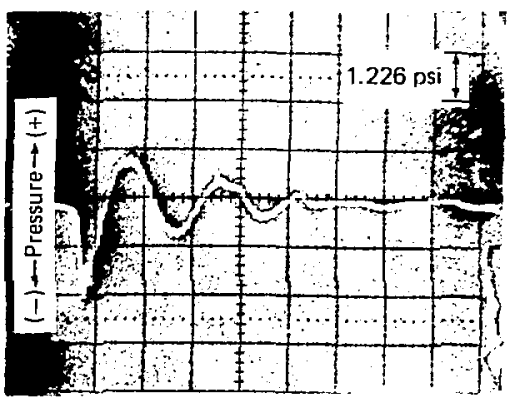

Fig. 60. Typical VLF (a) and pressure (b) at the bottom of the flask (5-litre flask) single downcomer, 2.5 1. water; nominal pressure ratio $15: 5$, timescale $=10$ $\mathrm{ms} / \mathrm{cm}$. 
Table 22. Variation of maximum dynamic response to blowdown with downcomer fi.11 leve1.

\begin{tabular}{|c|c|c|c|c|c|c|}
\hline Run & $\begin{array}{l}\text { Nomina } 1 \\
\text { press. ratio } \\
\text { atm/ullage }\end{array}$ & $\begin{array}{l}\text { Force, } \\
\text { Down }\end{array}$ & $\begin{array}{l}\text { J.b } \\
\text { Up }\end{array}$ & $\begin{array}{c}\text { Pressure, } \\
+\end{array}$ & $\begin{array}{c}\text { psig } \\
-\end{array}$ & Fill $\underset{\%}{\text { level, }}$ \\
\hline $1 / 21-2$ & $15 / 5$ & 95.0 & 45.0 & 2.39 & 0.37 & 100 \\
\hline $1 / 21-3$ & $15 / 5$ & 97.5 & 44.0 & 2.61 & 0.43 & 100 \\
\hline $1 / 21-5$ & $15 / 5$ & 81.0 & 41.5 & 2.25 & 0.33 & 80 \\
\hline $1 / 21-6$ & $15 / 5$ & 76.5 & 39.0 & 2.27 & 0.31 & 80 \\
\hline $1 / 21-7$ & $15 / 5$ & 60.0 & 35.0 & 1.69 & 0.22 & 60 \\
\hline $1 / 21-8$ & $15 / 5$ & 54.5 & 33.0 & 1.34 & 0.23 & 40 \\
\hline J: $21-9$ & $15 / 5$ & 40.0 & 29.0 & 1.08 & 0.18 & 20 \\
\hline $1 / 21-10$ & $15 / 5$ & 27.5 & 22.5 & 0.92 & 0.10 & 0 \\
\hline $1 / 21-11$ & $15 / 7.5$ & 72.5 & 40.0 & 2.08 & 0.37 & 100 \\
\hline $1 / 21-12$ & $15 / 7.5$ & 47.5 & 30.0 & 1.19 & 0.29 & 40 \\
\hline $1 / 21-13$ & $15 / 7.5$ & 45 & 30.0 & 1.40 & 0.26 & 40 \\
\hline
\end{tabular}

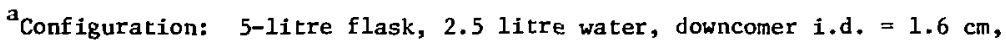
downcomer submergence $=3.2 \mathrm{~cm}$.

Figure 60 shows that af ter $\sim 20 \mathrm{~ms}$, the traces are gradually distorted from a smooth sintrid by pool surface breakup followed by pool splash. The positive Arift of the base line for the pressure trace (Fig. 60) is the result of rise in ullage pressure due to the continued gas flow into the flask. The negative pressures associated with the peak upload that are listed in Table 22 were not corrected for the baseline change; the baseline change is a function of the gas flow rate, which is very nonlinear with time. Critical analysis indicates that the amplitude and not the direction of change of the pressure at the bottom of the flask is affected by the continuing rise in base pressure.

Straight lines have been drawn through the data plotted in Figs. 61 and 62 to indicate the trends. Additional tests are required to establish error bounds for the data; the indicated trends, however, should be correct. The peak pressure at the pool bottom (corresponding to the peak upload) increases with DFL, and 


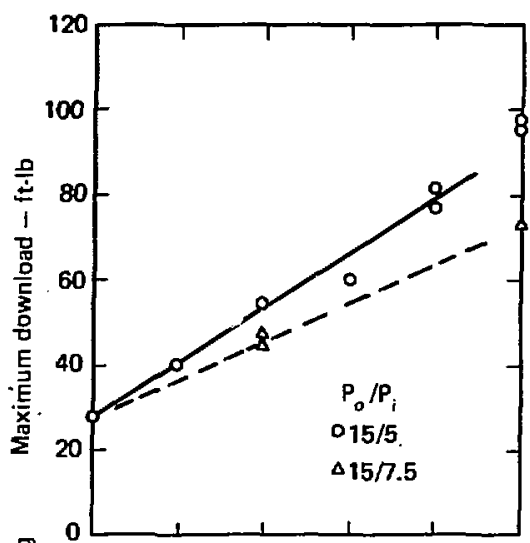

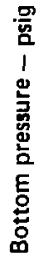

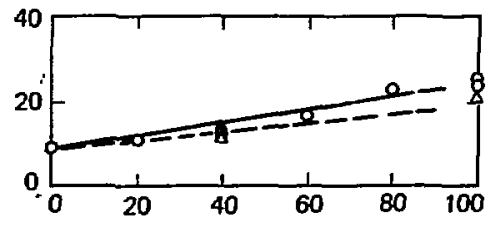

Downcomer fill level - \%

Fig. 61. Effect of downcomer fill leve 1 on the maximum download and pressure at the bottom of the flask (5-litre flask, single downcomer, 2.5 litre water).

the pressure at the bottom of the pool at maximum upload shows the same trend (Fig. 62), but in a negative direction.

Figures 61 and $\epsilon 2$ show that both maximum download and maximum upload reduce with downcomer fiiz iavel. The peak pressure at the bottom of the pool also decreases with downcomer fill level. The same trends are observed for both pressure ratios;
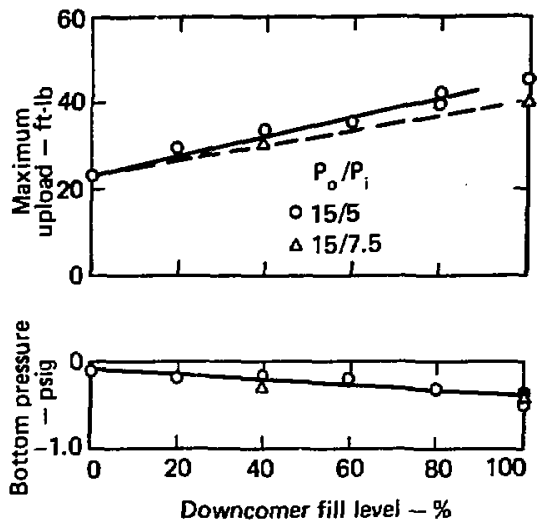

Fig. 62. Effect of downcomer fil1 level on the maximum upload and pressure at the bottom of the flask (5-litre flask, single downcomer, 2.j litre water).

the loads are lower at a lower pressure ratio (15:7.5) is water is initially in the downcomer (DFL $>0$ ). Although measurements at zero fill level are made only for $15: 5$, the loads appear independent of initial pressure ratio for an initially empty downcomer ( $D F L=0)$.

The maximum upload results from both levitation of the pool caused by the download and vertical oscillations of the bubble. As the download decreases with reduced DFL, the download is reduced and the maximum upload decreases. Since the reduction in fressure at the bottom of the flask results from levitation, the pressure reduction will be less when 
levitation decreases; this is the trend exhibited in Fig. 62.

The pressure data in Fig. 62 are indistinguishable for the two pressure ratios studied (compare $o$ and $\Delta$ ). Further experiments are required for confirmation.

Conclusions

The results of experiments with the LLL 5-1itre test apparatus show the following effects of downcomer fill level on the maximum loads of the VLF:
- The maximum download and maximum upload reduce with initial level of fluid ir the downcomer. The maximum download experiences the higher reduction; for an initially empty downcomer, the maximun download is $30 \%$ of that for an initially full downcomer. The corresponding value for the maximum upload is $49 \%$.

- The amount of reduction in vertical load with initial fluid level in the downcomer decreases with the ratio between external and ullage pressures.

\section{OVERALL CONCLUSIONS}

The conclusions for each study have been presented in the separate sections. Presented in this section are the primary conclusions; most are based on comparison of table-top results with other results, especially those from the 1/5-scale torus experiment.

The primary conclusions are as follows:

- Pool dynamics in the pressure suppression pool resulting from postulated LOCA exhibit significant three-dimensional effects. This was observed in the 1/64-scale torus tests and confirmed by the 1/5-scale torus experimental results.
- The 1/5-scale torus experiment confirms table-top results, which indicated that the VLF is insensitive to the enthalpy flux parameter.

- The character of the VLF is best sumnarized in Fig. 4 (repeated for convenience as Figs. 51 and C.I).

- The VLF may be decomposed into two damped sinusoidal components, a low frequency component and a high frequency component.

- The VLF reduces with initial downcomer fill level. When the downcomer is initialiy empty, the VLF is a smooth sinusold. 


\section{ACKNOWLEDGMENTS}

E. McCauley conceived the tabletop model studies reviewed in this report. Investigation of the applicability of proposed air scaling laws was snitiated by F. Morrison. Valuable technical assistance in performing the experiments was provided by J. Robson, T. Schaffer, and $L$. Trent. Photographic and cinemato- graphic coverage of very high quality was furnished by J. L Caywood and

B. D. Walker, Our secretaries

S. Calvert and $\mathrm{N}$. Falco - aided later by $D$. Olson - did a superb job deciphering the manuscripts and preparing the tables.

Administrative leadership was provided by $V$, Karpenko and $C$. Walter.

\section{GLOSSARY OF TERMS}

\begin{tabular}{|c|c|c|c|}
\hline Variabie & Description & $\mathbf{E}$ & Time \\
\hline c & Specific heat & $U$ & Flow speed \\
\hline D & Diameter & $y$ & Ratio of specific heats \\
\hline $\mathbf{F}$ & Force & $\rho$ & Density. \\
\hline $\mathrm{E}$ & Friction Factor & Subscript & Description \\
\hline$g$ & Gravitational constant & & \\
\hline $\mathrm{h}_{\mathrm{o}}$ & Stagnation enthalpy & a & Down \\
\hline k & Spring constant & $\mathbf{g}$ & Gas \\
\hline K & Flow resistance $f \frac{L}{D}$ & i & Initial ullage condition \\
\hline L & Leng th & \& & Liquid \\
\hline$\dot{\mathrm{m}}$ & Mass flow rate & $\mathrm{m}$ & Model system \\
\hline $\mathbf{M}$ & Mass & ma & Actual model \\
\hline$P$ & Pressure, absolute & 0 & Drywell condition \\
\hline $\mathbf{R}$ & Gas constant & $P$ & Constant pressure \\
\hline $\mathbf{s}$ & Characteristic dimension & $\mathbf{r}$ & Reference system \\
\hline $\mathrm{T}$ & Temperature & $\mathbf{u}$ & $\mathrm{Up}$ \\
\hline
\end{tabular}




\section{References and Notes}

1. R. G. Altes, J. H. Pitts, R. F. Ingraham, and E. K. Collins, Mark I 1/5-Scaze Boiling Hater Reactor Pressure Suppression Experiment Facility, Lawrence Livermore Laboratory, Livermore, Calif., UCRL-52340 (1977).

2. E. K. Collins and W. Lai, Final Air Test Results for the 1/5-Scale Wark $I$ Boiling Water Reactor Pressure Suppression Experiment, Lawrence Livermore Laboratory, Livermore, Ca1if., UCRL-52371 (1977).

3. W. M. Shay, W. G. Brough, and T. B. Miller, Instrumenting a Pressure Suppressiun Experiment for a Mark I Boiling Water Reactor - Another Measurement Engineering Challenge, Lawrence Livermore Laboratory, Livermore, Calif., UCRL-52314 (1977).

4. 1). Lord and D. Dixon, Photographic and Video Techniques Used in the 1/5-Scale Mark I Pressure Suppression Experiment, Lawrence Livermore Laboratory, Livermore, Calif., UCRL-52324 (1977).

5. W. Lai, Data Processing System for the Mark I 1/5-Scale Boiling Water Reactor Prescure Suppression Brperiment, Lawrence Livermore Laboratory, Livermore, Calif., UCRL-52333 (1977).

6. H. Lai and E. K. Collins, Mark I 1/5-Scale Boiling Hater Reactor Pressure Suppression Experiment, Quick Look Report, Lawrence Livermore Laboratory, Livermore, Calif., UCID-17446-6 (1977).

7. W. Lai and R. E. Ingraham, Mark I 1/5-Scale Boiling Water Reactor, Pressure Suppression Experiment Quick Look Report, Lawrence Livermore Laboratory, Livermore, Calif., UCID-17446-7 (1977).

8. W. Lai and E. K. Collins, Mark I 1/5-Scale Boiling Water Reactor Pressure Suppression Experiment Quick Look Report, Lawrence Livermore Laboratory, Livermore, Calif., UCID-17446-5 (1977).

9. E. W. McCauley, W. Lai, J. Meier and W. Stein, Mark I 1/5-Scale Boiling Water Reactor Pres'rre Suppression Experiment, Sumary of Effects Due to Vent Line Orifice Variations - Air Test Results, Lawrence Livermore Laboratory, Livermore, Calif., UCID-17539 (1977).

10. J. H. Pitt: Mass Flowrates Through the Vent Lines Durin: Air Tests of the 1/5-Scale Mark I BWR Pressure Suppression System, Lawrence Livermore Laboratory, Livermore, Calif., UCID-17601 (1977). 
11. W. G. Anderson, P. W. Huber, and A. A. Sonin, Madeling of Pool SweZZ Hydrodynamics: Progress Report, Pub. No. 77-01, Fluid Mechanics Laboratory, Dept. of Mechanical Engineering, Massachusetts Institute of Technology, Cambridge, Mass. ([977). (A more complete version was presented as "Small-Scale Modeling of Hydrodynamic Forces in Pressure Suppression Systems: Tests of Scaling Laws," Thermal Reactor Safety, American Nuclear Society, Sun Valley, Idaho, July 21 - Aug. 4, 1977.)

12. J. E. Torbeck, D. L. Galyardr, and J. P. Walekr, Mark I 1/12-Scale Pressure Suppression Poगl Swell Tests, Boiling Water Reactor System Dept., General Electric Co., San Jose, Calif., NEDE-13456 (1976).

13. F. J. Moody, "Appendix A," Ref. 12.

14. B. W. Davis, Characterization of the Fressure Suppression Experinent Load Response and Source Analysis, Lawrence Livermore Laboratory, Livernore, Calif., UCID-17552 (1977).

15. W. H. McMaster, MAITAI: A Two-Dimensional EuZerian Hydrodynomic Code, Lawrence Livermore Laboratory, Livermore, Calif. (in preparation).

16. E. W. McCauley, R. W. Martin, W. Lai, F. A. Morrison, and S. B. Sutton, BWR Hark I Pressure Suppression Pool Dymamics Studies, Lawrence Livermore Laborazory, Livermore, Calif., UCRL-78830 (1976). (Presented at the Tech. Comnittee Neeting, IAEA, Cologne, Fed. Rep. of Germany, 7-9 December 1976.)

17. E. W. McCauley and J. K. Meier, Mark I BWR Pool Dynamics - A Preliminary Investigation into Effects of Downcomer Spacing, Lawrence Livermore Laboratory, Livermore, Calif., UCID-17676 (1977).

18. J. H. Pitts, 1/64-Scale Model Tests of a Mark I Boiling Water Reactor Pressure Suppression System, Lawrence Livermore Laboratory, Livermore, Calif., UCID-17625 (1977).

19. E. W. McCauley and J. H. Pitts, Bench Scale Experiments to Test Aip-Water Scaling Hypothesis for the Lawrence Livermore Laboratory's 1/5-Scale, BWR-Mark I Pressure Suppression Experiment Program, Lawrence Livermore Laboratory, Livermore, Calif., UCID-1727-76-2 (1976).

20. F. J. Moody, A Systematic Procedure for Scale Modeling Problems in unsteady Fluid Mechanics, Boiling Water Reactor Systems Dept., General Electric Co., San Jose, Calif. unpublished (1977).

21. V. T. Berta, LOFW Quick-Look Report of Mini-Blowdown Experiment Series Results, Idaho National Engineering Iaboratory, Idaho Falls, Idaho, QLR76-1 (1976). 
22. W. Lai and E. W. McCauley, BWR Mark I Pressure Suppression Study - Eenoh Mark Experiments, Lawrence Livermore Laboratory, Livermore, Calif., UCID17661 (1977).

23. E. W. McCauley and W. Lai, BWR Mark I Pressure Suppression Study Characterizarion of the Vertical Load Function, Lawrence Livermore Laboratory, Livermore, Calif., UCID-17675 (1977).

24. NRC-RSR/DSS/DOR Review Group Meeting (January 5, 1977).

25. W. Lai and E. W. McCauley, BWR Mark I Pressure Suppression Study - Effect of Downcomer Filz Level on the V. Eicul Load Funetion, Lawrence Livermore Laboratory, Livermore, valif., UCID-17662 (1977). 
APPENDIX A

TYPICAL TRANSDUCER DATA SHEETS 


\section{Products, Inc.}

XPressure Transducer

Customer P.O. \# 7601145

MODEL NO. XTMS $x=190-100 A$ SERIAL NO. $2546-7-9-8 /-83$

Tested to: $\square$ Kulite Specifications $\square$ Customer Specs.

*INPUT

LEAD CONNECTIONS

Red (t)

OUTPUT

Black (-)

\Green (+)

White (-)

*Before connecting, adjust supply voltage not to exceed maximum voltage.

\begin{tabular}{lll}
\hline Rated Pressure 100 psia & $\square$ Gage & $\square$ Sealed \\
Maximum Pressure 200 psia & $\square$ Absolute & $\square$ Differential \\
Maximum Pressure Reference Side & $\square 30 \mathrm{psi}$ & $\square$
\end{tabular}

CAUTION: Do not press on the pressure sensitive area with a sharp object.

Tested at $\square 5$ VDC 10 VDC

Maximum Input Voltage $\square 5$ VDC $\triangle 10$ VDC

Sensitivity $0.08 / 6 \quad \mathrm{mv} / \mathrm{v} / \mathrm{psi}$ ( $\square$ Nominal)

Zero Pressure Output $\square$ Less than $\pm 3 \%$ F.S.

Input Impedance __137 Ohms Output Impedance 250 Ohms

TEMPERATURE COMPENSATION MODULE

$\square$ None Supplied

$\square$ Near End of Leads

A Inside the Transducer from Housing

$\square$ Other

TEMPERATURE COMPENSATION MODULE INCLUDES

A Thermal effect on zero

$\square$ Thermal effect on sensitivity (see Note A)

Thermal effect on zero $\$$ less than I2 F.S. $100^{\circ} \mathrm{F}$

$\square$ Thermal effect on sensitivity $\square$ less than $\%$ F.S. $/ 100^{\circ} \mathrm{F}$

For compensated range $80^{\circ} \mathrm{F}$ to $180^{\circ} \mathrm{F}$

Note A: When compensation of thermal effect on sensitivity is not included in the module, please consult the appropriate product bulletin for the recommended method of excitation.

REMARKS O-RINC SUPPLIEI _MAXIMUM TORQUE 1,5 IN. LBS

Tested by K.C. Inspected by $\quad$ Date $4 / 11 / 75$

Fig. Al. Typical transducer data sheet: test report. 
To: Tom Schaffer, Calibration of Kistler Mod 932 Force Link, SN 39039 ,

Range 0-250 bs, Chg amp SN 322, JK, on 8/18/76, Sens 8.25, Range 200, Tension

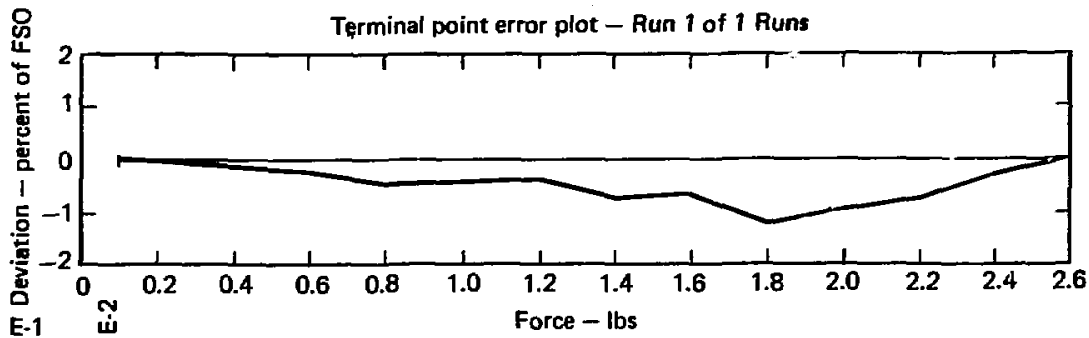

\begin{tabular}{|c|c|c|}
\hline Input & \multicolumn{2}{|c|}{ Output } \\
\hline Force & (Volts) & (Volts) \\
\hline Ibs & Incr & Decr \\
\hline 0.0 & 0.002 & 0.002 \\
20.000 & -0.199 & -0.199 \\
40.000 & -0.400 & -0.400 \\
60.000 & -0.602 & -0.602 \\
80.000 & -0.803 & -0.803 \\
100.000 & -1.006 & -1.006 \\
120.000 & -1.208 & -1.208 \\
140.000 & -1.411 & -1.411 \\
160.000 & -1.613 & -1.613 \\
180.000 & -1.815 & -1.815 \\
200.000 & -2.017 & -2.017 \\
250.000 & -2.522 & \\
\hline
\end{tabular}

\begin{tabular}{|c|c|c|}
\hline \multicolumn{3}{|c|}{ Terminal point values } \\
\hline Theoretical & \multicolumn{2}{|c|}{ Deviation (volts) } \\
\hline (Volts) & Incr & Decr \\
\hline 0.002 & 0.000 & 0.000 \\
-0.200 & 0.001 & 0.001 \\
-0.402 & 0.002 & 0.002 \\
-0.604 & 0.002 & 0.002 \\
-0.806 & 0.003 & 0.003 \\
-1.008 & 0.002 & 0.002 \\
-1.210 & 0.002 & 0.002 \\
-1.412 & 0.001 & 0.001 \\
-1.614 & 0.001 & 0.001 \\
-1.816 & 0.001 & 0.001 \\
-2.018 & 0.001 & 0.001 \\
-2.522 & 0.0 & 0.0 \\
\hline
\end{tabular}

Excitation $=0.0$ volts

Sensitivity $=-1.00960 \mathrm{E}-02$ volts/lbs

Spen $=-2.5240$ voits

Zero offeet $=0.0016$ volts

Error bend $x-0.12 \%$ to $+0.0 \%$ of FSO

Input resistance = N/A Ohms: Output resistance $=N / A$ ohms

Shunt calib $=N / A$

LLL-force and pressure calibration facility bldg 231, rm 1662 ext 8609

Fig. A2. Transducer data sheet: typical load cell calibration. 


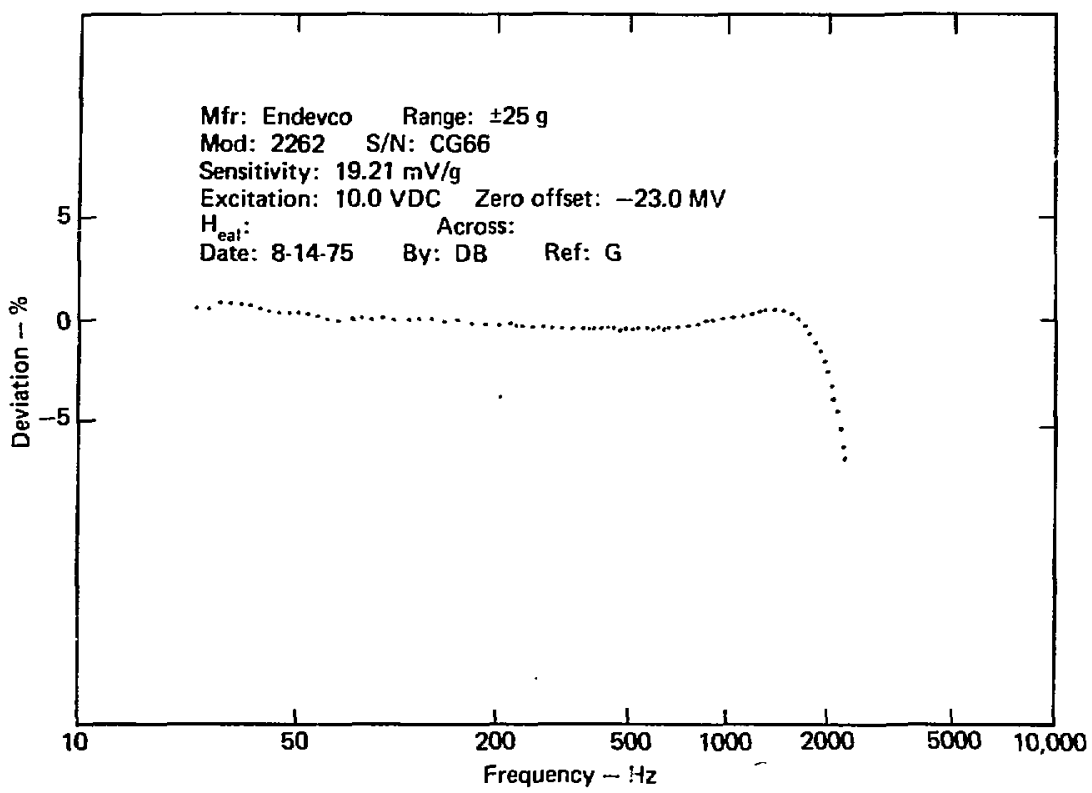

Fig. A3. Transducer data sheet: accelerometer calibration. 


\section{APPENDIX B REANALYSIS OF AIR-WATER POOL DYNAMICS SCALING}

The original analysis, summarized in Section 4, may be found in Ref. 19. The reanalysis presented here emphasizes the improvement and omits the detailed mathematical development. If we assume negligible damping, the basic parameters characterizing a vibrating spring-mass system are spring constant $\mathrm{k}$ and mass $\mathrm{M}$ of the system. Inclusion of the parameters gives

$F=\phi\left(L, \rho_{\ell}, g, P_{i}, P_{0}, t, M, k, f, \gamma\right)$.

No new dimensions were introduced, so that the number of dimensionless groups increased from six to eight. By judicious combination of independent groups, we obtain for Model $\mathrm{B}^{*}$

$$
\begin{aligned}
& \frac{F}{L^{3} \rho_{\ell} g}= \\
& \psi \frac{P_{i}}{L \rho_{\ell} g}, \frac{P_{O}}{L \rho_{\ell} g}, \frac{t^{2} k}{M}, \frac{M}{L^{3} \rho_{\eta}}, \frac{k}{L P_{i}}, f, \gamma .
\end{aligned}
$$

When compared with the res Lts in Eq. (1) (Section 4), shows that the characterjstic time group has been $\bmod \lrcorner$ ied from $t^{2} g / L$ to $t^{2} k / M$; the latter group is recognized as similar to that of the period of an undamped oscillator. In addition, two new

\footnotetext{
${ }^{*}$ Please refer to section 4.
}

groups have appeared. A ratio of the masses

$$
\frac{M}{\rho_{\ell} L^{3}}
$$

The mass $M$ and spring constant $k$ are ill-defined since the vibrating system has not been identified. However, the period of vibration of a spring-mass system is proportional to $\sqrt{\mathrm{M} / \mathrm{k}}$ and may be extracted from measurements. Neglecting damping, the results show that the model and reference period ratio is

$$
\frac{T_{m a}}{T_{p}}=\sqrt{\frac{M_{m a}}{k_{m a}} \frac{k_{r}}{M_{r}}}=\frac{7}{20},
$$

where ma designates the actual mode1 and $r$ designates the reference. This ratio can be applied to correct the lapse time between maximum download and maximum upload presented in Table 16. For Mode1 $B$ and D

$$
t_{m}=\sqrt{\frac{\mathrm{L}_{m}}{\mathrm{~L}_{r}}} t_{r},
$$

where subscript m designates the model. From this analysis

$$
t_{r}=t_{m a} \sqrt{\frac{M_{r}}{k_{r}} \frac{k_{\text {ma }}}{M_{\text {ma }}}} .
$$


Af ter combining Eqs. (B2) and (B3), the corrected time is

$$
\begin{aligned}
T_{m a} \sqrt{\frac{P_{i}}{\rho_{e} L^{2}}}=\sqrt{\frac{k_{r}}{M_{r}} \frac{M_{m a}}{k_{m a}}}\left(\frac{L_{r}}{L_{m}}\right) \\
t_{m} \sqrt{\frac{P_{i}}{\rho_{e^{2}} L^{2}}} .
\end{aligned}
$$

ipplying Eqs. (B4) and (B5) to the

or

$$
t_{m a} \sqrt{\frac{g}{L}}=\sqrt{\frac{L}{L_{m}}} \sqrt{\frac{k_{r}}{M_{r}} \frac{M_{m a}}{k_{m a}}} t_{m} \frac{g}{L} .
$$

Equation (B4) shows that the time group for the model must be corrected by the square roots of the length ratios and period ratios. By a similar analysis, the corrected time group for Model $C$ is results in Table 16 , we obtain the results in Table $B l$. Now, the differences are consistently low, and the improvement is obvious. Recall that two additional groups have been introduced. The new groups contain the unknown mass and spring constant of the sytem. It is 1ikely that one or both of these groups changes between the prototype and model. Hence, either or both of the new dimensionless groups may account for the remaining discrepancy.

Table Bl. Reanalyzed results for the time interval between maximum download and inaximum upload.

\begin{tabular}{llllr}
\hline Model & $\left(t \sqrt{\frac{g}{\mathrm{~L}}}\right)$ ref. & $t_{\mathrm{ma}} \sqrt{\frac{\mathrm{g}}{\mathrm{L}}}$ & $\begin{array}{c}\text { Difference between } \\
\text { means, \% }\end{array}$ \\
\hline B & 0.1407 & 0.1156 & -17.8 & $01 \mathrm{New}$ \\
$\mathrm{C}$ & 3.15 & 3.08 & -2.0 & +64 \\
$\mathrm{D}$ & 0.1407 & 0.111 & -20.8 & +33 \\
\hline
\end{tabular}




\section{APPENDIX C VIBRATION STUDY OF THE FLASK SUPPORT SYSTEM}

\section{INTRODUCTION}

The oscillatory nature of the RVLF (Fig. Cl) pronpts suspicion that the the oscillations are structurally induced. This study was conducted to

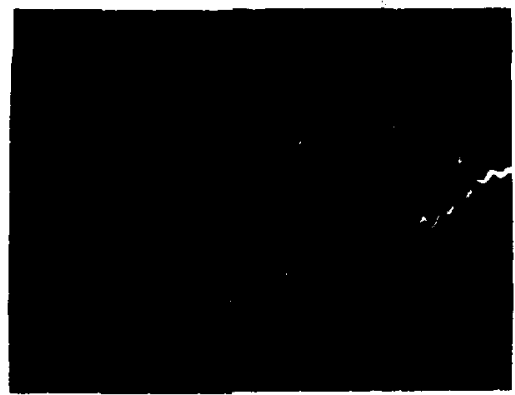

Fig. C1. Origin of VLF characteristics. (a) Hydrodynamic origin: peak downforce results from ejection of water slug into the pool. (b) Hydrodynamic origin: second peak of downforce becomes dominant as downcomer initial fill level is reduced. (c) Hydrodynamfc origin: maximum upforce given by average, results from combination of pool levitation and compression due to pool swell. (d) Hydrodynamic origin: low frequency carrier wave due to verticat oscillations of the expanding air bubble. Frequency increases with ullage pressure. oscillations are in phase with pressure oscillations at bottom of pool. (e) Hydrodynamic origin: high frequency on carrier wave not fully characterized; slight reduction with increase in ullage pressure, oscillations in phase with pressure oscillations at the bottom of the pool.
Insure that vibration of the experimental apparatus (Figs, 31 and 32) did not affect the RVLF or other measurements.

PROCEDURE

Figures C2 and C3 show that the downcomer/flask system fs supported by a strut assembly (three-legged) from a load cell secured to a hoilzontal crossbeam. The beam ends are firmly fastened to vertical rods attached to a metal table. Vibration characteristics of the support systen were investigated systematically to insure absence of support structure resonances in the VLF frequencies of interest. Oscillations were excited by a hammer blow. Those frame components found to exhibit excitable frequencies near observed oscillations in typical VLF's were selectively stiffened to permit separation of effects.

\section{RESULTS AND DISCUSSION}

Init: ally, the excited frequencies were deduced from the integrated load cell response; additional measurements vere made with an accelerometer during the later course of experimentation. The high frequency content of the 


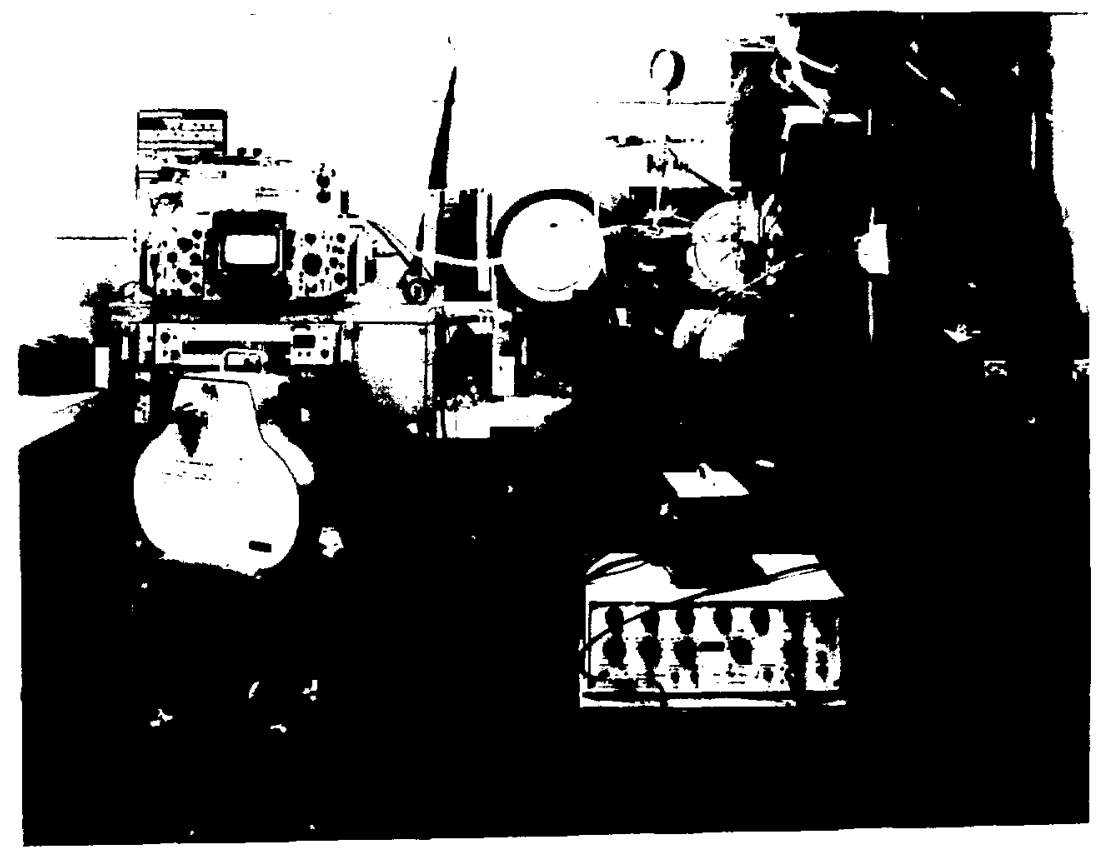

Vig. C2. Test apparatus.

response depended on the strength of the hammer blow. Stiffness was judged b: the lowest frequency oscillation which of ten contained harmonics. In spite of these difficulties, the results will show that the method used is adequate.

\section{High Inertia Support System}

Figure C2 shows the original support system which has high inertia by virtue of the $250 \mathrm{lb}$ of lead bricks strapped firmly to the crossbar. Attachment of the mass in this way increased the resonance frequency of the support. Table $\mathrm{Cl}$ tists $t^{i} \mathrm{e}$ lowest excited frequencies sensed by the load cell when a hammer blow was applied to the positions H1-H5 as indicated in the footnote; refer to Fig. C2 to correlate these positions with the system. The flask, fluid, and downcomer ere attached during these tests. The data show a slight increase in frequency when other than the crossbar or flask support is struck; this siggests that a different mode of vibration was excited. 
(a) Plan view

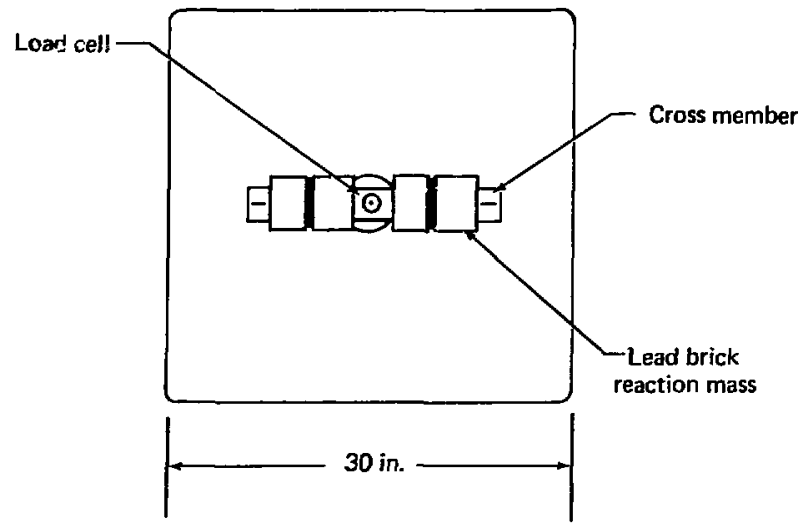

(b) Elevation

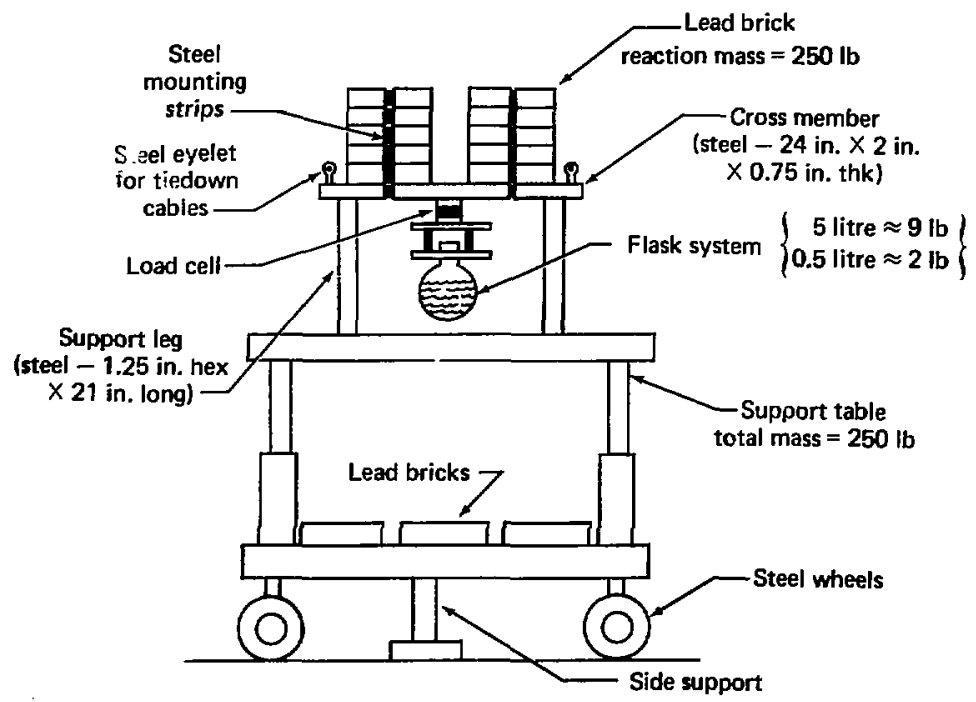

Fig. C3. Block diagram of scaling test equipment. 
Table C1. Vibration frequencies of original experimental apparatus. Highinertia support system ( 250 1b lead bricks strapped firmly to crossbar) with flask, fluid, downcomer in place.

\begin{tabular}{|c|c|c|c|c|c|c|}
\hline Run & Lowest freq., ${ }^{a} \mathrm{~Hz}$ & $\mathrm{H1}^{\mathrm{b}}$ & $\mathrm{H} 2$ & H3 & H4 & H5 \\
\hline 5 & 400 & $\mathrm{X}$ & & & & \\
\hline 6 & 417 & & $\mathrm{x}$ & & & \\
\hline 7 & 455 & & & $\mathrm{x}$ & & \\
\hline 8 & 500 & & & & & $\mathrm{x}$ \\
\hline 9 & 588 & & & & $\mathrm{x}$ & \\
\hline
\end{tabular}

a Measured with load cell.

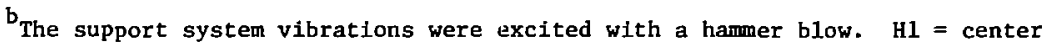
of crossbar; $\mathrm{H} 2$ = flask support; $\mathrm{H} 3=$ back edge of table, $\mathrm{H} 4=$ front edge of table; H5 = crossbar over end support.

Soft System

To insure that system frequency was attributable to the added mass, the lead bricks were renoved. The flask, fluid, and downcomer were supported by the cross bean through the load cell during these tests. The results of striking the system at the various points $\mathrm{H} 1, \mathrm{H} 2$, and $\mathrm{H} 5$, are listed in Table C2. This soft system was shown to have unacceptable vibration characteristics in Section 4.

Table C2. Vibration frequencies of soft support system (lead bricks removed from crossbar) with flask, fluid, downcomer in place.

\begin{tabular}{|c|c|c|c|c|c|c|}
\hline Run & Lowest freq., ${ }^{a} \mathrm{~Hz}$ & $\mathrm{H} 1^{\mathrm{b}}$ & $\mathrm{H} 2$ & H3 & $\mathrm{H} 4$ & H5 \\
\hline $10^{-r}$ & 100 & $\mathrm{X}$ & & & & \\
\hline 11 & 100 & & $\mathrm{x}$ & & & \\
\hline 12 & 100 & & & & & $\mathrm{x}$ \\
\hline 13 & 95 & $\mathrm{X}$ & & & & \\
\hline 14 & 95 & $\mathrm{X}$ & & & & \\
\hline
\end{tabular}

Measured with load ce1l.

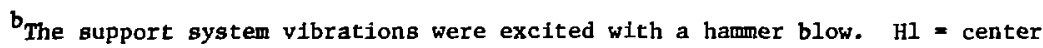
of crossbar; H2 = flask support; H3 = back edge of table; $\mathrm{H} 4$ = front edge of table; $H 5$ = crossbar over end support. 
Stiff Support System

A steel I-beam ( 016 1b), with cross-section shown in Fig. C4, was rigidly claiped to the crossbar in place of the lead bricks. The vibration characteristics of the new system were then systematically studied. The results are tabulated in Table $c 3$.

With the flask, fluld, and downcomer in place, a hammer blow at midspan of the crossbeam excited low frequency oscillations slightly less than $500 \mathrm{~Hz}$ measured by the load cell (Runs 18, 19, 20). These frequencies were $2100 \mathrm{~Hz}$ higher than the comparable test for the high inertia system

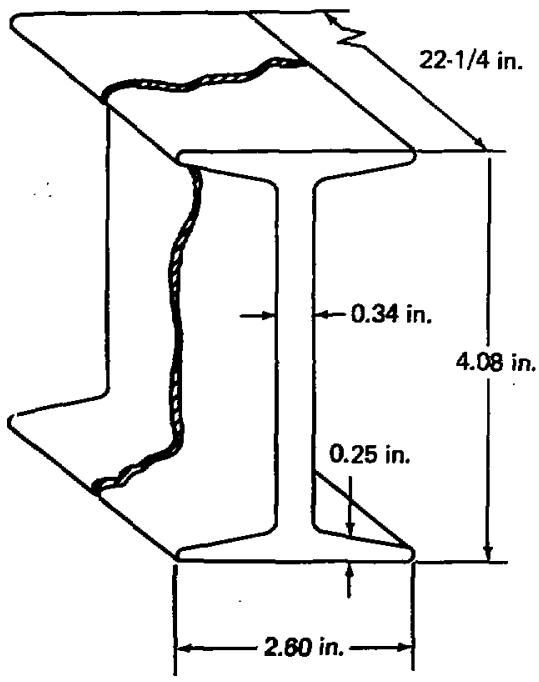

F1g. C4. Cross-section of I-beam used to rigidize crossbar of support system.
(Run 5, Table C1). This is attribuced to the stiffer system afforded by the I-beam. For these runs, ullage pressure was varied from 1 atm to a 20-in. vacuum. These oscillations seem to be independent of ullage pressure, and that suggests independence from air-water interaction.

The flask, fluid, downcomer, and flask support were then removed and an equivalent mass of lead ( $9 \mathrm{lb}$ ) was fastened directly to the load cell (Runs V1., V2, V4). The lowest frequency of oscillation observed was $1667 \mathrm{~Hz}$ (Table c3). The test was repeated after moving the dead weight to the end of: a 3/8-by-1?-3/4-in. rod that was attached to the load cell; the lead mass was thus positioned at approximately the center of mass of the liquid in the flask. The lowest frequency was then $405 \mathrm{~Hz}$ (Run V5). Reattaching the flask, fluid, downcomer, and flask support af ter removing the lead mass and rod confirmed the previous results (compare Runs v6, V7 with $18,19,20$ ). The flask was then emptied to determine the effect of the fluid. With the same excitation hammer blow at midspan, the lowest frequency was $2900 \mathrm{~Hz}$ (Runs v8, v9). The Influence of the fluid mass is evident.

To further isolate the vibrating source responding to the fluid mass, the flask, fluld, and downcomer were 
Table c3. Vibration frequen ies of the rigld support system - original flask holder."

\begin{tabular}{|c|c|c|}
\hline Run & Lowest freq. ${ }^{b} \mathrm{~Hz}$ & Test Condtions \\
\hline $\begin{array}{l}18 \\
19 \\
20\end{array}$ & $\begin{array}{l}483 \\
476 \\
492\end{array}$ & 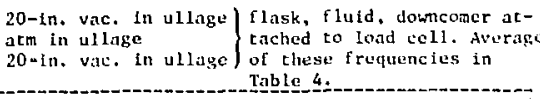 \\
\hline $\begin{array}{l}v_{1} \\
v_{2} \\
v_{4}\end{array}$ & $\begin{array}{l}1667 \\
1667 \\
1667\end{array}$ & $\begin{array}{l}\text { Lead weight }{ }^{c} \text { close coupled to load cell. } \\
\end{array}$ \\
\hline v5 & 405 & $\begin{array}{l}\text { Lead weight }{ }^{\circ} \text { at ond of } 3 / 8-i 11 .-b v-12-3 / 4-i n \text {. rod } \\
\text { attached to loid cell; dend weight at center of } \\
\text { mass of fluid. This fequency in Table } 4 \text {. }\end{array}$ \\
\hline $\begin{array}{l}v_{6} \\
v_{7}\end{array}$ & $\begin{array}{l}471 \\
462\end{array}$ & $\begin{array}{l}\text { Flask, fluid, downcomer atcached to load col1, } \\
1 \mathrm{~atm} \text { is uliage. Average in with Runs } 18,19,20 \text {. }\end{array}$ \\
\hline $\begin{array}{l}\text { yg } \\
\text { v9 }\end{array}$ & $\left.\begin{array}{l}857 \\
952\end{array}\right\}$ & $\begin{array}{l}\text { Empty flask, downcomer attached to loac cull. } \\
\text { Average of these frequencies in tible } 4 \text {. }\end{array}$ \\
\hline $\begin{array}{l}\text { v10 } \\
\text { v11 }\end{array}$ & $\left.\begin{array}{l}439 \\
438\end{array}\right\}$ & 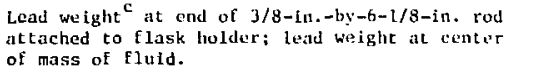 \\
\hline v12 & 500 & $\begin{array}{l}\text { Lead weight }{ }^{c} \text { close coupled to Elask holder, This } \\
\text { frequency in Table } 4 \text {. }\end{array}$ \\
\hline V16 & 500 & $\begin{array}{l}\text { Empty flask, domeomer attached to load ceil; lead } \\
\text { weight equivalent to fluidd attached to flask } \\
\text { tolder. }\end{array}$ \\
\hline
\end{tabular}

The orfiglal flask support was dssembled with 3-1/4-ia.-diamete $5-b y-0-3 / 8-$

in.-long tie rods. Excitation by applying hamer bluk to midspan of crossbeam.

beasured with load cell.

$c_{9}$ lbs lead we tght equlvalent of [lask, fluid, duwncomer, and flask hoider.

The Elask holder welghs 1.2 Lb.

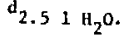

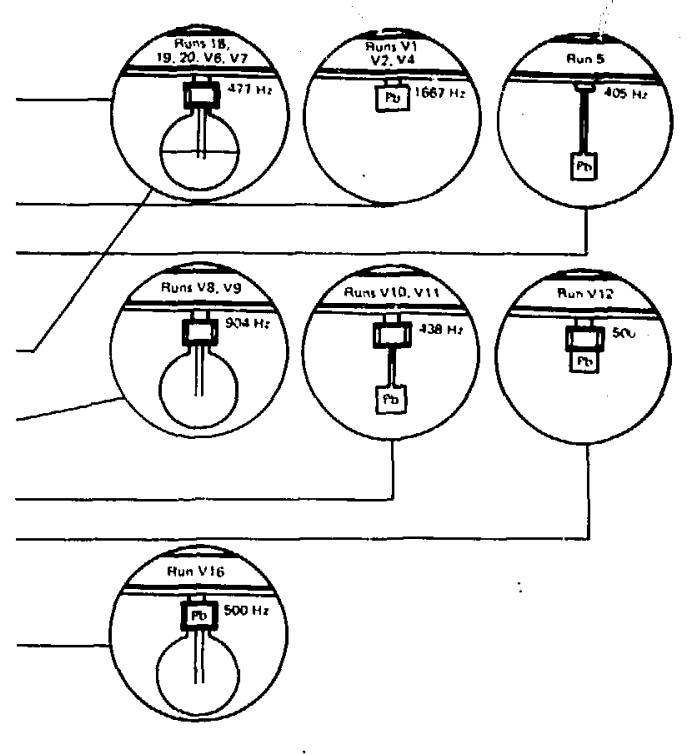


replaced with an approximately equivalent lead weight. This equivalent weight ( 911 ) ) was first suspended at the end of a 6-1/8-in. rod that, in turn, was attached to the bottom of the flask holder. This placed the weight at the center of the mass of the fluid. The response of the syscem was $2440 \mathrm{~Hz}$ (Runs v10, v1l) or essentially the same as the response when the flask, fluid, and downcomer were attached to the system (compare with kuns V6, V7). When the equivalent mass was attached directly to the bottom of the flask holder, the vibration frequency increased to $500 \mathrm{~Hz}$ (Table C3, Run V12); this increase is insignificant in comp.rison with tive change from an average of $477 \mathrm{~Hz}$ to $1667 \mathrm{~Hz}$ after replacing the flask, fluid, downcomer, and flask holder with an equivalent lead weight (9 1b) attached directly to the load ce11 (compare Runs 18, 19, 20 with v1, v2, v4). The responding source is evidently in the flask holder. * As a further check, an empty flask and downcomer were attached to the

*The flask holder may have a low resonance $\bar{I} r e q u e n c y$, as is sugge'sted in Section 4. Note also that the calculated resonance of the hex support legs (Fig. C2) is $2330 \mathrm{~Hz}$ with the high inertia system and $21030 \mathrm{~Hz}$ with the stiff support systen; these calculations assume that the weight of the crossbean is an integral part of the hex support leg. flask holder; the fluid was replaced wicl an equevalent mass of lead (5.5 1b) that was attached to the bottom of the flask holder in the region of the neck of the flask. The system again responded at $500 \mathrm{~Hz}$ (Table $\mathrm{C} 3$, Run VIG); evidently, the empty flask and downcomer had minimai toffect.

The results oí a systematic calculation of the resonance frequencies of the components that make up the rlask support are shown in Table $\mathrm{C} 4$. From this, it was determined shat the longitudinal or axial resonance of the tie rods chat hold the assembly together was close to measured values. For example, for the flask support assembly with 3-1/4-in. diameter tie rods and with flask, fluid, and downcomer attached the calculated reasonance was $403 \mathrm{~Hz}$, while the measured frequency was $477 \mathrm{~Hz}$ (see also configurations 1 and 2 of Table $\mathrm{C} 4$ for other results). These tie rods were then replaced by 3-3/4-in. diameter stainless steel bar stock that increased the calculated resonant frequency of the flask support to $1650 \mathrm{~Hz}$ and $2283 \mathrm{~Hz}$ with and without fluid in the flask, respectively (Table C4, configuration 3). However, the load cell measurements indicated an unexpectedly low average oscillating frequency of $606 \mathrm{~Hz}$ (average of Runs V22 to V26, Table c5). Test descriptions ind results with the rigid support system and 
Table C4. Caleulated axial resonance of flask support rods ${ }^{\text {a }}$ compared with measured frequenciess.

Conf iguration

Calculated

resonance

frequency,

Ave. measured

$\mathrm{Hz}$

frequenc $y^{\mathrm{c}}, \mathrm{Hz}$

(1) Flask support assembled with 3-1/4-in.

diam by 6-3/8-in. tie rods

- with flisk, fluid, downcomer

403

477

d

- with empty flask, downcomer

646

904

- 9-1b weight close coupled

$379^{\mathrm{b}}$

500

(2) 9-1b weight at end of 3/8-in.-by-

12-3/4-in. rod - direct attachment to

load cell

445

405

- -

(3) Flask support assembled with 3-3/4-in.-

by-5.3-in. round bar stock

- with flask, fluid, downcomer

- with empty flask, downcomer

$a_{F}=3.13 \sqrt{\frac{K}{W}}=3.13 \sqrt{\frac{E A}{L W}}$, units are Hz, \#, in.

$E=$ modulus of elasticity

$A=$ cross section area

$\mathrm{L}=$ length

$W=$ load supported by rod.

$\mathrm{b}_{\text {The }}$ 9-1b weight includes the weight of the flask support but was used for convenience. The excess weight decreases the calculated resonance frequency from $403 \mathrm{~Hz}$ to $379 \mathrm{~Hz}$.

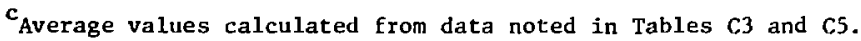

${ }{ }$ The accelerometer was not available at the time these tests were performed.

rigid flask holder are given in

Table C5.

An accelerometer with a magnetic base became available and this permitted selective determination of component frequencies. When positioned at the attachment point between flask holder and load cell, the accelerometer showed an average frequency of $1500 \mathrm{~Hz}$ (Table $\mathrm{C}_{4}$ or Table C.5, Run v33). With the accelerometer still positioned at the attachement point between the flask holder and load cell, simultaneous measurements were made with the load cell. The results confirmed the 
Table C5. Vibration frequencies of Iigld support system - new Itg i flask holder. ${ }^{a}$

\begin{tabular}{|c|c|c|}
\hline Run & Lowest freq., ${ }^{b} \mathrm{~Hz}$ & Test conditions \\
\hline $\begin{array}{l}\mathrm{v} 20 \\
\mathrm{v} 21\end{array}$ & $\begin{array}{l}1212 \\
1111\end{array}$ & $\begin{array}{l}\text { Enpty flask, downconer attached to load cell. } \\
\text { Average of these frequencies in Table C } 4 \text {. }\end{array}$ \\
\hline $\begin{array}{l}v 22 \\
v 23 \\
v 24 \\
v 25 \\
v \leq 6\end{array}$ & $\left.\begin{array}{l}628 \\
600 \\
600 \\
600 \\
600\end{array}\right\}$ & $\begin{array}{l}\text { Flask, fluid, downcomer attached to load cell. } \\
\text { Average of these frequencies in Table C4. }\end{array}$ \\
\hline$v 28$ & 1500 & $\begin{array}{l}\text { Vertical excitation of crossbeam at midspan; flask, } \\
\text { fluid, downcomer attached to load cell. Acceler- } \\
\text { ometer reading. }\end{array}$ \\
\hline v30 & 1500 & $\begin{array}{l}\text { Lateral excitation of crossbeam at midspan; } \\
\text { flask, fluid, downcomer attached to load cell. } \\
\text { Accelerometer reading. }\end{array}$ \\
\hline v31 & 1400 & $\begin{array}{l}\text { Vertical excitation of table top center (H3, } \\
\text { Fig. 2) flask, fluid downcomer attached to load } \\
\text { cell. Accelerometer reading. }\end{array}$ \\
\hline v33 & 1500 & $\begin{array}{l}\text { Vertical excitation of flask holder; flask, fluid, } \\
\text { downcomer attached to load cell. This frequency } \\
\text { in Table c4. Accelerometer. }\end{array}$ \\
\hline $\begin{array}{l}\text { v34 } \\
\text { v35 }\end{array}$ & $\begin{array}{r}605 \\
2000\end{array}$ & \begin{tabular}{l|l} 
Load cell & Flask, fluid, downcomer attached \\
Accelerometer & to load cell; 20-in. vac. in ullage.
\end{tabular} \\
\hline v36 & $\begin{array}{r}625 \\
1667\end{array}$ & $\begin{array}{l}\text { Load cell } \\
\text { Accelerometer } c\} \begin{array}{l}\text { Flask, fluid, downcomer attached } \\
\text { to load cell; ullage exposed to } \\
\text { atm. }\end{array}\end{array}$ \\
\hline
\end{tabular}

aThe new flask holder was assembled with 3-3/4-in.-diam-by-5.3-in.-1ong stainless steel bar stock. Excitation by applying hammer blow to midspan of crossbeam except as noted. vilage at atm except as noted.

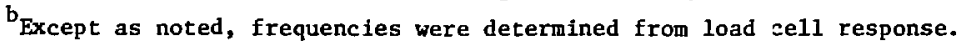

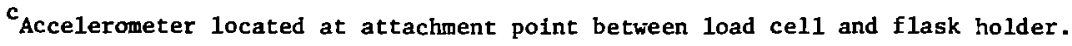

separate measurements (Table $\mathrm{C5}$, Runs v34, v35, V36, v37 and Fig: c4), i.e., the load cell showed oscillations of $7600 \mathrm{~Hz}$, whereas the accelerometer showed oscillations in the $\mathrm{kHz}$ range. Since the load cell was functioning properly, the measurements suggested that fluid motion resonance could be the source; the water-air system could oscillate as 
(a)

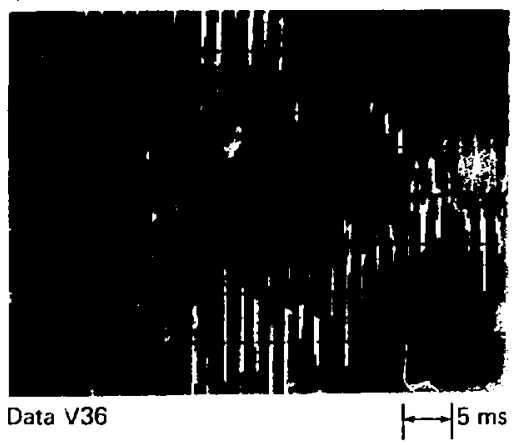

(b)

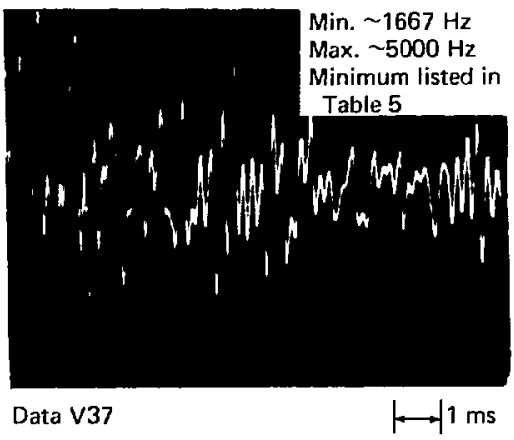

a spriag. This type of pool action was suggested earlier (see Ref. 24). At this point, the vibration study was suspended in favor of blowdown
Fig. L5. Load-cell (a) and acceleroneter (b) response to hammer blow at midspan. tests to provide evidence suitable to test the water-air spring hypothesis. The remainder of the data in Table C5 are self-explanatory. 